$$
\text { DOE/ID/129/7--T2 }
$$

\title{
RIPENESS SENSOR DEVELOPMENT
}

Arsin

Final Report of a Phase II Study

Q.STI

August 1995

Work Performed Under Contract No. DE-FC07-89ID12917

\author{
Prepared for the \\ U.S. Department of Energy \\ Under DOE \\ Sponsored by the Office of the Assistant Secretary \\ for Conservation and Renewable Energy \\ Office of Industrial Technologies \\ Washington, D.C. \\ Prepared by \\ Richard Stroshine \\ Agricultural Engineering Department \\ Purdue University \\ 1146 Agricultural Engineering Building \\ West Lafayette, IN 47907-1146 \\ Project Period: October 1, 1992 to June 30, 1995
}




\section{DISCLAIMER}

This report was prepared as an account of work sponsored by an agency of the United States Government. Neither the United States. Government nor any agency thereof, nor any of their employees, makes any warranty, express or implied, or assumes any legal liability or responsibility for the accuracy, completeness, or usefulness of any information, apparatus, product, or process disclosed, or represents that its use would not infringe privately owned rights. Reference herein to any specific commercial product, process, or service by trade name, tradernark, manufacturer, or otherwise does not necessarily constitute or imply its endorsement, recommendation, or favoring by the United States Government or any agency thereof. The views and opinions of authors expressed herein do not necessarily state or reflect those of the United States Government or any agency thereof. 


\section{TABLE OF CONTENTS}

EXECUTIVE SUMMARY

Page

INTRODUCTION

ii

ECONOMIC ANALYSIS

Estimation of Energy Savings

Grocery Store and Packing House Surveys 6

Grocery Store Survey Results $\quad 6$

Grower/Packer Survey Results $\quad 11$

Evaluations from Consultants 21

Consultant Evaluation - Apples, Pears, and Cherries 21

Consultant Evaluation - Citrus, Stone Fruit, Avocados and Mangoes 24

Summary of Economic Studies 28

SYSTEM COMPONENTS $\quad 30$

System Description $\quad 30$

MA-8 Magnet Assembly 32

MAR-8 Magnet Assembly 33

RF Coil Design and Shielding $\quad 35$

Gradient Coil $\quad 36$

Magnet Temperature Control $\quad 37$

Maintaining System Resonance 38

PULSE SEQUENCES FOR DETERMINATION OF SOLUBLE SOLIDS 40

CPMG Pulse Sequence 40

BNHE Pulse Sequence $\quad \cdot \quad 41$

SYSTEM EVALUATIONS $\quad 44$

Refractometer and HPLC Measurements $\quad 44$

Tests with Pseudofruits 48

Tests with Fruits 49

SUMMARY 55

REFERENCES $\quad 57$

APPENDIX A - Tabular Summary of Results of the Economic Survey 59 


\section{EXECUTIVE SUMMARY}

This is a final report for the Phase II study entitled "Ripeness Sensor Development." The overall objective of the study was the development of a prototype device capable of testing whole fruits for sugar content. Although ripeness and sugar content are not synonymous, they are closely related. Furthermore, the consumer's acceptance of or preference for fruits is strongly influenced by sugar content. Therefore, the device was called a ripeness sensor. The principle behind the measurement is proton magnetic resonance $\left({ }^{1} \mathrm{H}-\mathrm{MR}\right)$. For several decades, chemists, pharmacists and other scientists have been using ${ }^{1} \mathrm{H}-\mathrm{MR}$ to investigate chemical structure and composition. More recently, the technique has been used in laboratories of the food industry for quality control. This effort represents one of the first attempts to adapt ${ }^{1} \mathrm{H}-\mathrm{MR}$ to use in a commercial facility.

.The first section of this report summarizes an economic study. It includes an analysis of the annual energy loss in the U.S. which results from over-ripe fruit. Also included are results of a survey that was sent to chain grocery stores and fruit and vegetable packing houses. Two consultants, who were familiar with the fruit industry, were hired to evaluate how the sensor could be used. Results indicated that the most appropriate place for ripeness sorting of fruits is in the packing house. This would require a high-speed on-line device capable of handling 40 fruits/sec. However, a slower device, capable of sorting up to 12 fruits/minute, would also be useful for quality control. Ideally, the device would be portable and could be taken into fields and orchards for "spot" measurements.

The second section of the report describes the electronic equipment and magnet assemblies which were built and tested. It includes information on the construction and shielding of the radio frequency coils through which the fruits pass. It also addresses issues such as controlling magnet temperature and maintaining the system on resonance. These are necessary to achieve the maximum sensitivity in measurements.

Section three describes the Balanced Normalized Hahn Echo (BNHE) pulse sequence, which was developed specifically for measurements of the sugar content of fruits. The BNHE pulses detect differences in sugar content by measuring the effect of the sugar on the self diffusion constant of water. For many fruits, the accuracy of the measurement can be improved by measuring each fruit's spin-spin relaxation constant $\left(\mathrm{T}_{2}\right)$ and then correcting the BNHE measurement.

The last section of the report describes measurements conducted on sucrose solutions, cylindrical samples cut from fruits, and whole fruits. The soluble solids content (closely related to sugar content) of the fruits was determined using a hand-held refractometer. The refractometer method is described and evaluated. In tests on 8 apples and 5 oranges, refractometer measurements were compared with measurements of High Performance Liquid Chromatography (HPLC). This type of evaluation is particularly important for fruits which are high in acid, such as oranges. In these fruits, the refractometer measurements may differ from the true sugar content by 1 to $2 \%$ (absolute). Sucrose solutions were used for calibrating the equipment and for evaluating equipment performance. Results of measurements on sucrose solutions were noticeably better than results on whole fruits. This was attributed to the heterogeneity of the fruit. A prototype was tested which was capable of measuring soluble solids content of apples and sweet cherries to within $\pm 1.0 \%$ (absolute). Performance was not as good on several other types of fruits. However, research continues with the conviction that sugar contents of other fruits can also be measured to within $\pm 1.0 \%$ (absolute) or better. 


\section{INTRODUCTION}

The objective of this Phase II study was the development of a prototype of a proton magnetic resonance $\left({ }^{1} \mathrm{H}-\mathrm{MR}\right)$ sensor which could be used for the determination of the percent soluble solids in fruits and vegetables to within $\pm 1 \%$. For many fruits and some vegetables, sugar is the primary component of soluble solids. Therefore, the predictions of the sensor are often closely correlated with the sugar content of the fruit, and therefore its sweetness. The sugar content of most fruits and some vegetables changes during the ripening process and this permits the sensor reading to be used as an indicator of ripeness. Grocery stores and consumers must discard fruits and vegetables which spoil before they can be sold. During phase I of the study (Cho and Stroshine, 1992) the literature on fruit losses was reviewed and a telephone survey of groceries and wholesalers was conducted. The results indicated that, in some cases, over-ripeness caused losses of approximately $15 \%$ of the fresh produce. When fruit is discarded, the energy used in producing, transporting, and storing the fruit is also lost. This loss is substantial because the annual U.S. production of the 17 major fruits and vegetables is 39 million tons. There would be additional losses of imported fruits and vegetables. The magnitude of the losses and the benefits which could be gained from sorting fruits by ripeness are discussed in more detail in the first section of this report. The section is entitled "Economic Evaluation."

${ }^{1} \mathrm{H}-\mathrm{MR}$ instruments are based on the interaction of two perpendicular magnetic fields with the protons (hydrogen nuclei) in the sample. Samples are placed within a strong magnetic field $\left(\mathrm{B}_{0}\right)$ which is produced by either permanent magnets, electromagnets or superconducting magnets. Protons associated with sugar and water molecules in the sample align with the magnetic field producing a net magnetization, $\mathrm{M}_{0}$, in the sample. The protons' predisposition towards orientation within the $B_{0}$ magnetic field is further exploited by another relatively small magnetic field $\left(B_{1}\right)$. The $B_{1}$ field is generated by sending a radio frequency $(R F)$ pulse through a coil surrounding the sample. The transient $B_{1}$ magnetic field is at right angles to the $B_{0}$ magnetic field. The frequency of the RF field in relation to the strength of the $B_{0}$ magnetic field determines which molecular units are affected. In pulsed ${ }^{1} \mathrm{H}-\mathrm{MR}$, the RF signal is applied for a prescribed period of time, causing a predictable re-orientation of $\mathrm{M}_{0}$. When the $\mathrm{RF}$ pulse is finished, the transient field dissipates rapidly and the protons return to their original orientation. The rate of return is dependent on the particular molecule with which the proton is associated and occurs more slowly for the protons in the water than for the protons in the sugar. The movement of $\mathrm{M}_{0}$, which includes precession, induces a very small alternating current signal in a receiving coil (which can be the same coil used to generate the transient field). This signal can be amplified and viewed on an oscilloscope or captured by a computer and further analyzed

Two types of RF pulses are typically applied to the sample, $\pi / 2$ or $90^{\circ}$ pulses and $\pi$ or $180^{\circ}$ pulses. The $\pi / 2$ pulses cause $M_{0}$ to rotate $90^{\circ}$ and the $\pi$ pulse causes $M_{0}$ to rotate $180^{\circ}$. A variety of pulse sequences have been developed to measure characteristics of the sample. The signal produced by the application of a $\pi / 2$ pulse is called a Free Induction Decay (FID). More complicated pulse sequences consisting of combinations of $\pi / 2$ and $\pi$ pulses are used to measure parameters called the spin-lattice relaxation $\left(T_{1}\right)$ and the spin-spin relaxation $\left(T_{2}\right)$. The FID signal and both $T_{1}$ and $T_{2}$ of fruits and vegetables are affected by their soluble solids level. However, the FID signal is affected by magnet homogeneity and differences can only be detected in very homogeneous magnets, which are also relatively expensive. The measurement of $T_{1}$ is relatively slow, often requiring up to 5 minutes per sample. Therefore, $\mathrm{T}_{2}$ measurement was evaluated as a means 
of rapidly measuring the soluble solids content of fruits and vegetables. However, it appeared that $\mathrm{T}_{2}$ measurements were influenced by other factors, such as fruit firmness. Therefore, the basis for the measurements of soluble solid became the Hahn Echo (HE) pulse sequence. When a steady (constant with time) gradient in the $\mathrm{B}_{0}$ field is applied across the sample, the HE measures differences in the diffusion coefficient of water which is in turn affected by the percent of dissolved solids in the fruit. A unique pulse sequence, designated the Balanced Normalized Hahn Echo (BNHE), was developed. This pulse sequence was used to determine an echo ratio (ER) which was relatively independent of sample size. The ER was well correlated with sugar content for sugar solutions containing various weight percentages of sucrose. It was also found to be relatively well correlated with soluble solids of various fruits as measured with a refractometer. The BNHE pulse sequence is described in more detail in the section entitled "PULSE SEQUENCES FOR DETERMINATION OF SOLUBLE SOLIDS/BNHE Pulse Sequence" and results with tests on sucrose solutions and fruits is given in the section entitled "SYSTEM EVALUATIONS.".

The feasibility studies for the ${ }^{1} \mathrm{H}-\mathrm{MR}$ sensor were conducted during a Phase I project which began October 2, 1989 and continued through June 30, 1991. These efforts included design of a magnet assembly (Cho et al., 1990), tests with high field (200 $\mathrm{MHz}$ ) laboratory equipment on small samples cut from fruits (Cho et al., 1991), and tests on whole sweet cherries using a 10 $\mathrm{MHz}$ instrument built by Bruker/IBM Instruments Co. (Stroshine, et al, 1991). Purdue's Agricultural and Biological Engineering Department began to build a ${ }^{1} \mathrm{H}-\mathrm{MR}$ sensor during the summer of 1990. One of the major components built during 1990 and 1991 was a magnet assembly, the MA-3, which was capable of testing samples with diameters up to $30 \mathrm{~mm}$. During the summer of 1991, electronic components, needed to enable the MA-3 to be used for ${ }^{1} \mathrm{H}-\mathrm{MR}$ tests, were purchased from Southwest Research Institute (SWRI) of San Antonio, Texas. During the spring of 1992, additional electronic components were purchased from SWRI. This gave researchers a complete LL-4 low field magnetic resonance sensor. SWRI built the equipment to operate at a frequency of $5.25 \mathrm{MHz}$. The LL-4 included software capable of analyzing signals and determining values of $T_{1}$ and $T_{2}$. The MA-3 and the LL- 4 were used for tests on small fruits such as sweet cherries and small plums, and for pieces cut from larger fruits such as apples and peaches.

On July 1, 1991, Magnetic Instrumentation, Inc. of Indianapolis, Indiana became an industrial partner in the development of this technology. Their long-term goal was the development of a commercial unit. During the first several months of their participation, they provided technical advice and assisted with the assembly of circuits. During 1992 Purdue personnel designed a larger magnet assembly, the MA-8, capable of testing fruits with diameters up to $8 \mathrm{~cm}$. The frame for the larger magnet was built in the central machine shop at Purdue University during the spring of 1993. Magnetic Instrumentation engineers assembled the frame and magnets during the summer and fall of 1993 and the first tests with the MA-8 and SWRI's LL-4 system were conducted on oranges and avocados in December of 1993 (Stroshine, et al. 1993). For the first 12 months of testing, the MA-8 was used with the LL-4 electronic equipment developed by SWRI.

Magnetic Instrumentation began development of electronic components for their prototype in the spring of 1992. The approach taken during the first several months of the project was to use a pre-amplifier designed by a Purdue graduate student (Awan, 1992) in conjunction with a circuit which incorporated a commercially available microcontroller. The circuit would have replaced the pulse programmer and computer. In 1993, Magnetic Instrumentation modified their approach and decided to develop components which could be used with an industrial computer or PC. A pulse programmer was designed and built by Dr. John Nyenhuis, an Associate Professor of Electrical 
Engineering at Purdue. The pace for development of electronic components accelerated rapidly during 1994, when Magnetic Instrumentation hired several electrical engineers and an electronics technician who were experienced in design and development of RF components. The company completed their first unit, the LF-1, in December of 1994. Preliminary tests with the equipment demonstrated a reasonable level of performance (Stroshine et al, 1994). During the first six months of 1995, Magnetic Instrumentation engineers continued to make design improvements which were implemented as an improved prototype, the LF-1A, received for testing in June of 1995.

The MA-3 and MA-8 magnets have a homogeneity of 600 to $1000 \mathrm{ppm}$. This is relatively inhomogeneous by magnetic resonance standards. This means that the FID signal is dominated by the inhomogeneity so that it is difficult to obtain information on the sample from the FID curves. The $\mathrm{T}_{2}$ measurement is less sensitive to magnet homogeneity and, since the $\mathrm{BNHE}$ pulse sequence is similar, it was assumed that the echo ratio (ER) would also be relatively insensitive. During the summer of 1993, a magnet assembly was ordered from the Field Effects division of Intermagnetics General Corporation. The magnet was to accommodate a sample with diameter up to $8 \mathrm{~cm}$ and was to have a homogeneity of $50 \mathrm{ppm}$. The homogeneity could be reduced by addition of a spoiler plate to one of the pole faces. The magnet, the MAR-8, was received in August of 1994. It was used for evaluations of the effects of magnet homogeneity on $\mathrm{T}_{2}$ and ER measurements. These experiments are described in the section entitled "SYSTEM EVALUATIONS/Effect of Magnet Homogeneity."

The sections which follow summarize the major results of the study. The first section describes an economic evaluation of benefits which the industry would gain from use of the sensor. The next two sections describe the system and pulse sequences used to interrogate the sample. The second section includes design considerations and evaluations of several components. The last section summarizes tests conducted with SWRI's LL-4 and Magnetic Instrumentation's LF$1 \mathrm{~A}$. 


\section{Economic Analysis}

This section of the report summarizes estimates of the energy savings which could potentially be achieved through use of the sensor. It also gives results of two surveys. One survey was sent to produce managers of grocery chain stores and the other was sent to operators of fruit packing houses. Two consultants, both of whom had worked extensively with the fruit industry, were hired to evaluate how the sensor might be used in the industry and the effects of the use of the sensor. This section also contains their reports.

\section{Estimation of energy savings}

The sensor's effectiveness and efficiency in reducing post-harvest loss will be affected by the point in the marketing system where it is used. Savings will decrease when the sensor is used further down the line. The optimum point of use would be in the vicinity of the orchards where it is produced, i.e., at the packing houses. To estimate potential benefits arising from utilization of the sensor, an analysis of energy savings from use of the device at the packing house level was performed (Ray, 1993). Major factors considered were: commodity, loss rate, and energy invested during transportation and storage.

Ray (1993) calculated energy invested at each step of the distribution process. Energy invested in fruit production was estimated from average values for energy productivities (Fluck and Baird, 1980). Calculations for energy required to remove field heat and heat of respiration in packing houses were similar to example calculations from USDA Handbook \#66 (Hardenburg et al., 1986). Energy invested in freezing, canning, transportation, and storage were also based on examples and information from Fluck and Baird and USDA Handbook \#66. Energy invested by the retailer during marketing and the consumer during storage were neglected. The calculations were applied to the 1991 production data listed in USDA Agricultural Statics Reports (USDA, 1992) for 12 major fruits and 4 major vegetables.

Results of the calculations are summarized in Table 1 . It was assumed that $30 \%$ of the packinghouse loss would be eliminated in the case of the fruits and 33\% would be eliminated in the case of vegetables. The successive rows of Table 1 give estimates for each step as the fruit travels through the distribution stream. It was assumed that losses would be lower further "downstream" because the fruit would be higher in quality and less likely to spoil. The first column of data shows the weight of fruit at each point in the distribution stream. The next two columns show the estimated losses with and without the use of the sensor. Columns 4 to 6 give similar data for the vegetables. The bottom lines summarize the total estimated losses, the amount of energy invested in producing the fruit, and the energy which is lost. The current situation (columns 2 and 5) versus the situation where the sensor is used in most major packinghouses (columns 3 and 6). The estimate of the total energy saved by sorting the 12 major fruits was $1.06 \times 10^{13} \mathrm{Btu}$. This is the difference between the invested energy lost without the sensor, $2.97 \times 10^{13} \mathrm{Btu}$, and the energy lost when the sensor is used, $1.91 \times 10^{13} \mathrm{Btu}$. Similarly, the estimated energy savings for the 4 major vegetables was $0.32 \times 10^{13} \mathrm{Btu}$. This gives a total energy savings of $1.38 \times 10^{13} \mathrm{Btu}$. 
Table 1. Estimate of overall distribution system loss with and without use of the fruit quality sensor by packing houses sorting 12 major fruits (apples, apricots, avocados, bananas, cherries, grapes, grapefruit, oranges, papayas, peaches, pineapple, and strawberries) and 4 major vegetables (cantaloupe, honeydew melons, tomatoes, and watermelons).

\begin{tabular}{|c|c|c|c|c|c|c|}
\hline \multirow{2}{*}{$\begin{array}{l}\text { Distribution } \\
\text { location }\end{array}$} & \multirow{2}{*}{$\begin{array}{l}\text { Weight of } 12 \\
\text { Major Fruits } \\
\text { in the } \\
\text { Distribution } \\
\text { Stream w/o } \\
\text { the Sensor } \\
\text { (10 } 10^{6} \text { Tons) }\end{array}$} & \multicolumn{2}{|c|}{$\begin{array}{c}\text { Estimated Product } \\
\text { Loss } \\
\left(10^{6} \text { Tons }\right)\end{array}$} & \multirow{2}{*}{$\begin{array}{c}\text { Weight of } 4 \\
\text { major } \\
\text { Vegetables in } \\
\text { the } \\
\text { Distribution } \\
\text { Stream w/o } \\
\text { the Sensor } \\
\left(10^{6} \text { Tons) }\right.\end{array}$} & \multicolumn{2}{|c|}{$\begin{array}{l}\text { Estimated Product Loss } \\
\left(10^{6} \text { Tons }\right)\end{array}$} \\
\hline & & $\begin{array}{l}\text { Without } \\
\text { use of } \\
\text { the } \\
\text { Sensor }\end{array}$ & $\begin{array}{c}\text { With } \\
\text { use of } \\
\text { the } \\
\text { Sensor }\end{array}$ & & $\begin{array}{l}\text { Without } \\
\text { use of the } \\
\text { Sensor }\end{array}$ & $\begin{array}{l}\text { With use } \\
\text { of the } \\
\text { Sensor }\end{array}$ \\
\hline Production & 24.07 & 0.00 & 0.00 & 6.68 & 0.00 & 0.00 \\
\hline Packinghouse & 20.46 & 3.61 & 2.53 & 4.78 & 1.90 & 1.33 \\
\hline Storage & 19.85 & 0.61 & 0.55 & 4.51 & 0.27 & 0.26 \\
\hline Transport & 18.78 & 1.07 & 0.96 & 4.05 & 0.46 & 0.45 \\
\hline Wholesale & 18.16 & 0.62 & 0.50 & 3.80 & 0.25 & 0.22 \\
\hline Retail & 17.34 & 0.82 & 0.44 & 3.48 & 0.32 & 0.19 \\
\hline Consumer & 16.33 & 1.01 & 0.06 & 3.10 & 0.38 & 0.02 \\
\hline Total Losses & - & 7.74 & 5.04 & - & 3.58 & 2.47 \\
\hline $\begin{array}{l}\text { Invested Energy } \\
\left(\mathbf{1 0}^{13} \text { Btu }\right)\end{array}$ & 7.01 & - & - & 1.03 & & \\
\hline $\begin{array}{l}\text { Energy Loss } \\
\left(\mathbf{1 0}^{13} \text { Btu) }\right.\end{array}$ & - & $(-) 2.97$ & $(-) 1.91$ & - & $(-) 1.01$ & $(-) 0.69$ \\
\hline
\end{tabular}




\section{Surveys of Grocery Chain Stores and Packing Houses.}

Two surveys were developed: one for the grower/packer and the wholesaler, and one for large chain grocery stores. Questions were formulated through discussions with people involved in the growing, packing and retailing of fresh fruits and vegetables. Several industry contacts felt that wholesalers would not be able to use the sensor, because most do not repack their fruits and vegetables before they ship to retailers. Therefore, no surveys were mailed to wholesalers. A total of 98 surveys were mailed to large chain grocery stores and 187 surveys were mailed to grower/ packers. The 187 grower/packer surveys included the following numbers which handled specific types of fruits: 49 citrus, 21 peaches/nectarines, 12 mango, 8 avocado, 11 melon and miscellaneous, 19 New York apple, 47 Michigan apple, 41 Washington apple. The total exceeds 178 because several of the packers packed more than one type of fruit.

\section{Grocery survey results:}

The response rate from the grocery store survey was $27 \%$. Nearly all respondents indicated that the sensor should be used at the packing house and that there is little use for the sensor at the retail level. The responses are summarized in the histograms that follow.

Figure 1 indicates that approximately $44 \%$ of the respondents felt that the ripeness sensor would improve the uniformity and quality of produce if it were used at their facility. However, as shown in Figure 2, nearly all of those responding thought these improvements would be brought about through use of the sensor by packing houses. The number of ripeness categories into which the fruit should be sorted was related to the type of fruit (Figure 3). All respondents felt that two categories would be sufficient for oranges. Approximately half of the respondents recommended two categories for peaches while the other half felt that three categories would be desirable. The majority of respondents thought that two categories would be sufficient for apples.

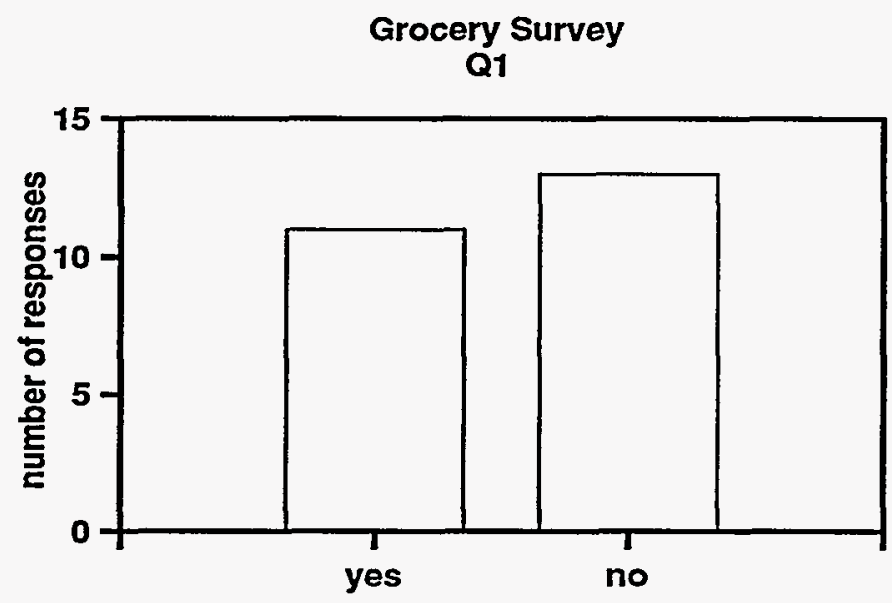

Figure 1. Grocers' opinions regarding reduction of waste or improvement of uniformity and quality for customers if a sorter were used at their facility. 


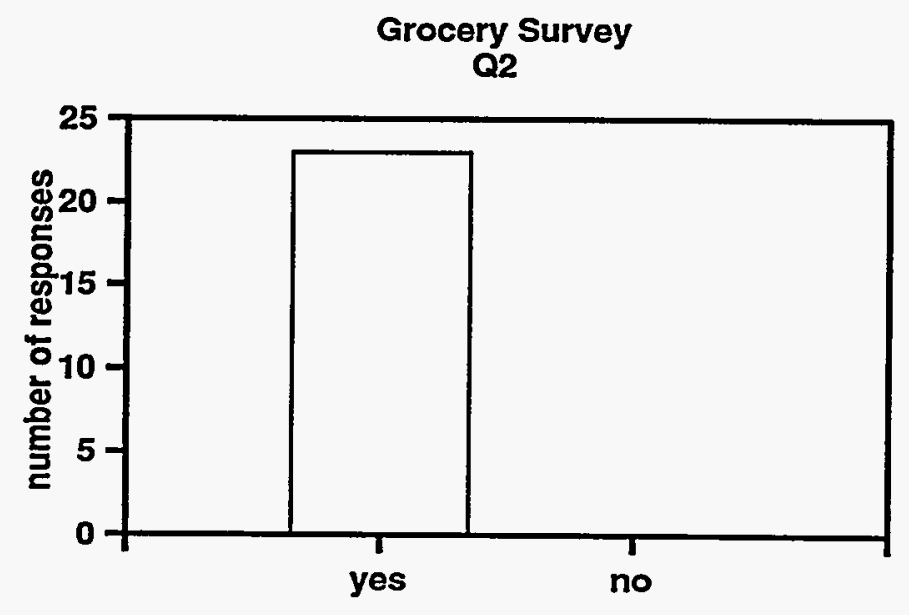

Figure 2. Grocers' opinions regarding reduction of waste or improvement of uniformity and quality for customers if a sorter were used on fruit prior to its arrival at their facility.

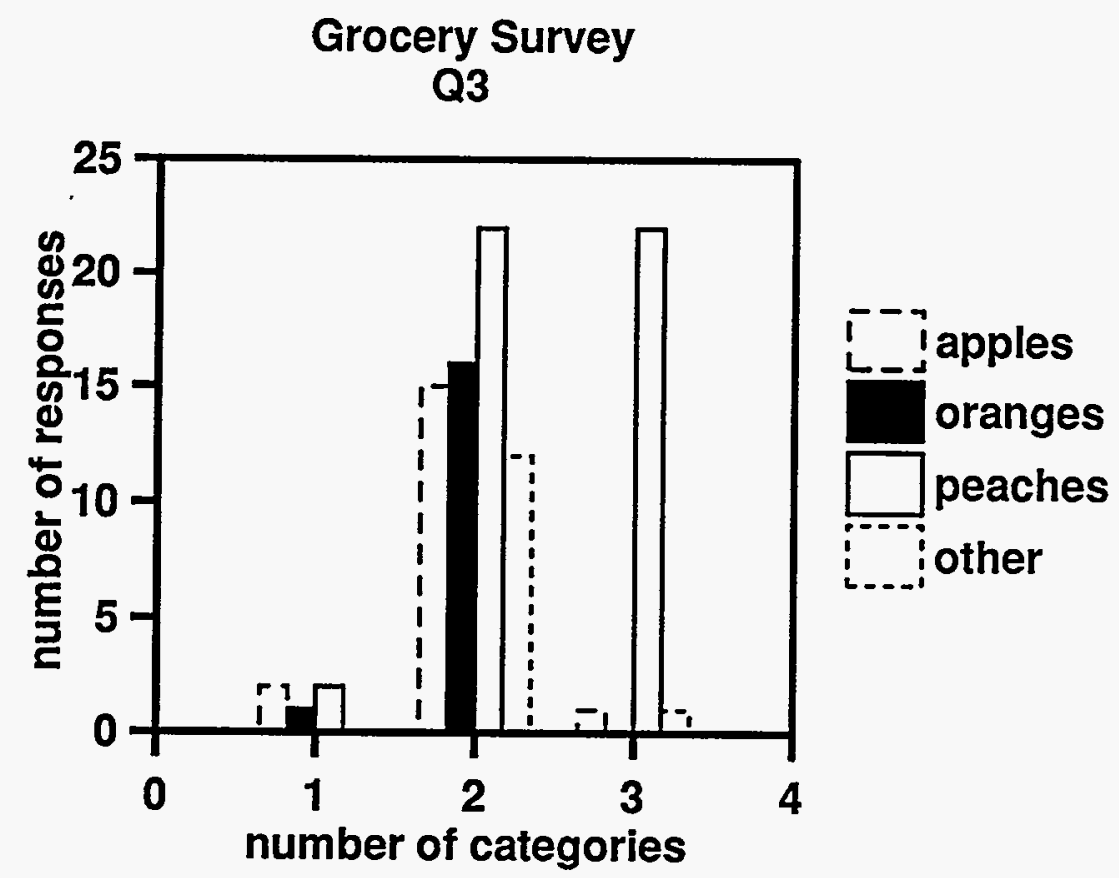

Figure 3. Number of categories desired for sorting various fruits. 


\section{Grocery Survey \\ Q4}

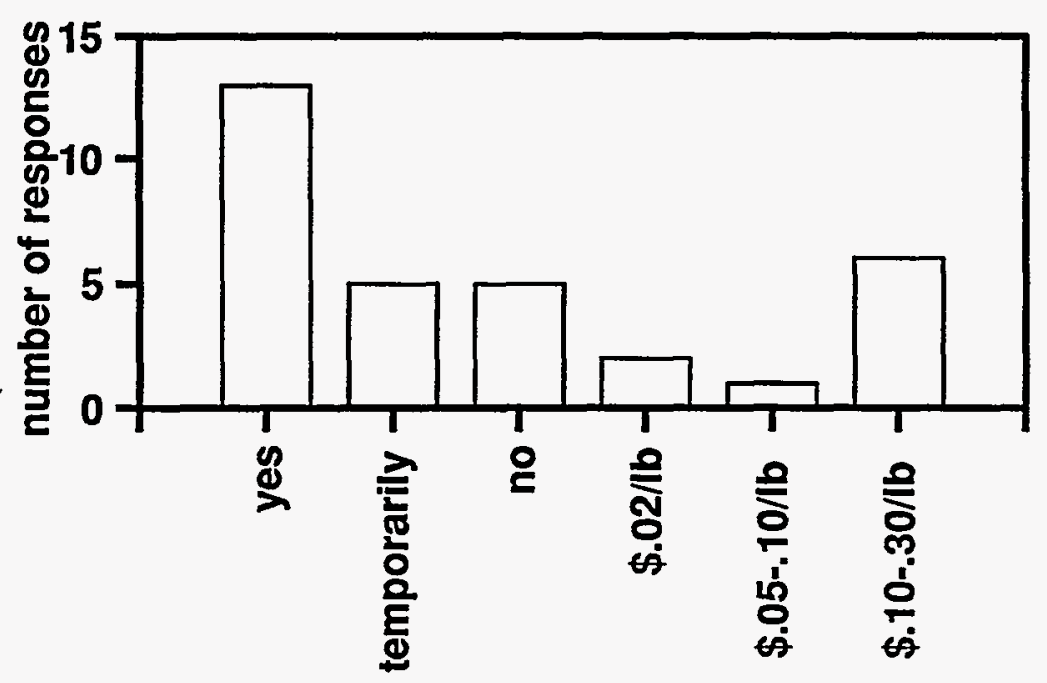

Figure 4. Grocers' opinions regarding the charging of a premium for produce identified as being of higher and more uniform quality by the ripeness sensor.

The grocers were asked whether they thought they could charge a premium for produce of higher and more uniform quality as determined by the ripeness sensor. Although the majority felt that they could charge a premium (Figure 4), approximately 5 indicated that the premium would only be temporary and that as the sensor was used more widely, the higher quality would become the standard. Among those who thought a premium could be charged, the majority thought they could ask $\$ 0.10$ to $\$ 0.30 / \mathrm{lb}$ for the higher quality fruit.

Grocers were also asked several questions relating to the economics of using the sensor. When asked about their annual losses associated with over-ripe fruit several respondents estimated that they lost 1 to 2\% of their fruit (Figure 5). Many gave dollar estimates and these varied widely. No doubt part of the variation had to do with the volume of produce handled by their stores. Several estimated their losses were $\$ 250,000$ to $\$ 500,000$ while several others estimated losses as in excess of $\$ 2,000,000$. Obviously, the ripeness sensor could bring about substantial savings for these stores. As a follow-up question, the produce managers were asked to estimate their yearly gain if they could reduce waste by $70 \%$ and charge a premium for high quality fruits (Figure 4). The responses (Figure 6) varied widely. Some did not think the sensor would work and others were unable to give an estimate. Several others estimated their savings would be relatively small. Five of the respondents saw a potential savings of $\$ 100,000$ or more. However, when the stores were asked how much their company would be willing to pay for a sensor which could sort 12 to 60 pieces of fruit per minute, only two said they would be willing to pay $\$ 10,000$. The choices listed varied from $\$ 10,000$ to $\$ 50,000$ in increments of $\$ 10,000$. The responses apparently reflect the assessment that the sensor should be used by the packing houses.

The last question on the survey asked respondents to list those fruits for which the sensor would be of benefit. As shown in Figure 8, the largest number, 15, felt it would be useful for exotics (presumably these are tropical fruits). However, nearly as many listed stone fruits (peaches, 
nectarines, plums, etc.). Plums were listed separately by 6 respondents. The third highest number of respondents listed citrus as appropriate fruits for testing. Nearly as many listed apples and melons. Several also thought the sensor would be useful for sorting grapes and tomatoes.

Grocery Survey

Q5

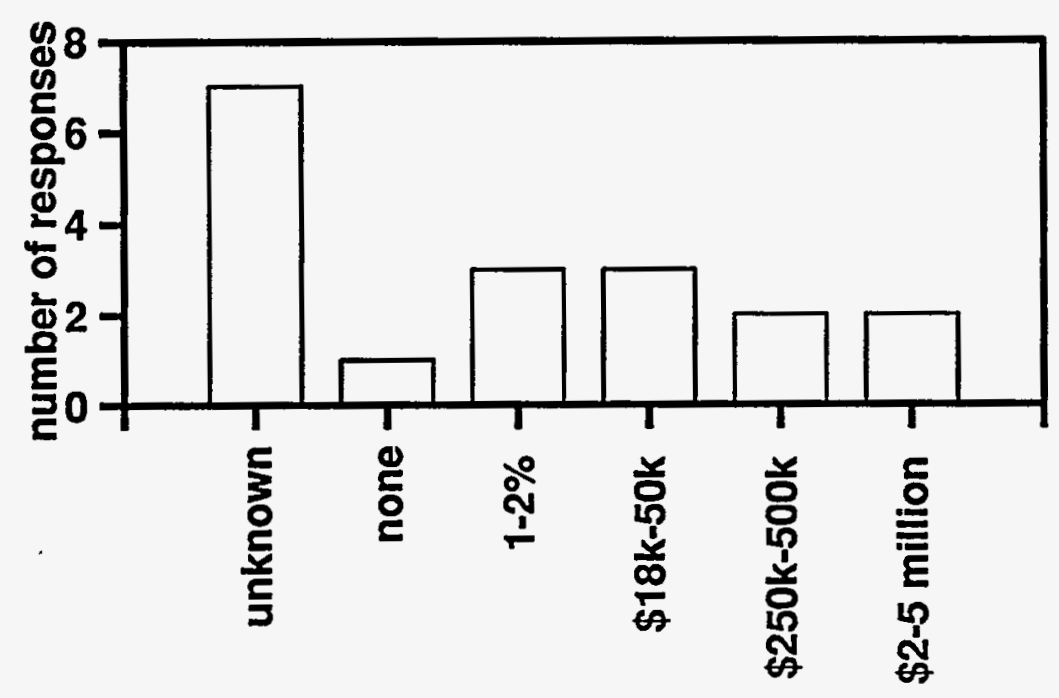

Figure 5. Estimated annual loss to facility for produce which arrives over-ripe or becomes overripe before it is sold.

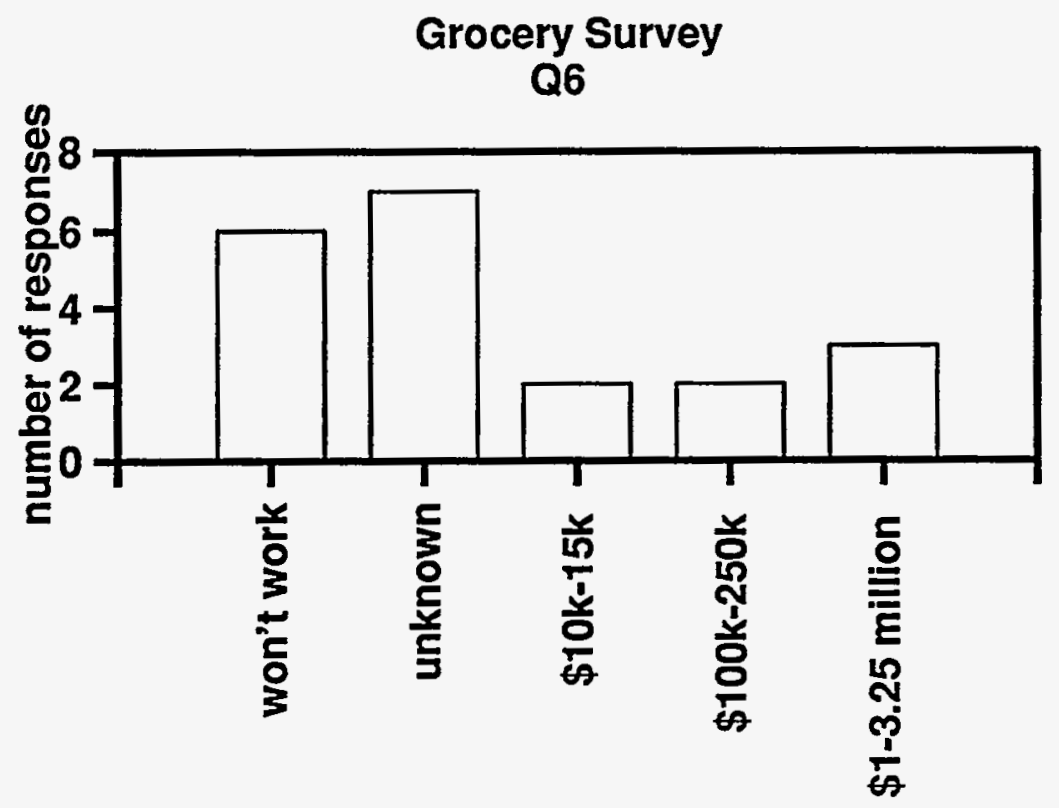

Figure 6. Estimated yearly financial gain assuming premiums could be charged (Fig. 4) and 70\% reduction of waste from over-ripeness. 

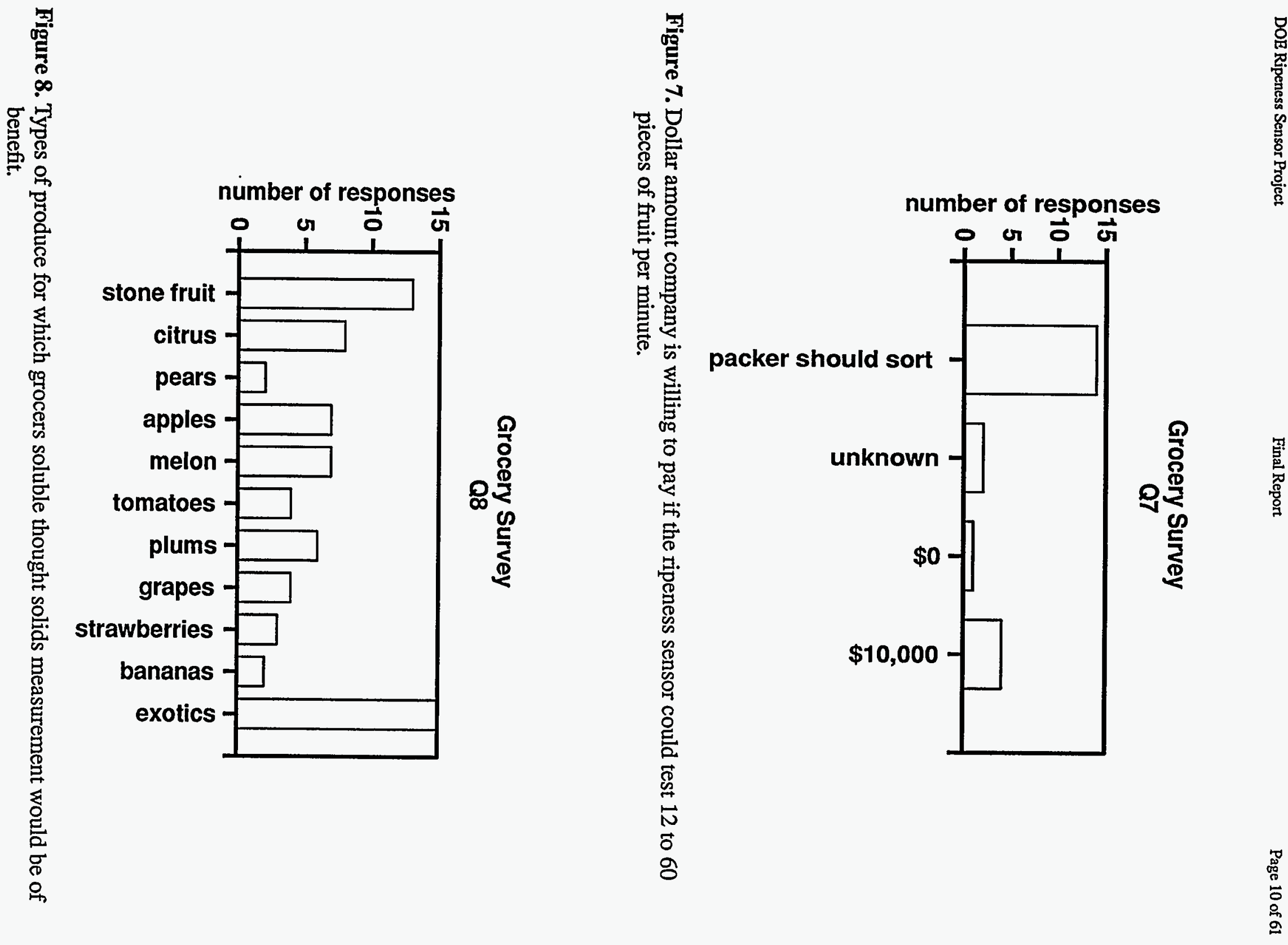


\section{Grower/Packer survey results:}

One-third of the growers/packers surveyed sent in their responses. Response rate varied with the type of fruit handled. Response rates of various groups were as follows: New York apples $47 \%$, Washington apples $54 \%$, Michigan apples $28 \%$, citrus $31 \%$, peaches/nectarines $14 \%$, avocados $12 \%$, miscellaneous $36 \%$. The high response rate among Washington apple growers/packers is probably a reflection of their greater emphasis on quality and marketing. The Washington Tree Fruit Association has established aggressive marketing campaigns which extend into overseas markets. The Association also sponsors research which addresses problems of concern to growers and packers.

Comments from apples growers indicated that firmness is a greater concern than soluble solids content. Citrus growers wanted to determine the sugar to acid ratio of the oranges before harvesting. (Note: This ratio is related to soluble solids level and it may be possible to estimate the ratio on the basis of the soluble solids level). Packing houses expressed a desire to have a fully automated sorter which would handle 300 fruits/minute per lane on an eight lane sorter. These would fit nicely with existing color and size sorters. Several respondents expressed a desire to have a unit which could test 4 or 5 fruits per minute if it were portable and could be taken to an orchard for checking fruits sampled from trees. Results would be used to make decisions about readiness for harvest.

Responses to specific questions are summarized in Figures 9 through 24. The first question asked whether the packer would be willing to use a sensor if it were capable of testing various numbers of fruit per minute as shown in Figure 9. Interest was very low until the capacity reached 120 fruits/minute. Apparently 300 fruits/minute would be an acceptable rate for many. Several growers/packers wrote in 2,000 fruits/min.

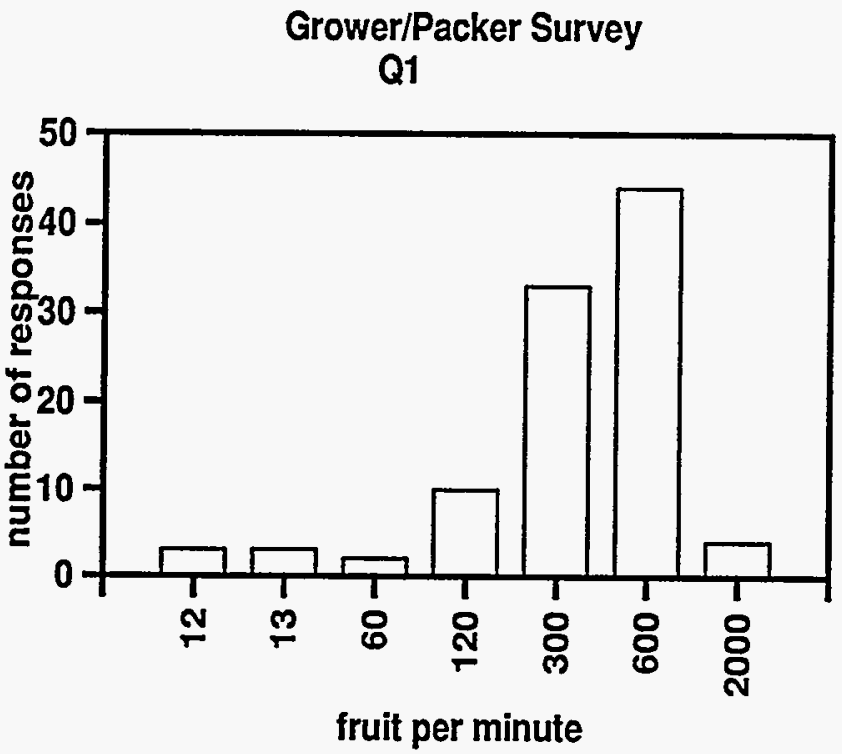

Figure 9. Without regard to the cost of the sensor, the number of fruits per minute growers/packers would want the sensor to be capable of testing. 


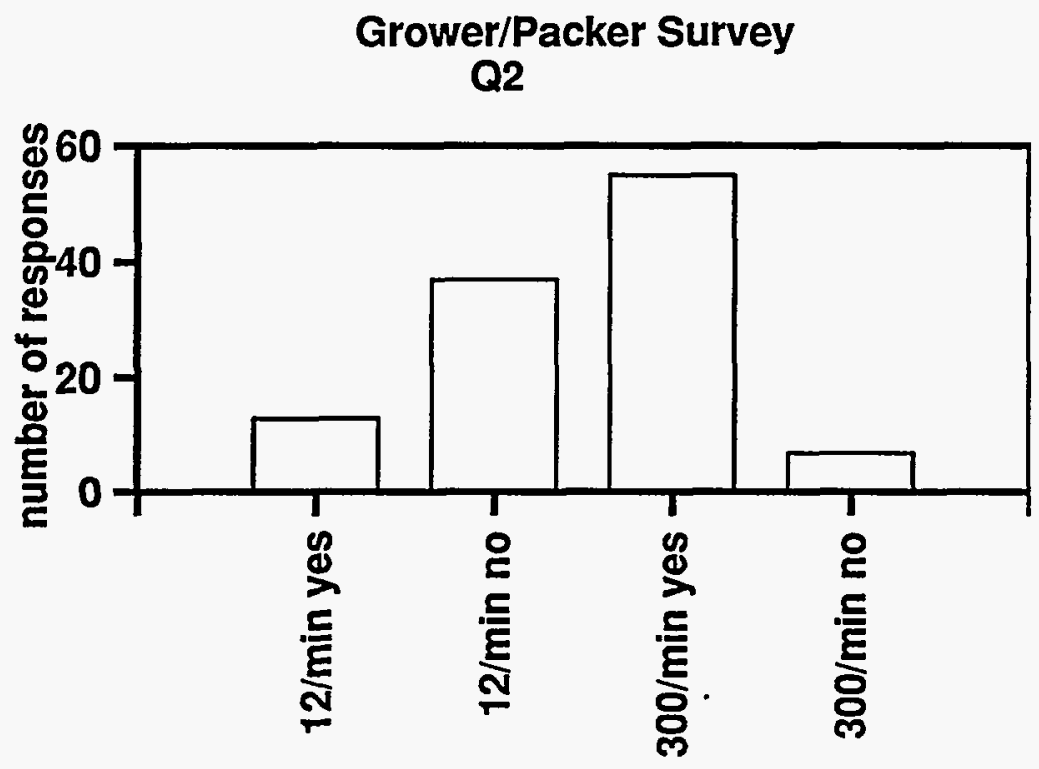

Figure 10. Usefulness of this sensor if added to or replaced current grocers' sorting or quality check methods if it could test 12 fruits/minute, 300 fruits/minute.

Figures 10 and 11 summarize opinions of the growers/packers regarding the usefulness of a slow ( 12 fruits $/ \mathrm{min}$ ) versus a fast ( 300 fruits $/ \mathrm{min}$ ) sensor. Although approximately 10 felt that they could utilize the slower device (Figure 10), the majority wanted only the faster device. Approximately the same number, 10 , responded that the slower sensor could be used in such a manner that it would improve the uniformity of the fruits sent to their customers (Figure 11).

The next several questions asked growers/packers about the precision which they would require before they would be willing to use the sensor and how much they would be willing to pay for the sensor. Most of the respondents wanted a high speed sensor that could test apples to the nearest $1 \%$ or $2 \%$ brix (Figure 12). The number willing to sort apples to the nearest $2 \%$ was slightly higher. A slower sensor would undoubtedly be more precise, and, accordingly, growers/ packers wanted greater precision from the slower sensor. The maximum price which they would be willing to pay for the slower sensor was $\$ 10,000$ (Figure 13) and the maximum price was $\$ 100,000$ for the faster sensor.

For questions 6 through 12 of the survey, growers/packers were asked to choose one type of fruit for which they felt the ripeness sensor would be highly beneficial and give responses for that type of fruit. The first question was whether the slow and fast sensors would change the percentage of fruits which would be diverted to processing. Although some felt that the slower sensor would change this percentage (Figure 14), most felt that the percentage would change only if the faster sensor were used. The proportion who felt that the slower sensor could reduce waste or improve fruit uniformity and quality was similar (Figure 15). Most felt that the slower sensor would not enable them to achieve a quality or uniformity which would justify a premium (Figure 16). Furthermore, only approximately half of the respondents felt they could charge a premium for fruit sorted with the sensor and the premium they thought they could achieve was $\$ 0.01$ to $\$ 0.05 / \mathrm{lb}$. 


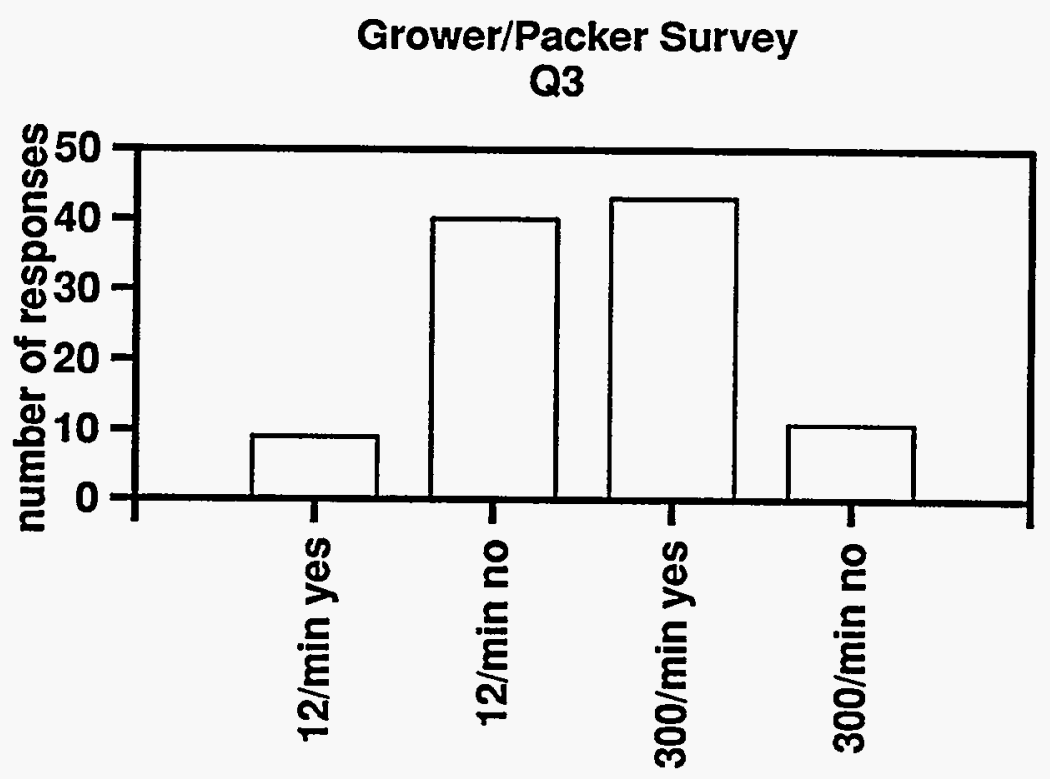

Figure 11. Growers/Packers' opinions regarding the sorter's ability to provide more uniformity for their customers if it could test 12 fruits/minute or 300 fruits/minute.
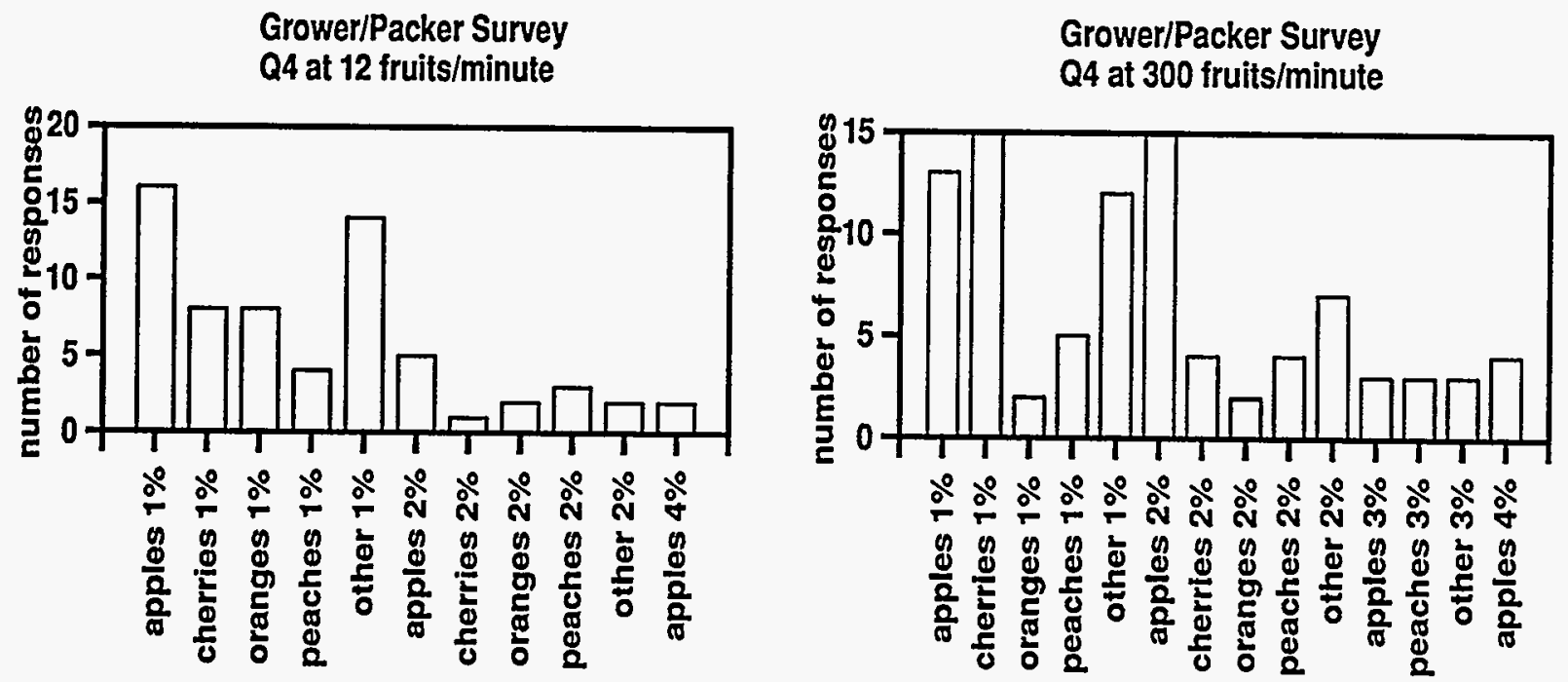

Figure 12. Growers/Packers interest in a sensor if it could test 12 fruits/minute (left) or 300 fruits/ minute (right). Percentages indicate the desired precision in measurement of percent brix for different fruits. 

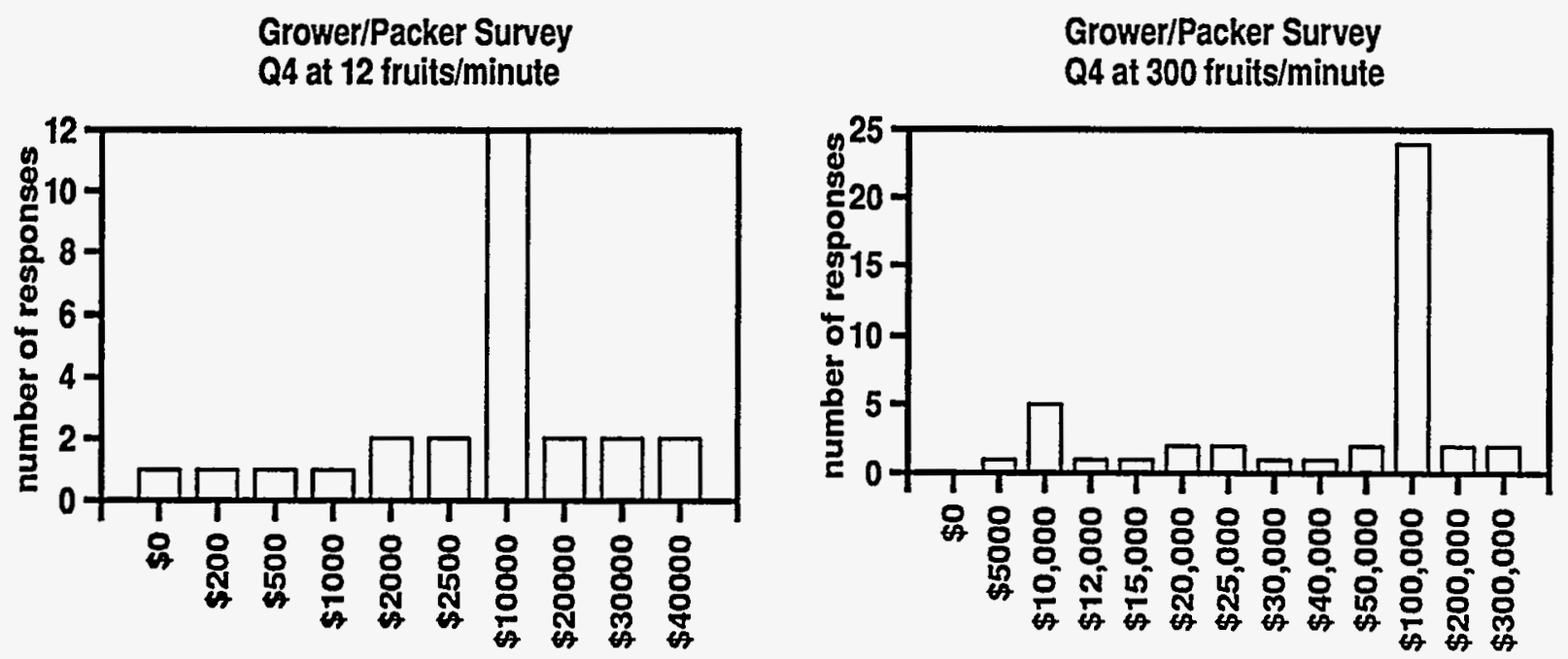

Figure 13. Growers/Packers interest in a sensor if it could test 12 to 60 fruits/minute(left) or 300 fruits/minute (right) and the dollar amount their company would be willing to pay for the sensor.

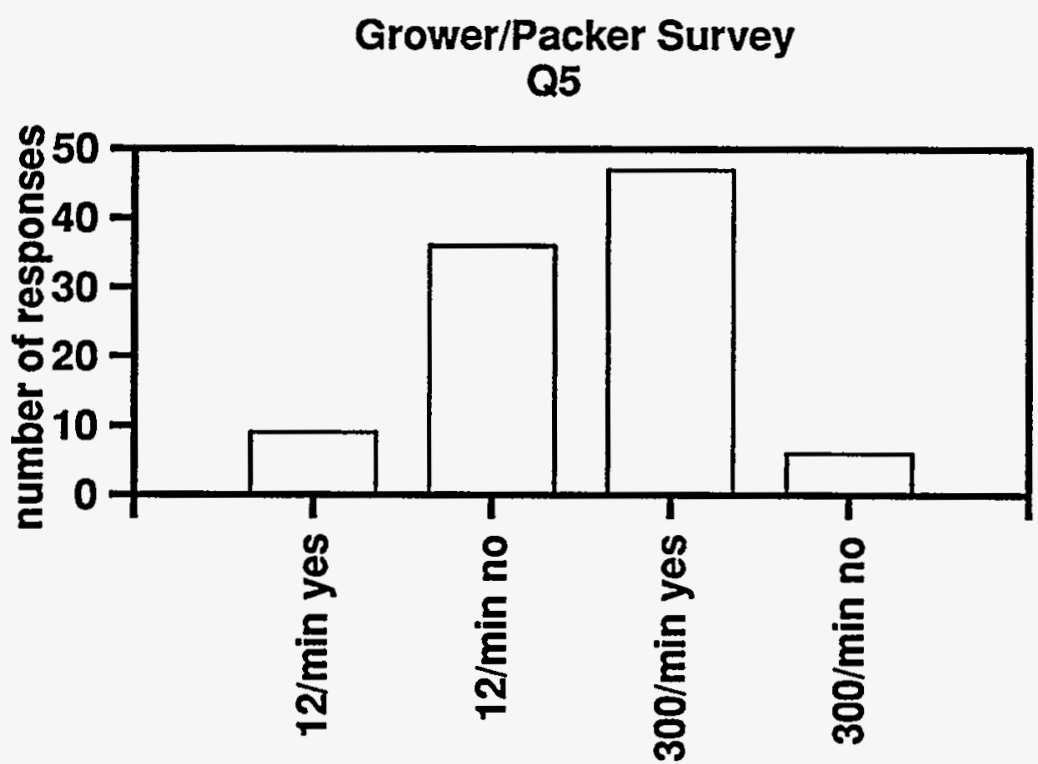

Figure 14. Growers/Packers' opinions regarding the sorter's capability to change the amount and/ or selection of produce sent directly to processing if it could test 12 fruits/minute, 300 fruits/minute. 


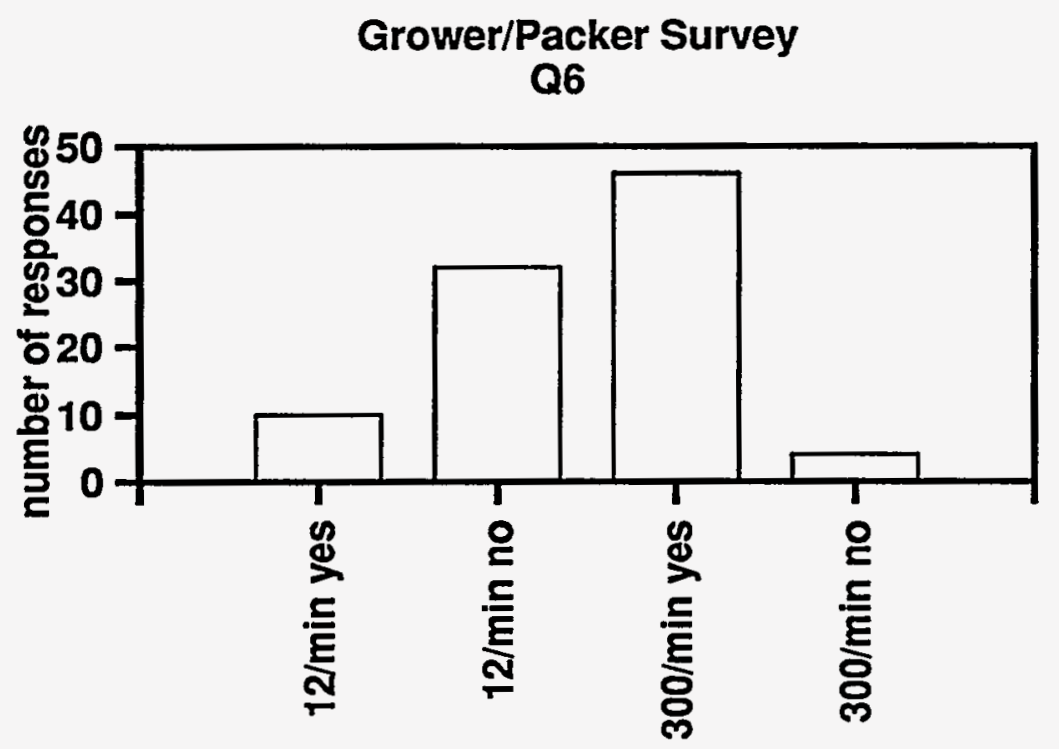

Figure 15. Growers/Packers opinions regarding sensors' capability to reduce waste or improve uniformity and quality for their customers if used to sort produce at their facility if it could test 12 fruits/minute, 300 fruits/minute.

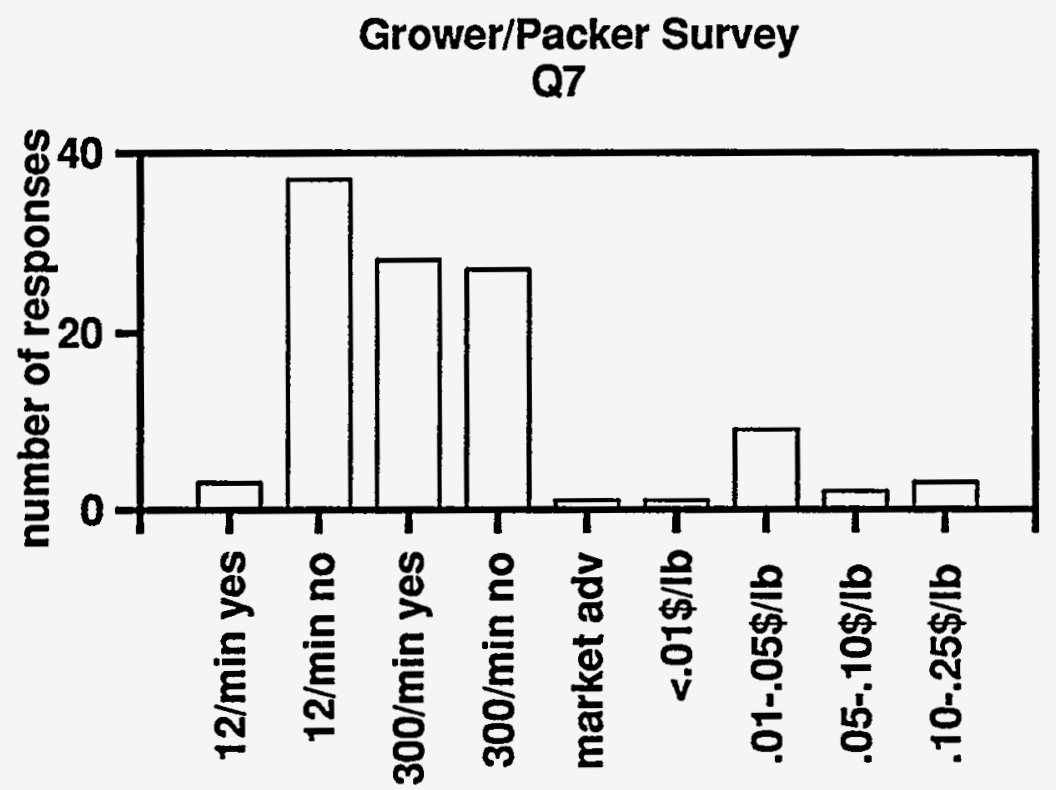

Figure 16. Growers/Packers' opinions regarding whether a premium could be charged for produce of higher and more uniform quality as judged by this machine if it could test 12 fruits/minute, 300 fruits/minute. 
When growers/packers were asked to circle all those methods which they used to sort produce, most responded that they performed a visual inspection, that they used machine vision, and that they checked for firmness (Figure 17). The numbers checking for firmness were probably high because a large proportion of the respondents were concerned with apples, a crop where firmness is very important. At the time this report is being written, only a destructive device, the MagnessTaylor pressure tester, is available for firmness. Therefore they are probably only sampling and testing. Approximately 15 respondents performed laboratory analysis, and these also would have been on samples. Of those growers/packers who sent fruit to processing on the basis of sorting, the decision to do so was most frequently made on the basis of incidental defects, bruising and color (Figure 18). Sometimes it was made on the basis of size and firmness.

Several questions addressed the levels of losses the growers/packers experienced from overripe fruit. Most commonly, less than $6 \%$ of the fruit was lost due to over-ripening (Figure 19). Although annual losses due to over-ripening were usually less than $\$ 200,000$, in at least one instance they were estimated as more than $\$ 1,000,000$ (Figure 20). Respondents were also asked to estimate the yearly financial gain which would result from using the ripeness sensor, if they could charge premiums and reduce losses from over-ripening by $70 \%$. Estimates varied widely and ranged from none to $\$ 750,000$ (Figure 21 ).

The last three questions on the survey were optional. Respondents were asked for which fruits brix measurements would be of benefit. The fruits most commonly listed were apples and stone fruit and many respondents also listed cherries (Figure 22). Again, the large number listing apples is probably a reflection of the large number of apple growers/packers included in the survey. When respondents were asked about the benefit of sensing firmness, by far the most common choice was apples (Figure 23). The last question on the survey, apart from a request for additional comments, was a request for other quality factors which should be measured. Responses are summarized in Figure 24 and are listed by the type of fruit handled.

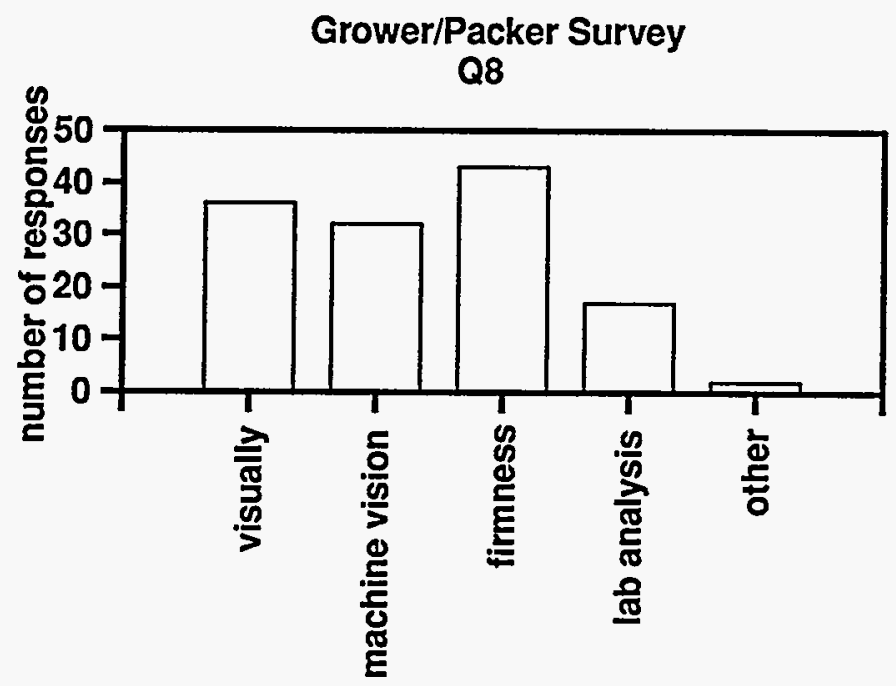

Figure 17. Methods used by growers/packers to sort produce. 


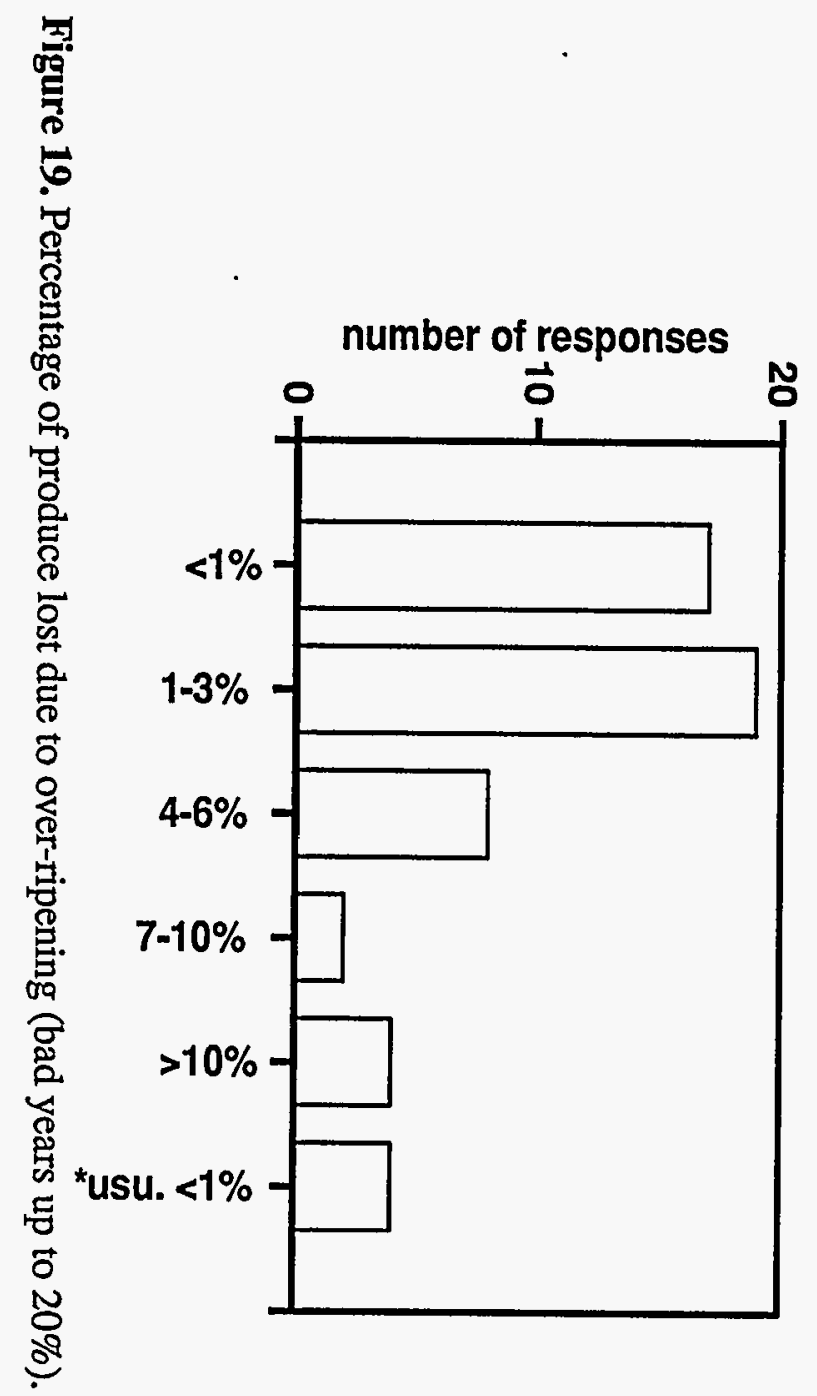

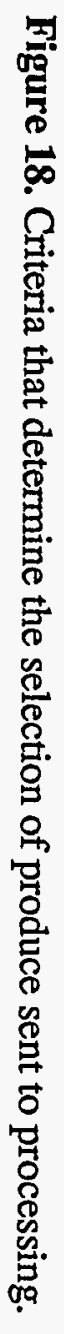

incidental defects number of responses

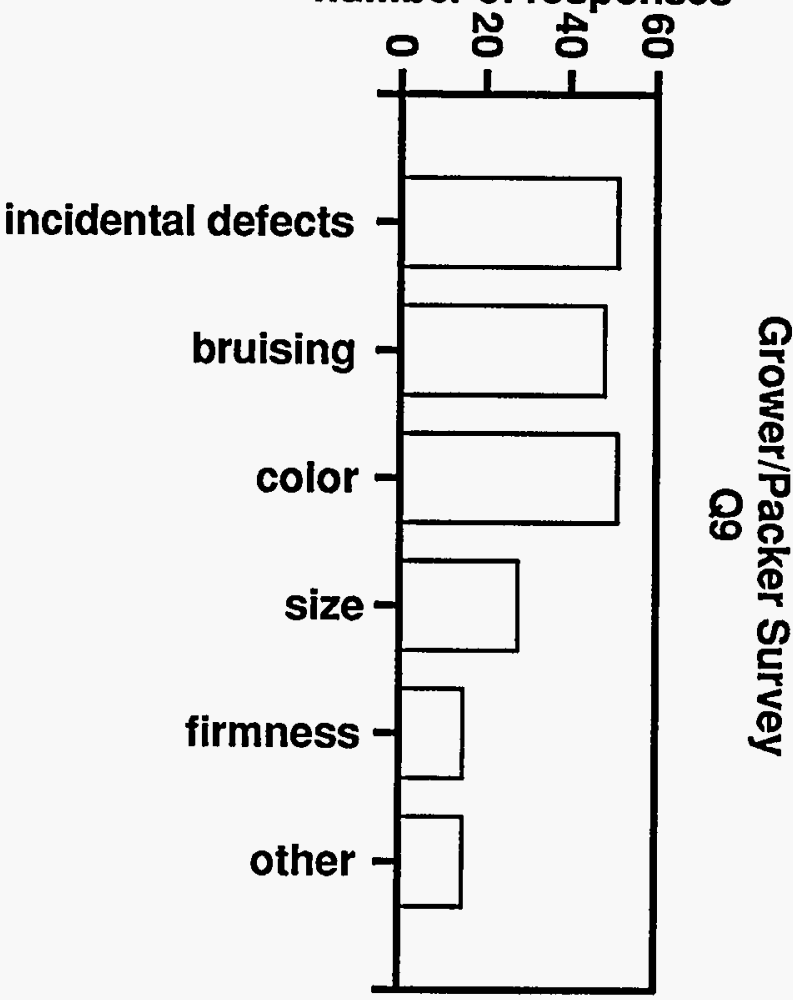




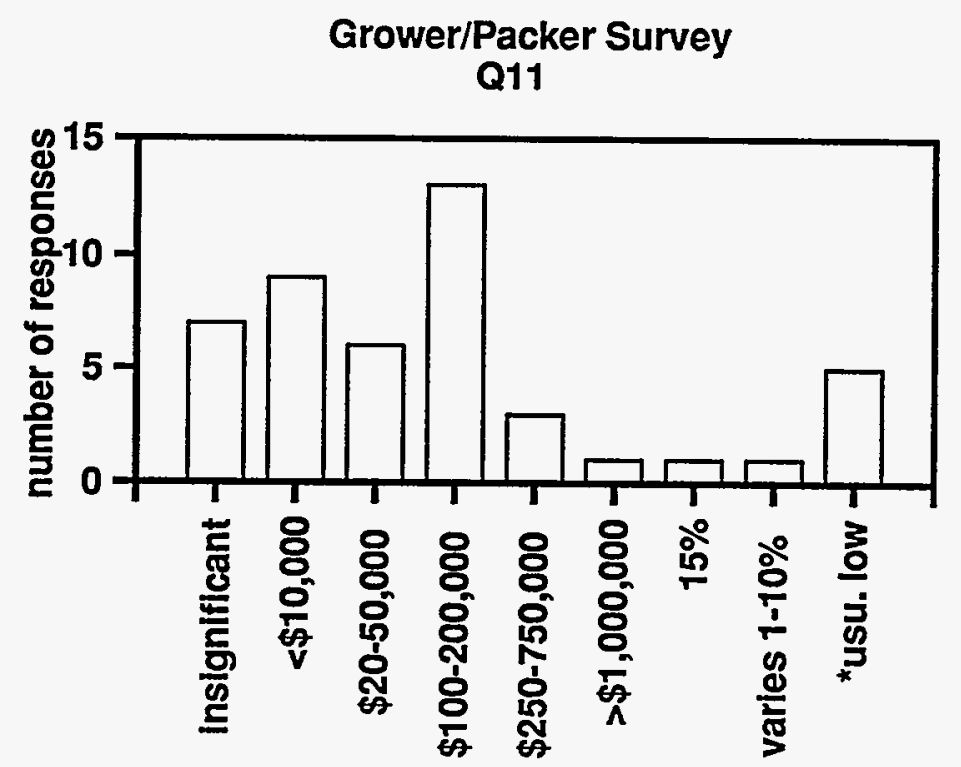

Figure 20. Growers/Packers' estimate of annual loss to their company in dollars for produce that over-ripens (* bad years heavy losses--one company lost $\$ 4$ million in 1989).

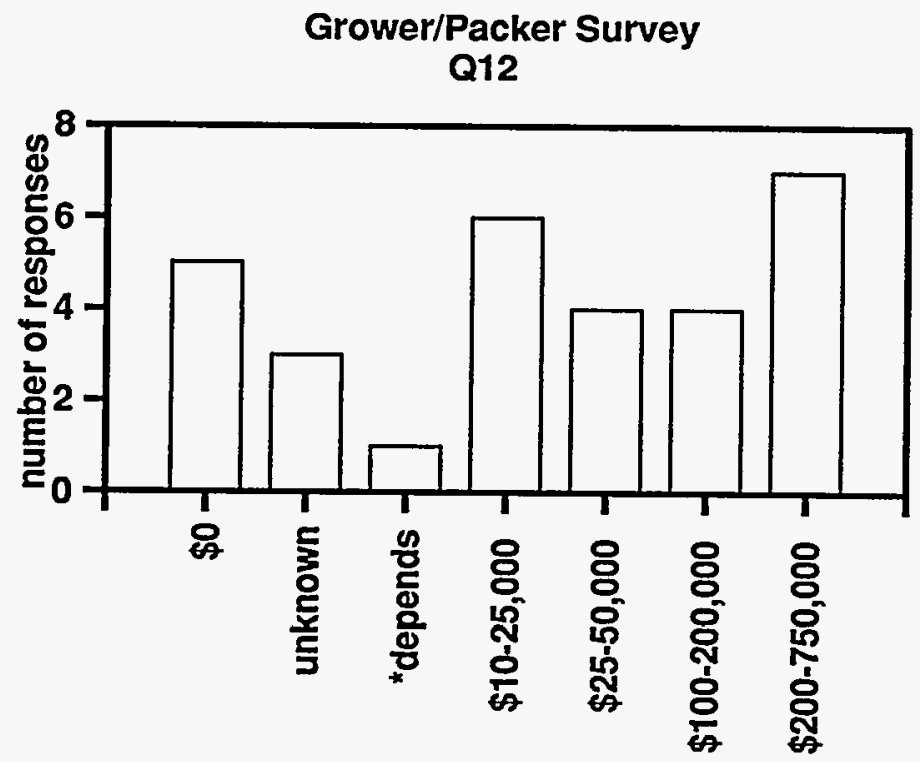

Figure 21. Estimated yearly financial gain assuming growers/packers could charge premiums (Fig. 1.18) and reduce waste caused by over-ripeness by $70 \%(*$ bad years heavy losses). 

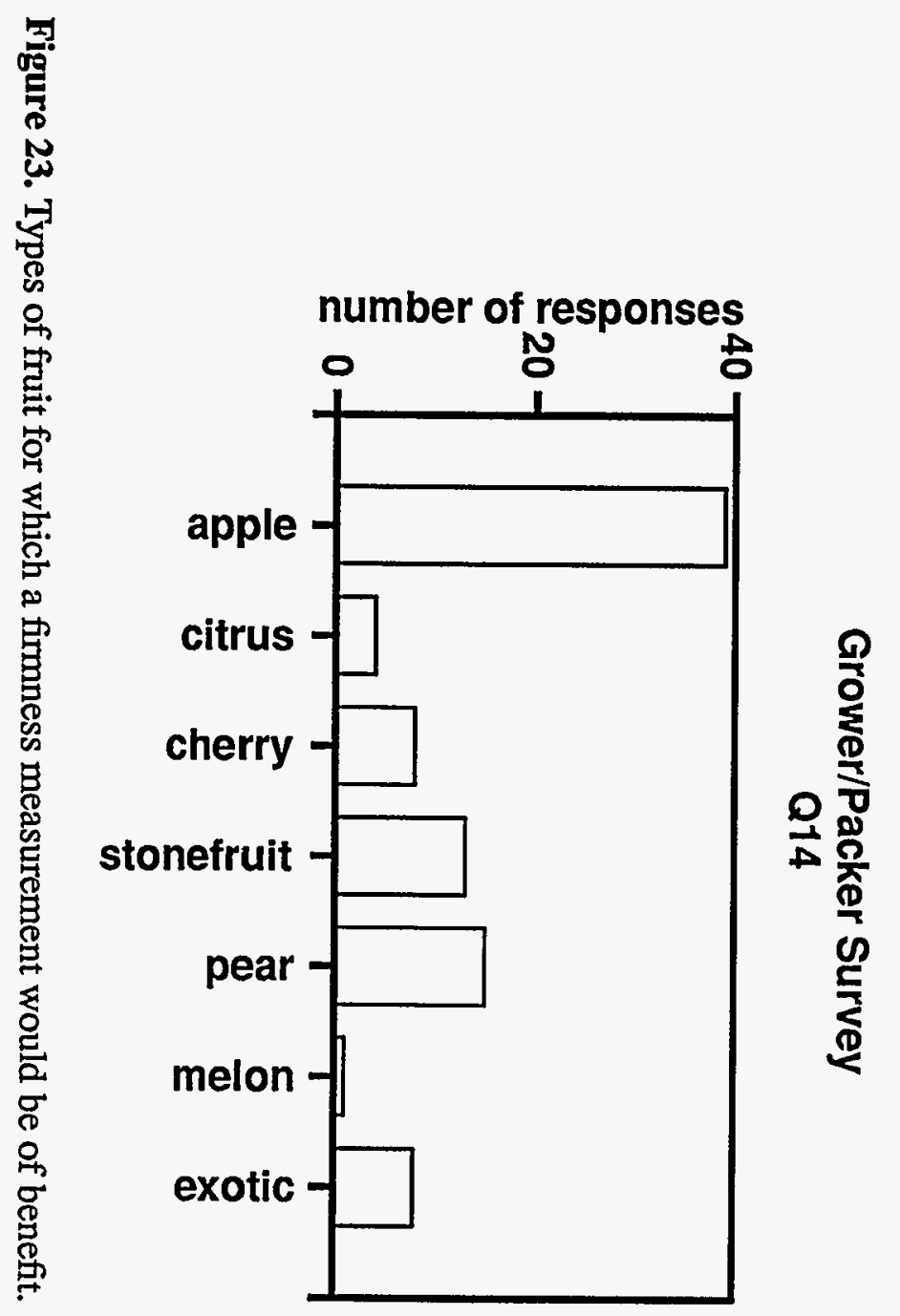

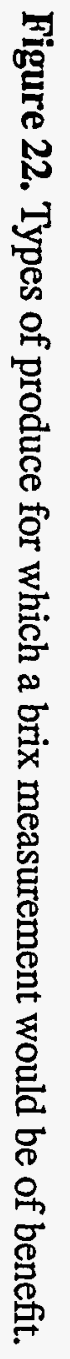

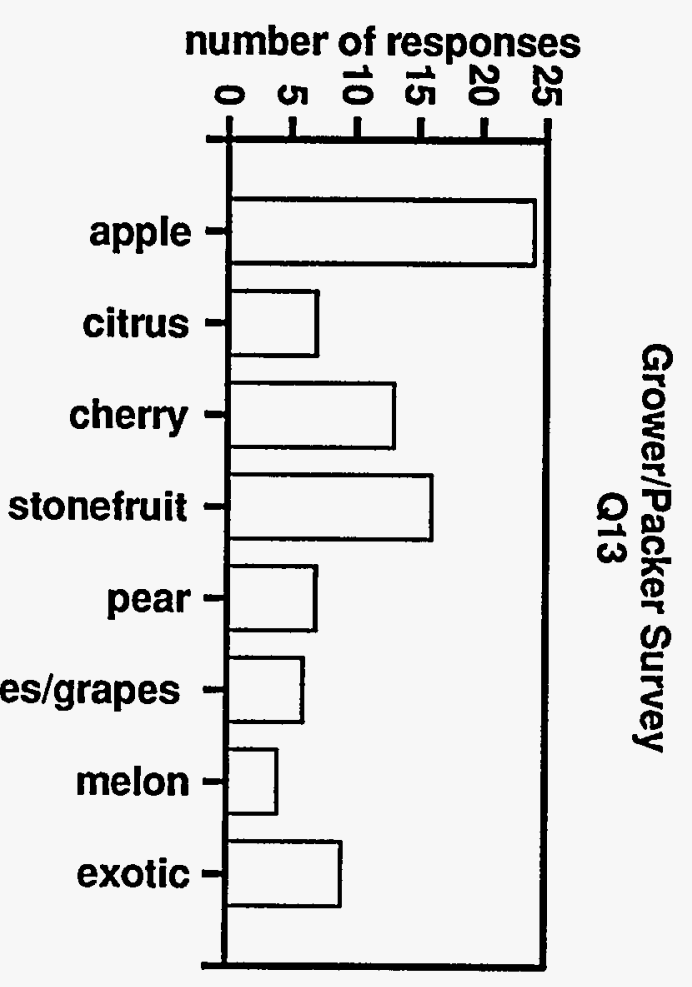



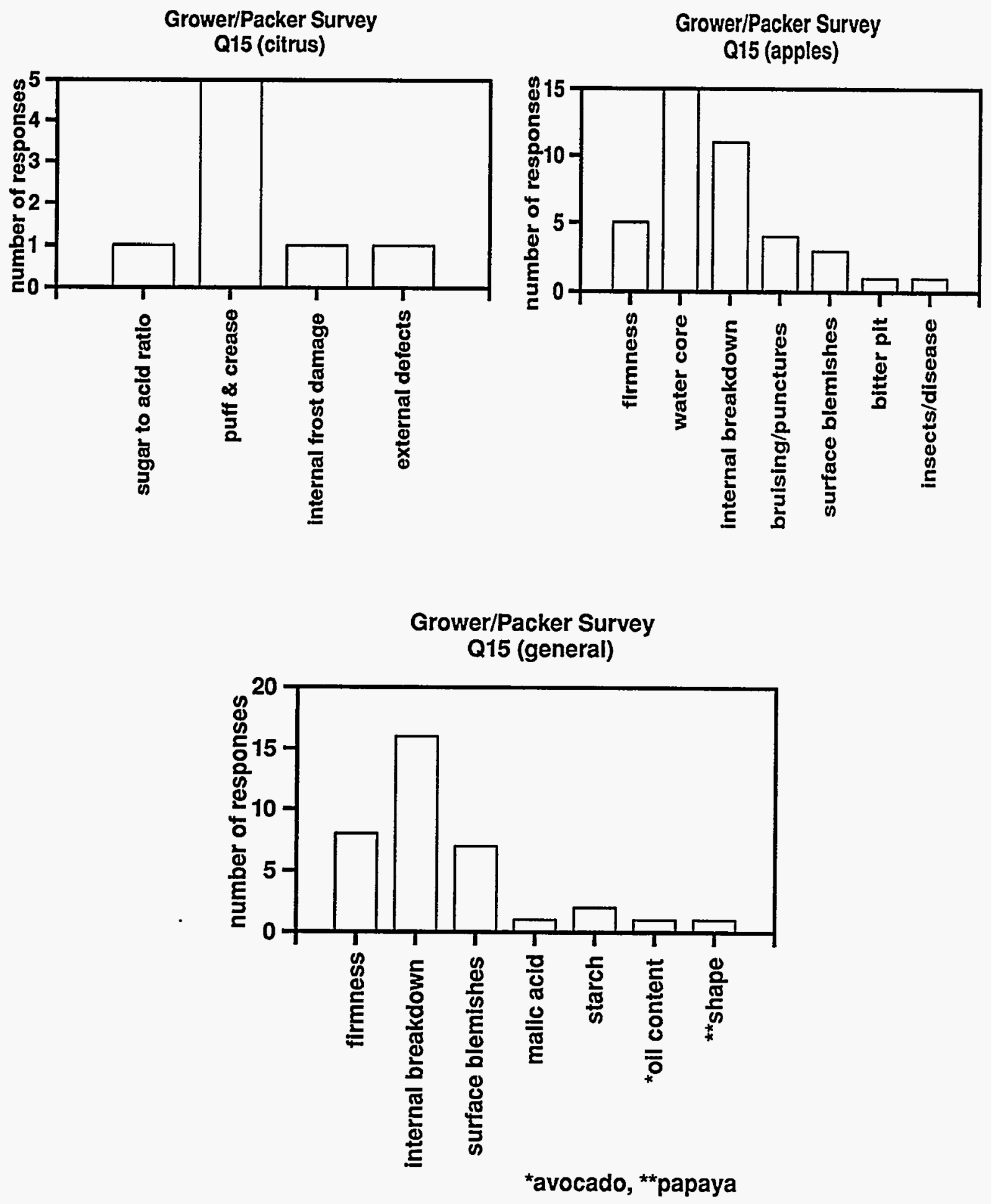

Figure 24. Quality factors which growers/packers feel it would be beneficial to measure. 


\section{Evaluations from Consultants}

The following two sections are reports from consultants in the fruit industry. These were professionals who have worked in the fruit industry for a number of years and are familiar with the concerns of the industry. The report on apples, pears, and cherries was written by an agricultural economist who also works at the IMPACT Center at Washington State University. One of the goals of the center is to help the agricultural industry in the state of Washington develop international markets. In many cases, quality is an important factor in opening such markets. This consultant reviewed the results of Purdue's survey and added insights from his knowledge of the industry.

The consultant who reported on citrus, stone fruit, avocados and mangos has served as a consultant for approximately 20 years. At one time he had managed an orchard. He has established numerous contacts with growers, packers, and processors in the citrus industry, where his consulting is focused. However, he also has contacts with industry people involved with other types of fruits. He made personal visits to many of his contacts and used the survey questions as a basis for his discussions.

\section{Consultant's Evaluation: Ripeness Sensor for Apples, Pears and Cherries}

The following report was written by Dr. Desmond O'Rourke, Consultant and Member of the IMPACT Center (International Marketing Program for Agricultural Commodities and Trade) at Washington State University. His business address is: 104 Hubert Hall Washington State University, Pullman, Washington 99164-6214.

Current Trading Environment: Large food retailers presently control consumers' access to fresh fruits. These retailers are able to put the onus on suppliers to guarantee consumer satisfaction with the products supplied. While fresh deciduous fruit (such as apples, pears and cherries) are shipped at a fixed FOB price from shipping point, retailers have the ability to reject an entire load, or part of a load, or to demand a price adjustment for perceived shortfalls in quality. In general, the shipper will accede to the retailer's request, although he may sometimes seek an inspection by an independent inspector. Generally, the grower retains ownership of the lot until payment is received from the retailer. Thus, the packinghouse has no great incentive to contest price adjustments with the retailer since the cost will be deducted from the final return to the grower. This deduction will not be indicated separately on the grower's returns, so the grower can not identify the cause of the deduction.

Chain retailers who could identify customers for fruit of different ripeness might occasionally wish to sort fruit in their central warehouses. However, because they handle so many different produce items, few retailers are likely to have the personnel capable of segregating their products in such a sophisticated manner. A few retailers who wish to make fruit quality a competitive tool may be willing to develop a central quality control system that would utilize sensors. By the time Washington fresh fruit reaches the retail distribution center, it has on average already traveled 2000 miles, too late to redress any quality problems that may be found. On the other hand, packinghouses have the necessary motivation and personnel to utilize a ripeness sensor effectively.

Thus, the key point in the marketing chain where a ripeness sensor would be most likely to be adopted would be in the packinghouse at shipping point. Packinghouses would be the prime target 
for the proposed sensor. Attitudes of packinghouse operators to nondestructive sensors are currently in the formative stages. In the recent past, standards of acceptability have been based largely on external appearance. However, a growing number of U.S. consumers are becoming increasingly concerned about the internal quality of the fruit they eat. In addition, exports are growing to countries where concern about internal quality is already high. Japan is now the largest export market for U.S. sweet cherries. It is expected that apples from Washington State will enter the Japanese market for the first time in 1995. This will lead to an increase in interest in internal quality sensors among firms packing for export.

Target Fruits: Among the packinghouses surveyed in Washington, Michigan and New York, responses were sufficient to give a representative picture of the economic possibilities for a ripeness sensor. Survey responses conformed to the present reviewer's past experiences and current understanding of the situation in the fresh deciduous fruit industry. The packinghouses which responded to the survey overwhelmingly indicated that apples were the fruit for which a ripeness sensor would be most important. However, the survey was conducted during a season when Washington packinghouses in particular were handling a record crop and were having unusual difficulties with apple quality, especially new varieties. In other years, quality problems in pears, sweet cherries or other fruits might have caused equal concern about those fruits. Again, because Washington State ships most of its apples long distances and dominates U.S. exports of apples, it has to be much more concerned about internal quality than its rivals in the Midwest or east who are within hours of large metropolitan markets.

Effectiveness of Proposed Sensor: The proposed sensor can measure ripeness in terms of sugar level. However, responding packinghouses were most concerned about their ability to measure and control firmness of apples. There is clearly a need to find a way to relate measures of sugar to indicators of firmness. Additionally, it is important to be able to demonstrate to packers that sugar as measured by the sensor is closely correlated with consumer satisfaction and willingness to repurchase apples.

Precision in such measures would also be critical. For example, Washington Red Delicious must exceed 12 pounds in firmness in order to be shipped fresh out of state. In some years, when apples are relatively firm, only a small tail of the firmness distribution will fall in the critical range between 11 and 12 pounds. Thus, errors in allocating these marginal fruit to either the fresh market or to the processing (salvage) market will have little effect on average quality of the fresh pack or on total returns. However, in one year out of five, up to 20 percent of the distribution may fall in the 11-12 pound range. In such a situation, it would be important for any sensor to be able to distinguish very precisely between fruit that could go fresh and fruit that would not qualify for the fresh market. Another important issue mentioned by respondents was that the sensor should be capable of being retrofitted to existing packinghouse lines.

Attitudes of Packinghouse Respondents: Packinghouse respondents indicated that their primary use of a ripeness sensor would be to measure and sort each unit of fruit crossing the packing line. Thus, most would need a sensor for each lane of a multiple lane operation that could handle at least 300 fruit per minute, and about half of these would prefer a sensor that would handle 600 fruit per minute. The key benefits they expected from such use was an increase in customer satisfaction from assurance of a more uniform pack. While some expected a price premium from being able to differentiate ripeness, most did not. This was especially true as more and more sheds 
adopted the sensor so that it no longer provided a competitive advantage. The expected dollar gain from use of the sensor was low relative to the total revenue that these businesses generate.

Effect on Processing Diversion: Most respondents thought that use of faster sensors would increase processing diversion, but this would lead to offsetting results. On the one hand, more fruit would be sold in a lower price market. (In 1994, apples for juice have sold for $\$ 40$ per ton, compared to $\$ 200$ per ton for fresh market apples.) On the other hand, the quality of the fresh pack, and the reputation of the packinghouse would rise, with possible eventual gains in price premiums. Since diversion is now achieved largely through visual checks, the addition of an accurate, objective sensor could lead to increased diversion, particularly in years of lower quality. One packinghouse pointed out a longer-term benefit of an objective sensor. They would be better able to diagnose what was causing poorer fruit and take actions to reduce the incidence of poorer fruit.

The estimated loss due to overripe fruit was quite low, $<3$ percent for most respondents. However, many commented that losses varied widely between years and were only occasionally severe. This means that in purchasing a sensor system, the buyer would have to weigh both the expected frequency and the expected severity of poor fruit occurring over the useful life of the system. Thus, the decision would be much more complicated than for a phenomenon which occurred regularly with the same severity.

Effect on Retail Losses: Retailers report considerable losses from fruit that must be disposed of as unsalable. Many of these losses are attributed to over-ripeness, although mishandling, poor stock rotation, lack of cooler space or cosmetic aspects may be contributing factors. There is clearly an opportunity to educate retailers about how a ripeness sensor could be used as a key element in a program to reduce fruit losses.

Retailers and food processors are currently involved in a nationwide effort, labeled Efficient Consumer Response (ECR), to squeeze waste out of the food system. The goal of ECR is to move product through the food system at the same rate as it is utilized by consumers. The biggest single efficiency target is reduction of the various costs associated with excessive inventory, such as interest charges, storage costs, product deterioration or the need for special price "deals" to move surplus inventory. Eventually, ECR will be applied to the produce industry where the perishable nature of the product makes inventory problems more difficult and costly.

Energy saving will be particularly important to retailers of produce. Energy is a major component of the cost of storage, transportation and display of perishables. Unless a produce item is usable by the consumer, all the energy devoted to moving it from the production area has been wasted. Control and management of the stage of ripeness of produce is essential if this energy waste is to be reduced. In some seasons, and on some fruits and vegetables, up to 20 percent of the product and the accompanying energy load are wasted.

Willingness to Pay: Respondents appeared to be aware of the potential usefulness of the proposed sensor to their operations. However, they varied widely in their willingness to pay for a set of sensors. The leading packers appeared to be willing to pay up to $\$ 30,000$ for an effective sensor, or $\$ 500,000$ for a system with sensors on each lane. These innovators would require demonstrated effectiveness. If they introduced ripeness sensors, the followers in the industry would have 
to fall in line fairly quickly. This has been the experience with electronic color sorters.

Other Uses of Ripeness Sensor: Individual respondents saw specific benefits for their operations even from sensors that could handle only 12 fruit per minute. Used only on a sampling basis, sensors could: 1) reduce wrongful classification of fruit; 2) sort out immature fruit either in the orchard or before packing; 3) speed up sampling processes and free up quality control personnel for other activities; 4) be another step towards fully automated packing; and 5) improve diagnoses of the causes of overripe fruit and reduce its incidence. Clearly, a ripeness sensor available only at sampling speed could still be a valuable tool for many packinghouses.

Summary: Apples are the fruit of greatest concern to these packers of deciduous fruits. Firmness is the characteristic in apples which currently causes the most problems. A ripeness sensor is not the exact equivalent of a firmness sensor. However, the resulting sensor would be very desirable if the relationship could be established between ripeness and firmness, or the sugar sensor could be shown to correlate closely with consumer satisfaction and willingness to repurchase fruit. The leading packinghouses have the resources and the expertise to use a ripeness sensor and to pay for it. Once they adopted such a sensor, competitors would be forced to follow suit to remain competitive. The leading retailers have the resources to pay for a sensor, but rarely the personnel or motivation to use it. As their campaign to streamline the food system picks up steam, they may become more interested in the energy and cost savings a sensor can bring them.

The worldwide competitive battle in deciduous fruit increasingly hinges on the ability of packers to deliver a quality fruit to each individual consumer. Continued efforts to perfect sensors that can nondestructively measure various internal characteristics are vital to the long-term competitiveness of the U.S. fruit industry.

\section{Consultant's Evaluation: Ripeness Sensor for Citrus, Stone Fruit, Avocados, and Mangoes}

The following report was written by Mr. Alvin Friesen, consultant to the citrus industry. His address is: Agricultural Consulting Services, 1355 Stanford Avenue, Upland, California 91786.

The FRESH FRUIT industry today is making remarkable changes in what is being offered to the consumer. The industry is recognizing that the nutritional value of fruits and vegetables is an important consideration for many consumers. For almost all fruits and vegetables, increasing emphasis is being placed on flavor, wholesomeness, and eye appeal. This has escalated the search for new varieties that mature at the proper time and can be shipped to market mature and ready to eat with "picked from the tree" flavor. Major changes in handling and packaging methods have made these changes possible.

This report discusses the demand of today's sophisticated consumer for high quality produce and especially the demand for tree ripened flavor by citrus, stone fruit, avocado, and mango growers and shippers. Specifically, I asked them about their interest in a non-destructive tester which could be used to determine "ripeness" (i.e., "sweetness" or sugar content).

CITRUS: There are three main growing areas of citrus in the United States: California-Arizona, Texas and Florida.The citrus grown in California-Arizona is grown for fresh consumption with only that portion which is cosmetically imperfect or under sized being diverted to by-products or juice. The two major varieties are the Navel and Valencia orange. Current plantings are 
approximately 131,000 acres of Navels and 84,000 acres of Valencias. For the evaluation of a ripeness sensor in this industry, I interviewed numerous shippers of Navel oranges because this variety would be the most likely to benefit from this technology.

When citrus fruit is harvested, all the fruit is removed from the tree at one time. This differs from the methods used for stone fruit where as many as four pickings may be made as fruit ripens over a short period of time. Citrus fruit can and does remain on the tree for as long as six months and continues to increase in sweetness or sugar content during that time. Citrus trees can have multiple blooms and this will give a range of maturity on the same tree.

Fruit harvested at the beginning of a crop season generally is in greater demand and receives a higher price. It is also being harvested at minimum state standards for maturity. The minimum currently in effect is an 8 to 1 sugar to acid ratio. This ratio does not give consumer satisfaction and results in reduced sales after the initial sales are made, usually in about 2 weeks. There is no way for the consumer to tell the difference between an orange with the minimum 8 to 1 sugar ratio and an orange with a 9 to 1 sugar to acid ratio. The orange with the 9 to 1 ratio gives a much higher level of consumer satisfaction. A device such as the ripeness sensor could greatly improve the product as well as give additional revenue for a superior grade.

Most of the packing houses are equipped with electronic grading machines for sizing and for grading on the basis of exterior appearance. The fruit is singulated in a cup and passes under a scanner for viewing. The capacity is increased to the desired level by using multi-lane installations. Speed of these graders varies greatly between manufacturers, but in order to be accepted by the industry, a ripeness sensor used for on-line sorting would have to achieve the same or nearly the same speed as the company's current grading equipment. A good average would be 6 to 8 fruit per second per line. Another aspect to consider is fruit diameter. Generally the largest oranges packed would be a size 40 or 48 . This number denotes the number of oranges in a carton. The average diameter of a size 40 orange is 3.71 inches and the average diameter of a size 48 is 3.56 inches.

An evaluation of the economic returns achieved by a packer through use of the ripeness sensor is further complicated in citrus because the condition that makes it valuable diminishes with the advance of maturity in the orange, generally in about 2 months. This could make the industry rethink the need to have it as an integral part of the grading line. The ability to have a portable unit could have merit and could even allow it to be moved among commodities in a geographic area.

The ability to recover cost with a "guarantee of ripeness" is difficult to measure. Knowing current consumer trends, shippers could easily receive a $\$ 1.00-\$ 2.00$ premium per carton for this fruit. Shipments in the early part of the Navel season average from 1,000 to 1,500 cars per week. (Note: A car is the equivalent of one thousand 40 pound cartons). This demand would last for two to three months or until all oranges on the tree were of satisfactory consumer acceptance. A range of 30 to 50 percent of the fruit shipments during that time frame should make the premium grade. A side benefit of being able to make deliveries that meet with consumer satisfaction would be repeat sales.

The Texas citrus industry was hit by several killing freezes and has not recovered totally from that disaster. Most of the new planting and production is centered around grapefruit, and because of size limitations on the current sensor, I did not do any interviews for grapefruit. 
The Florida shippers have shown little interest in a ripeness sensor as a minimum maturity device. Their fresh citrus fruit (both tangerines and oranges) is generally much higher in brix than that produced in California and, on the basis of taste, gives a high level of consumer satisfaction. Florida does not have the cosmetic or blemish free exterior that is usually expected from California-Arizona citrus. A major portion (80\%-85\%) of Florida oranges are grown for concentrate. The maximum return is realized when the brix-acid ratio reaches 16 or better. The growers will wait until this ratio is reached before harvesting. This fruit is used almost entirely for orange concentrate (FCOJ). This is the highest quality and grade and it is sold on the orange futures market. A listing of FCOJ usually has color and brix as the basis of quality. Several of these shippers indicated that a portable sensor that could be used on the back of a pickup could have merit.

There is a great potential for ripeness sensing in Florida grapefruit. It is harvested in September for the Japanese export market. This is a premium market and would be able to receive valueadded revenue. I suggest we continue to gather data on the smaller sizes of grapefruit so that the industry can see how a ripeness sensor could be used. Having had extensive experience in the Japanese market for the last 22 years I think the Japanese would pay an additional $\$ 1.00-\$ 2.00$ for a "guarantee of maturity".

A RIPENESS SENSOR used in the citrus industry, either in California-Arizona or Florida, will have to be practical. This means it should be a user-friendly machine. The personnel in today's packing houses will generally be familiar with computers. However technical adjustments and problem solving would have to remain a function of the manufacturer. The wholesaler does not have time or space to repackage and if the value added is requested by the consumer, it will be up to the grower-shipper to provide that service. I could see only a limited number of retail supermarkets making use of a sensor but most likely for other than citrus. In most areas back room supermarket employees are members of a union, and their wages are generally at least 3 times higher than the wages paid by the shipper. This makes repacking in the back room almost prohibitive.

STONE FRUIT: Major stone fruits for which the ripeness sensor could be used are primarily peaches, nectarines, and plums. During the last ten years the plant breeders have placed much of the emphasis, when developing new varieties, on size, color and firmness. Taste has seldom, if ever, been considered. The major objective appears to have been to get the fruit to market so it looks good without bruising even after having been run at high speed over packing equipment. Only in the last several years has taste and consumer satisfaction been given a higher priority.

Increased retail demand for better tasting, high-maturity peaches or nectarines has motivated many of the major shippers to get involved in tree-ripe programs. The objective of such programs is to leave the fruit on the tree longer. Gentler handling methods are used to ensure that acceptable quality, mature fruits are delivered to the consumer. This may be a natural application for the RIPENESS SENSOR. Demand for tree-ripened fruit was once limited to markets only hours from the source, because of bruising in handling and transportation. In the past "tree-ripe" was a byproduct of conventional packing operations. However, today most shippers are managing their orchards with high-maturity in mind. 
Shippers that I talked with requested a sensor that could be portable for use in orchards. The picker starts the process. Once the fruit is picked, the shipper will want to market the fruit, regardless of the quality. The management would use the sensor as a guide for training pickers on what fruit to harvest. New varieties tend to be highly colored yet still not mature. A method of educating the picker on the color and firmness characteristics of mature fruit is essential. Studies show consumers are reluctant to buy firm fruit unless they know the fruit is ripe. Otherwise, they will purchase staples such as bananas, apples and oranges.

The California Tree Fruit Agreement has done considerable research on maturity. Some ongoing work on nectarines, plums, and peaches was carried out from 1980 to 1992 by Carlos H. Crisosto, U.C. Davis, KAC. He discussed advantages and disadvantages of different maturity indices. The use of ground color, although an imperfect index, actually appeared to be the most practical and reliable method for determining minimum maturity. By correcting color chip sequences in the optical sorters, some of the limitations of this maturity index could be overcome. He found that fruit firmness was an excellent indicator of maximum maturity and he concluded that a combination of ground color and fruit firmness may be better than a single index to assay stone fruit maturity. Fruit soluble solid contents (SSC) varied among orchards and from tree to tree. Therefore, it was not a reliable indicator of fruit maturity. However, SSC is a good indicator of fruit quality. The development of new technologies in the near future, such as near infrared (NIR), magnetic resonance (MR), and light transmittance (LT) will lead to an ideal, non-destructive, and reliable maturity index.

Further studies are being done by David Slaughter, UC Davis, on NONDESTRUCTIVE SENSING OF QUALITY ATTRIBUTES IN PEACHES AND NECTARINES. This study was done in 1992 and determined that non-visible near infrared (NIR) light could be used to determine the soluble solids, sucrose and fructose content of intact peaches without damaging the fruit.

In summary, the opportunities for commercial use of a ripeness sensor are possibly the greatest in the stone fruit industry. The ability to provide high quality fruit to the consumer on a consistent basis would not only give consumer satisfaction but would open doors of opportunity in increased sales. If a sorting machine could be designed to separate peaches, nectarines or plums which have very high soluble solids or sugar contents, such fruits could be marketed separately to consumers who are willing to pay a premium.

AVOCADOS: The California avocado industry had a record crop in 1993. It harvested nearly $570,000,000$ pounds. With this kind of volume, marketing personnel had to try new merchandising technics. As a sales tool, Calavo, which markets nearly 40 percent of the crop, established regional ripening centers to give customers the product "ready to eat". The 1994 crop will only be one-half of that of last season. However, with such bumper crops possible in the future, the packers are looking at every possible advantage that technology can provide.

It has been shown that avocados are often purchased by consumers on the basis of an "impulse" and therefore the introduction of "ripe-ready tonight" has stimulated sales. Because fruit is firm when shipped to retailers, a ripening room is used where each box is opened and ripe fruit is separated from the remaining fruit. This could be an excellent application for the RIPENESS SENSOR. Calavo has established seven ripening centers for this purpose. Further discussions should be held with Calavo to see if the sensor could be used in such facilities. 
The export market has only recently been tapped by the avocado industry. The major market is Japan. Fruit selection is very critical and fruit arriving must be uniform in maturity. Several of the handlers interviewed felt a device such as the sensor could be a valuable asset. Currently, sorting is done on the basis of color. This is not always a reliable indicator. There is only minimal loss of over-ripe fruits at the shipping level because over-ripe fruits are processed into frozen guacamole.

It should be possible to obtain a premium for avocados of uniform ripeness, especially in the food service industry. Without further study I could not estimate the dollar amount of this premium.

MANGOES: The mango is the most popular fruit in the world; it has universal appeal for its sweet flavor. The nutritional value of mangoes is a source of vitamins $A$ and $C$, potassium and fiber. The U.S. has the lowest per capita consumption of mangoes in the world. The United States imports most of its mangoes from Mexico, which has provided about 85 percent of the total U.S. mango supplies during the past five years. Imports increased by 34 percent during the first five months of 1993, compared to the same period in 1992. Planting continues to increase in Mexico and all of Central and South America as well.

Mangoes are packed at the source and heat-treated. This treatment is very hard on the fruit. New methods of treatment are being studied. After certification by U.S.D.A. most of the fruit passes through customs at Nogales, Arizona. Many of the jobbers in this market repack for firmness and export to Canada as well as Europe. It could be commercially feasible to use of a ripeness sensor for the smaller sizes. However, much of the pack is four inches or more in diameter. Mexico's mango production is being extended over a 10 month season and with the passage of NAFTA the governors of the mango producing states have shown keen interest in modernizing facilities in their areas. Much of the harvest is produced by small growers, who may join with a few neighbors to build a shed. They are not equipped to perform the fumigation process needed to market in the U.S. The market may change in the next 5 years. Currently, the opportunities to use a ripeness sensor are limited. However, the industry should be watched carefully. If the ripeness sensor were used for mangoes in the marketing system currently in place, it would probably be for sorting by the super markets.

\section{Summary of Economic Studies}

Energy savings which could potentially be achieved by use of the sensor were estimated from data on production of 12 major fruits and 4 major vegetables. Assuming approximately $30 \%$ of the packinghouse losses would be eliminated by use of the sensor, the estimated energy saving was $1.38 \times 10^{13}$ Btu.

Two surveys were mailed, one to produce managers of grocery chain stores and another to fruit packing houses. The grocery survey indicated that losses attributed to over-ripeness are usually small, about 1 to $2 \%$, but they are variable. In some cases the dollar value of losses can be substantial. The grocers would prefer that the sensor be used for on-line sorting at packing houses so that they would receive quality fruits which were not over-ripe. Many groceries felt that sorting into two categories of soluble solids levels would be sufficient. Some groceries were receptive to the idea of purchasing a sensor capable of sorting 12 to $60 \mathrm{fruits} / \mathrm{min}$. However, the maximum purchase price they were willing to pay was $\$ 10,000$. The groceries felt that, of the types of fruits 
which they normally handled, the ripeness sensor could best be used for sorting exotics (e.g. tropical fruits). The category which grocers selected with the second highest frequency was stone fruits (e.g. peaches, nectarines, plums).

Although most growers and packers said they would only be interested in a sensor which could sort 300 to 600 fruits per minute, a significant number said they would be able to use a slower sensor which sorted 12 to 60 fruits per minute. This slower sensor would be used for a quality control program in which samples taken from incoming trucks would be tested. Most growers/packers who were interested in the slower sensor wanted the device to be capable of measuring soluble solids content to the nearest $1 \%$. However, at least half of the growers/packers would be willing to accept an accuracy of $2 \%$ for a faster, on-line sensor. The vast majority of growers/packers listed $\$ 10,000$ as the highest price which they would pay for the slower (12 to 60 fruit/min) sensor while they listed $\$ 100,000$ as the price they would pay for the more rapid on-line sensor. The growers/packers were asked how much money they could save if they received a premium for sorted fruit and if they reduced losses due to over-ripe fruit by 70\%. The median estimate was $\$ 25,000$ with several being $\$ 200,000$ to $\$ 750,000$. Growers and packers felt that apples would be the best fruit to sort with such a sensor. However, this may reflect the fact that the largest percentage of growers/packers surveyed packed apples.

The consultant who evaluated use of the sensor for apples, pears and cherries affirmed that the best place to use the sensor would be at the packing house. He felt that the marketing procedures currently in use would allow the retailers to transfer the responsibility of providing higher quality (sorted) fruit to the packers and growers. A packer using the sorter would probably be able to receive a premium for sorted fruit until the sensor became widely used because at that point, the quality expectation will have changed. This consultant also pointed out that the retailers are very concerned about saving energy and this would help to increase pressure for reduction of waste by means of ripeness sorting.

The second consultant evaluated the use of the sensor for citrus, stone fruits, and avocados. He felt that the California growers, which market a high percentage of their fruit for fresh consumption, would be able to make use of the sensor during the beginning of the harvest season when there is a tendency to pick immature fruits. A high percentage of the Florida orange growers sell their fruit to juice processors, and these growers would be less interested in the ripeness sensor. The major opportunity for use of the sensor on stone fruit would be in conjunction with "treeripe" programs, where flavor of the fruit is a major consideration. In the case of avocados, the sensor could be used to select for uniform maturity. This would allow the packers to control the maturity of their fruit enabling them to better satisfy consumers.

Discussions with several survey respondents and the consultants brought out the fact that a slower sensor would be useful. Several packers/processors expressed a desire to have a portable unit which could be taken to an orchard in a pickup truck or van where it would be used for evaluating readiness for harvest. The slower sensor might also be useful for selection of fruits for specialty markets, such as the Japanese market, which demand high quality fruit and are willing to pay a premium. Many of the fruits shipped to Japan are presently being sorted and packed by hand, and it is unlikely that the slower speed would hinder the process. 


\section{SYSTEM COMPONENTS}

This section gives an overview of the components of the system. It also gives additional details on the MA-8 and MAR-8 magnet assemblies, the RF coil, and the gradient coil. The last subsection gives recommendations for maintaining the system on resonance.

\section{System Description}

Two systems were used for the tests conducted during this project. One, the LL-4 low power ( $1 \mathrm{~kW}$ RF amplifier) pulsed proton magnetic resonance $\left({ }^{1} \mathrm{H}-\mathrm{MR}\right)$ system was developed by the Southwest Research Institute (SWRI) of San Antonio, Texas. It was designed to operate at 5.35 $\mathrm{MHz}$. The frequency at which it operated could be altered by changing a chip in one of the electronic components, the RF switch, or by supplying an external signal from a frequency synthesizer. The magnets built or purchased for this project operated at frequencies between 5.35 and $5.55 \mathrm{MHz}$. The LL-4 system was purchased from SWRI in two increments. The first purchase was made in March of 1991 and received in August. It consisted of the RF pulse amplifier, the preamplifier, an RF switch unit, and an RF receiver. This permitted simple experiments to be conducted, but analysis of results required transfer of data to a spreadsheet for analysis. Additional funds became available when the Department of Energy approved funding for a phase II project. This permitted project personnel to order additional components in October of 1991. These components, which were received the last week of November 1991, included the following: a computer controlled pulse programmer; a digitizer; a PC bus interface board which was connected to the receiver and pulse programmer; and software which controlled the system allowing more complicated pulse sequences and more rapid analysis of data.

The second system used in these experiments was the LF-1, which was built by Magnetic Instrumentation, Inc. of Indianapolis, Indiana. It was first tested in December of 1994. The system was updated in May of 1995 and designated the LF-1A. The update incorporated changes to the $\mathrm{RF}$ power amplifier and the data acquisition system.

A general diagram of the ${ }^{1} \mathrm{H}-\mathrm{MR}$ systems used in these tests is shown in Figure 25 . The heart of the system is the computer, which controls the operation of the electronic components and analyzes the signal received from the digitizer. The pulse sequence is initiated when the operator types into the computer the appropriate command. The computer sends the required pulse sequence parameters to the pulse programmer (PPG) and triggers it so that it sends the pulses of the specified duration to the RF switch. In the LL-4, the PPG is a board in a separate chassis. In the LF-1A it is a board which is installed in the computer. The PPG pulse turns on the RF switch which then releases a digital pulse train of the appropriate frequency to the RF power amplifier. At the end of the pulse, the RF switch opens. The RF pulse train is amplified by the RF power amplifier to a power of approximately $1 \mathrm{~kW}$. (Note: the amplification levels of the LL-4 and the LF-1A differ). The amplified pulse train is sent to the T/R network, which is quite similar to the design described by Clark et al. (1973). The T/R network directs the power to the RF coil (the probe which holds the sample) where it excites the proton magnetic spins in the sample. After the pulse is turned off, a signal is generated by the sample. This signal is received by the same RF coil and travels through the $T / R$ network, which provides a passive voltage gain. This signal is further amplified by the pre-amplifier. Both the T/R network and the amplifier filter the signal so that the signal to noise ratio $(\mathrm{S} / \mathrm{N})$ is high enough for quadrature detection and filtering by the $\mathrm{RF}$ receiver. The receiver uses quadrature detection which consists of two phase-sensitive detectors. 


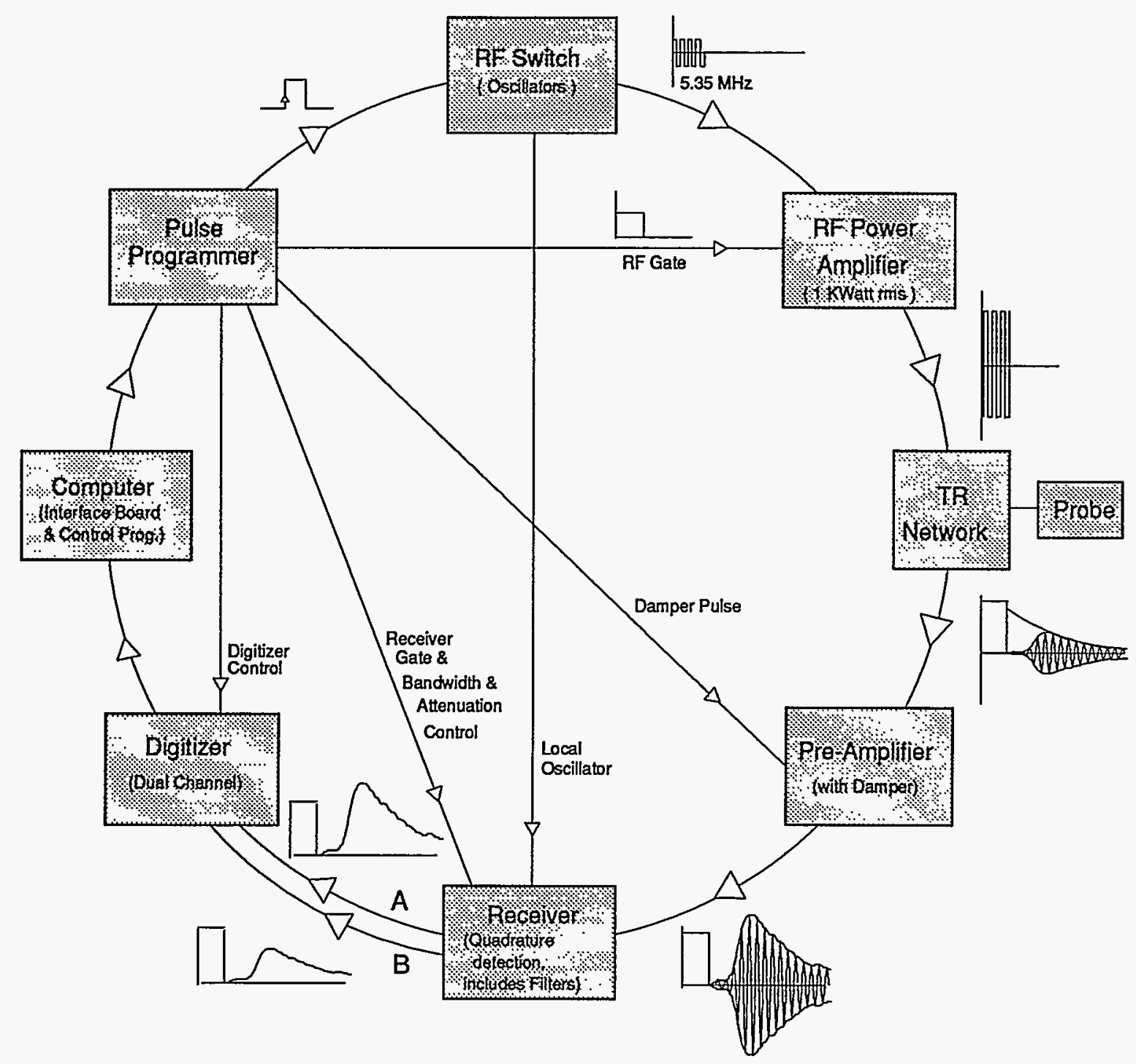

Figure 25. Diagram showing components of the proton magnetic resonance systems used for the fruit ripeness sensor tests.

After the quadrature detection, only the envelope of the signal remains. The signal is decomposed into two components, signal $\mathrm{A}$ and signal $\mathrm{B}$, having amplitudes $A$ and $B$, respectively. These two signals are digitized synchronously by dual digitizers (Figure 25) and sent to the computer. The amplitude of the signal is equal to $\sqrt{A^{2}+B^{2}}$ and the computer performs the square root operation, analyzes the signal, and displays the results.

The LL-4 and LF-1A were used with three magnets: the MA-3, the MA-8, and the MAR-8. The MA-3 can accommodate a sample with diameter up to $30 \mathrm{~mm}$. It was built during Phase I of the project and is described in detail by Cho et al. (1990). The MA-8 and MAR-8 magnets can accommodate samples with diameters up to $80 \mathrm{~mm}$. They are described in more detail in the two sections that follow. 


\section{MA-8 Magnet}

The MA-8 magnet was constructed from Neodynium Iron Boron and has a flux density of approximately $1300 \mathrm{G}$. Procedures used to design the magnet are summarized in Li, et al. (1992). The magnet's geometry, performance, and operating point were determined using design formulas which minimized the flux leakage and optimized the efficiency of permanent magnet material (Magnetic Materials Manufacturing Association 1988). They were used to determine an initial estimate of the thickness of the steel frame. The magnetic field distribution in the complicated geometry of the magnet assembly was predicted using three dimensional (3D) finite element analysis.

Four different permanent magnet materials were used to develop designs. The dimensions of the design were different because the amount of magnet material required varied with the type of material used. The four designs were compared on the basis of temperature stability, durability, cost effectiveness, and total weight. Before the finite element program was used for design of the larger magnet, both 3D and 2D models were evaluated by comparing numerical predictions of the field distribution in the MA-3 magnet with actual measurements. The field predicted by the 2D model varied by $20 \%$ from the measured values, and the predictions of the $3 \mathrm{D}$ model were within $3 \%$ of measurements. In both models, the relative magnitudes of the fields within the air gap (e.g. ratio of measured field strengths to maximum field strength) agreed quite well with measurements.

In the second step, the 3D finite element model was used to optimize the design of the MA-8 magnet. The thicknesses, lengths and shapes of the steel frames used to shunt the magnetic field across the air gap were varied. The variations were evaluated on the basis of the field strength and homogeneity within an $8 \mathrm{~cm}$ spherical working volume centered in the air gap.

The final step involved choice of an appropriate permanent magnet material. Factors considered were the stability of the field, the cost of the magnet and housing, and the difficulty involved in manufacturing the magnet. Four magnet materials were evaluated. The Ceramic (ferrite) material was eliminated because it is highly sensitive to ambient temperature fluctuations. Alnico- 8 was eliminated because it has a very low energy product in this application. This would make the magnet too thick and the housing too heavy. Sumarium Cobalt showed a relatively small gain in temperature stability over Neodynium Iron Boron (Nd-Fe-B), but is twice as costly. Therefore, $\mathrm{Nd}-\mathrm{Fe}-\mathrm{B}$ was chosen as the most appropriate material for the prototype.

A schematic of the MA-8 magnet is shown in Figure 26. During the spring of 1993, the frame for the magnet was built from low carbon steel (AISI 1006, Inland Steel Company, Chicago Illinois) by Purdue University's central machine shop. The frame is in two halves which bolt together along the centerline of the assembled magnet. The magnet material, which was purchased at-cost from Crucible Magnetics (Elizabethtown, Kentucky), came in small blocks $5.08 \mathrm{~cm}$ (2.0 in) square and $2.0 \mathrm{~cm}(0.785 \mathrm{in})$ thick which were magnetized. The 128 blocks had to be placed and glued onto the steel frame to form the magnet poles ( 64 blocks/pole), which were $40.6 \mathrm{~cm} \mathrm{x} 40.6$ $\mathrm{cm}$ (16 in $\mathrm{x} 16 \mathrm{in}$ ) and $2.0 \mathrm{~cm}$ thick ( $0.785 \mathrm{in})$. The positioning and gluing were done by Magnetic Instrumentation engineers during the summer and fall of 1993 . Once the blocks were in place, the $40.6 \mathrm{~cm} \mathrm{x} 40.6 \mathrm{~cm}$ (16 in $\times 16 \mathrm{in}$ ) pole faces were glued on top of the magnet material. They were machined to a thickness of $2.0 \mathrm{~cm}$ ( $0.8 \mathrm{in})$ from ultra low carbon steel (Intrak Plate from Inland Steel, Chicago, Illinois). 


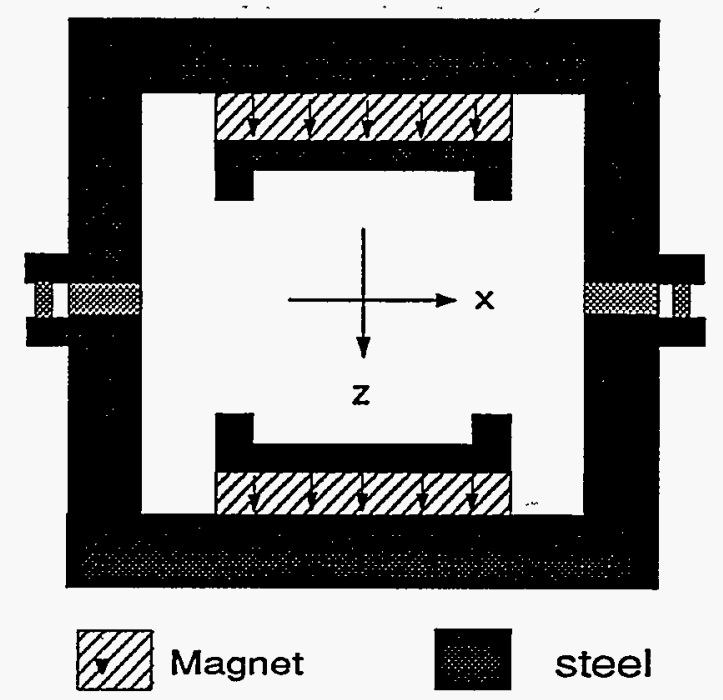

Figure 26. Schematic of the MA-8 magnet.

The final step in the assembly, connection of the top and bottom halves of the frame, was also performed by Magnetic Instrumentation. The two halves were separated by a spacer bar which was $2.54 \mathrm{~cm}$ (1.0 in) wide. This spacer bar was incorporated into the design to allow the air gap of the magnet to be adjusted, in the event large changes (e.g. 50 or more Gauss) were required to achieve the desired field strength. After the magnet was completely assembled, two shimming coils were added. These coils wrapped around the magnet poles and the pole faces. They consisted of 150 turns of 12 gauge wire arranged in 10 layers of 15 turns/layer.

The MA-8 became available for tests on whole fruits, such as apples and oranges, in December of 1993 (Stroshine, et al. 1993). For the first 12 months of testing, it was used with the LL-4 electronic equipment developed by SWRI. However, in December of 1994 it was used for tests with the LF-1 prototype developed by Magnetic Instrumentation (Stroshine, et al. 1994).

\section{MAR-8 Magnet}

The homogeneities of the $\mathrm{B}_{0}$ fields of the MA-3 and MA-8 magnets used with the ripeness sensor are between 600 and 1000 parts per million (ppm). By contrast, magnets used for most laboratory magnetic resonance instruments and magnetic resonance imaging typically have homogeneities of 50 to $100 \mathrm{ppm}$. A free induction decay signal (FID) can be obtained by the application of a single $90^{\circ}$ pulse to the sample. The decay constant for the FID signal is $\mathrm{T}_{2}{ }^{*}$ and it is affected by the spin-lattice relaxation constant, $T_{1}$, the spin-spin relaxation time constant, $T_{2}$, and the inhomogeneity of the magnetic field, $\Delta \mathrm{B}_{0}$ (Fukishima and Roeder, 1981):

$$
\frac{1}{\mathrm{~T}_{2} *}=\frac{1}{2 \mathrm{~T}_{1}}+\frac{1}{\mathrm{~T}_{2}}+\frac{\gamma \Delta \mathrm{B}_{0}}{2}
$$

If $\Delta \mathrm{B}_{0}$ is relatively small and $\mathrm{T}_{1}$ » $\mathrm{T}_{2}$ then the value of $1 / 2 \mathrm{~T}_{1}$ will be much smaller than $1 / \mathrm{T}_{2}$ and the FID decay signal will be sensitive to differences in $\mathrm{T}_{2}$. Under such conditions, the shape 
of the FID or the Fourier transformation of the FID signal can be used to detect differences in composition of the sample tested. However, when the magnet is relatively inhomogeneous, e.g. $600 \mathrm{ppm}$, the $\Delta \mathrm{B}_{0}$ term dominates the decay signal and it is impossible to distinguish differences in the signal attributable to $\mathrm{T}_{2}$.

An alternative to using the FID signal is to use the Carr-Purcell-Meiboom-Gill (CPMG) pulse sequence to determine $T_{2}$ directly. It is much less sensitive to magnet inhomogeneity than the FID. The BNHE pulse sequence (see section entitled "Pulse Sequences for Determination of Soluble Solids") used in this research is closely related to the CPMG. However, the effect of inhomogeneity is less certain when a steady gradient is applied for the purpose of measuring diffusion related properties of the sample.

Design of magnetic resonance magnets is relatively complicated. Companies which manufacture these types of magnets measure the $\mathrm{B}_{0}$ field distribution after they assemble a magnet. They then reduce fluctuations in $\mathrm{B}_{0}$ by adding small pieces of metal at appropriate locations on the magnet, pole face or the metal yoke. (The metal yoke is the steel frame which surrounds the magnet and returns the magnetic flux emanating from the "back" of the pole faces, i.e., the faces opposite to the air gap.) Some companies have developed specialized computer programs which allow them to calculate the locations where these pieces should be placed.

The design and construction of a homogeneous magnet were beyond the capabilities of the project personnel. Therefore, the Field Effects division of Intermagnetics General Corporation was employed to build a magnet having a $12.7 \mathrm{~cm}$ gap which would produce a 1256 Gauss field having a homogeneity of $50 \mathrm{ppm}$ in a spherical volume approximately $10 \mathrm{~cm}$ in diameter. The magnet was to have detachable shims which, when added, would decrease the homogeneity to $200 \mathrm{ppm}$. The magnet was also to be equipped with a shimming coil capable of adjusting the $\mathrm{B}_{0}$ field by 9 Gauss using a current of 5 amperes at a oltage less than 10 volts. In addition, the magnet was to have a gradient coil capable of producing a steady gradient of up to $2.0 \mathrm{Gauss} / \mathrm{cm}$. Magnetic field plots were to be supplied with the magnet.

The magnet arrived in August of 1994, approximately 6 months later than the anticipated delivery date. The magnet poles and pole faces were round, having diameters of approximately 30 $\mathrm{cm}$. For this reason, the magnet was designated the MAR-8. (The R indicates "round" and the 8 is the approximate diameter of the sample which the RF coil will accept, $8 \mathrm{~cm}$.) The homogeneity of the magnet without the disrupter plates was $106 \mathrm{ppm}$ in a "flattened" spherical volume with a diameter of $10 \mathrm{~cm}$. Homogeneity dropped off in the regions of the $5 \mathrm{~cm}$ sphere close to the pole faces. The truncated faces of the flattened sphere were $3.65 \mathrm{~cm}$ from the center line of the magnet air gap. In a spherical volume with diameter $3.5 \mathrm{~cm}$, centered along the center line of the magnet, the homogeneity was $46 \mathrm{ppm}$. When the disrupter plate was added, the homogeneities were 235 $\mathrm{ppm}$ and $57 \mathrm{ppm}$ in the $10.0 \mathrm{~cm}$ flattened spherical volume and $3.5 \mathrm{~cm}$ spherical volumes, respectively.

The MAR-8 magnet has several additional features which are different from those of the MA8. The shimming coil of the MAR-8 magnet is wrapped around the return yoke of the magnet rather than around the pole faces. (Note: If Figure 26 were a picture of the MAR- 8 , the shimming coils would be wrapped around the region where the spacer bars are located.) The MAR-8 magnet does not use a spacer bar. However, there are adjusting screws on the yoke which permit the frame, to which the pole faces are attached, to be moved approximately $0.5 \mathrm{~cm}$. This permits a slight adjustment of the nominal field strength of the $\mathrm{B}_{0}$ field. Finally, the gradient coils of the 
MAR-8 magnet are bonded to the magnet pole faces. This type of gradient coil, as compared to the quadrupole coil used with the MA-8 magnet (see the section below entitled "Gradient Coil"), requires less space and permits the RF coil to be much closer to the pole faces. The RF coil is shielded from the effects of the gradient coil by a round, thin copper plate which covers the gradient coil and is the same size as the pole face (see the section below entitled "Gradient Coil".)

\section{RF Coil Design and Shielding}

The design of the RF coil used in the sensor was evaluated by means of a finite element model developed with ANSYS finite element software. It was used to determine coil parameters which would give the optimum homogeneity of the $\mathrm{B}_{1}$ field (Wai et al, 1991). The optimum coil had a length equal to its diameter and consisted of 5 turns. The wire size, $d$, the coil diameter, $D$, and the number of turns, $n$, are given by the following formula:

$$
\frac{\mathrm{d}}{\mathrm{D}}=\frac{0.6}{\mathrm{n}-1}
$$

According to the finite element analysis, the number of turns required to achieve the optimum homogeneity was 5 . However, the strength of the $B_{1}$ field is directly proportional to the number of turns, the RF power and the RF pulse length. The RF power amplifier provides constant RF power and has a limited duty cycle. This means that the pulse length must be less than some limiting value. These restrictions make it necessary to use more than the "optimum" number of turns for the coil. The final design for the $30 \mathrm{~mm}$ diameter coil used 11 turns and the final design for the 80 $\mathrm{mm}$ coil used 14 turns. One advantage of using more turns is that it gives a higher $\mathrm{B}_{1}$ field strength and therefore shorter $90^{\circ}$ and $180^{\circ}$ pulses. This, in turn, reduces the effect of variations in sample size when the static field gradient technique is used. Discussions of the sample size effect are given in Wai (1993) and Wai, et al. (1995).

Other aspects of coil design are the filling factor and shielding. The filling factor is the ratio of sample volume to coil volume. The greater the filling factor, the greater the signal. However, the noise level is relatively constant, regardless of the sample size. Therefore, an increase in the filling factor increases the signal to noise ratio $(\mathrm{S} / \mathrm{N})$ and, in turn, the measurement accuracy. In experiments reported in the Phase I project (Cho and Stroshine, 1992) the noise level of the probe was $50 \mathrm{mV}$ or higher. During the tests conducted in Phase II, the coils were better shielded. Copper or aluminum boxes were constructed which completely enclosed the RF coils (with the exception of the open ends of the coil where the sample was inserted). The RF coils were wrapped around Plexiglass tubes which were supported by holes cut in opposite ends of the boxes. The importance of proper shielding became evident when the copper box used for the $30 \mathrm{~mm}$ RF coil was modified. The six individual copper sheets making up the copper box were not soldered together. When the seams were sealed with conductive tape, the noise was reduced from $50 \mathrm{mV}$ to $10 \mathrm{mV}$. Subsequently, an aluminum box was made for shielding of the coil. Five of the sides of the box were welded together and the sixth side (one of the ends) was attached by means of several screws. The noise level for this box was approximately $5 \mathrm{mV}$.

The effect of noise level on the signal can be illustrated by a simple calculation. When the BNHE pulse sequence (Wai, et al., 1995) is used to interrogate the sample, a one percent difference in sugar content of the sample produces a change of 0.007 in the echo ratio. If the signal coming from the sample is 1 volt, then a one percent difference in sugar content is equivalent to a $7 \mathrm{mV}$ change in the signal. 
The noise level in the $80 \mathrm{~mm}$ RF coil used with the MA-8 magnet was approximately $5 \mathrm{mV}$. The signal from small oranges typically has a magnitude of 1 or 2 volts and the signals from large apples are typically 3 to 4 volts. If the noise level is kept below $5 \mathrm{mV}$, the noise will have a relatively small effect on measurement accuracy.

\section{Gradient Coil}

The technique developed for the measurement of the sugar content of fruits depends upon the effects of sugar on the self-diffusion of water within the sample. Diffusion dependent measurements can be made by creating a gradient in the $\mathrm{B}_{0}$ field and then applying the Hahn echo pulse sequence (see section entitled "Pulse Sequences for Determination of Soluble Solids"). The initial tests conducted employed the "natural" gradient which was present in the MA-3 magnet. However, the gradient strength affects the precision of the measurement. In order to achieve better control over the strength of the gradient field, a gradient coil was placed around the RF coil.

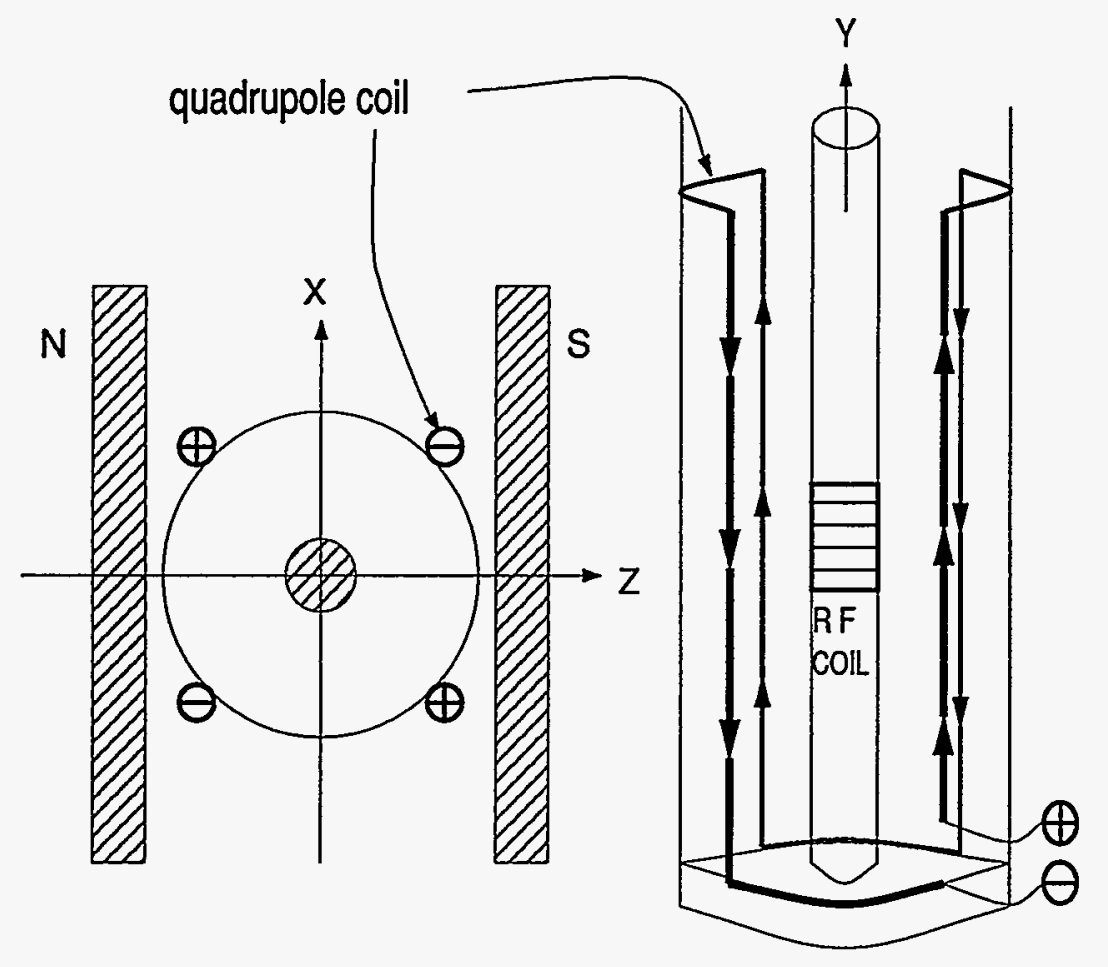

Figure 27. Schematic diagram of quadrupole coil used to produce a steady gradient.

The gradient coil designed for the ${ }^{1} \mathrm{H}-\mathrm{MR}$ sensor is of the quadrupole type. A simplified diagram of the coil is shown in Figure 27. As indicated in the figure, the $\mathrm{z}$ axis of the magnet is perpendicular to the two poles of the magnet and the magnet pole faces. The $\mathrm{x}$ axis is parallel to the pole faces. The quadrupole coil consists of two loops of wires fastened to a plexiglass tube. The plexiglass tube fits over the RF coil which is itself wrapped around a plexiglass tube having a diameter slightly smaller than the RF coil (and significantly smaller than the plexiglass tube used with the gradient coil). Two "legs" of one loop of the gradient coil are positioned at angles of $45^{\circ}$ to the $\mathrm{x}$ and $\mathrm{z}$ axes of the magnet and in the $+\mathrm{x}$ region, while two legs of the other loop are positioned at an angle of $45^{\circ}$ to these two axes and in the - $\mathrm{x}$ region. The direction of current flow is 
also indicated in Figure 26. Each of the loops was made from five layers of ribbon cable. The ribbon cable was $1.15 \mathrm{~cm}$ wide and contained ten 22 gauge wires. Thus, each loop had 50 wires. Details of the design of the quadrupole coil are given by Wai (1993).

When a DC current is applied to the gradient coil, the coil produces a gradient in the $\mathrm{B}_{0}$ field in the z-direction (perpendicular to the axis of the RF coil). The magnitude of the gradient varies with the DC current applied. The gradient coil can also produce noise in the RF coil. Therefore, it is necessary to shield the two coils from each other. This was accomplished by wrapping a thin sheet of copper around the RF coil.

\section{Magnet Temperature Control}

The field strength of a magnet is dependent on magnet temperature. Therefore, if the magnet temperature changes, the system can be maintained on resonance by changing the current applied to the magnet assembly shimming coils so as to maintain the $\mathrm{B}_{0}$ field at the proper level. In commercial applications of magnetic resonance, fluctuations in magnet temperature are reduced or prevented by using heaters to maintain the magnet several degrees above room temperature.

The effects of controlling magnet temperature were evaluated using the MA-3 magnet. Heating pads were attached to the top and bottom of the magnet's steel yoke. A thermocouple sensed the temperature at the top of the yoke, between the two heating pads. It was connected to a controller which maintained a relatively constant temperature at the thermocouple sensing point. The temperature controller was adjusted so that the temperature at the sensing point was approximately $5^{\circ} \mathrm{C}$ above room temperature. The exterior surfaces of the magnet assembly were covered with $5 \mathrm{~cm}$ of insulation to prevent heat loss. The steel yoke has a high thermal conductivity and this means that the magnet material, which is in contact with the yoke, should be at the same temperature as the yoke and should therefore remain relatively constant.

Experiments were conducted with the magnet temperature control system described above. Once each hour FID tests were conducted on pseudofruits filled with water. The shape of the FID indicates whether the system is properly tuned. When the system is out of tune, it can be re-tuned by adjusting the current to the shimming coils. During these experiments, the system was tuned . after each FID test and the current supplied to the shimming coils was measured. A change in this current meant that the magnet's field strength had changed. It was therefore used as an indication of the stability of the magnet temperature. Preliminary experiments suggested that the gradient and shimming coils may have produced heat which increased the magnet temperature. Therefore, in subsequent experiments, the power to these coils was turned off between FID tests.

The following are results of the final temperature control experiment that was conducted. At the beginning of the experiment, the room temperature was $22.1^{\circ} \mathrm{C}$. The test was begun at $12: 00$ p.m. At 8:00 a.m. the room temperature had been approximately $25.5^{\circ} \mathrm{C}$. By 1:00 p.m. (13:00) the room temperature had dropped to $21.7^{\circ} \mathrm{C}$ where it remained for the duration of the test. The temperature at the top corner of the magnet, approximately $15 \mathrm{~cm}$ from the edge of the heating pad, remained constant at $29^{\circ} \mathrm{C}$ throughout the test. As shown in Figure 28, the current supplied to the shimming coils varied from 2.60 to 2.55 amperes.

The MA-3 assembly has a field strength of 1256 Gauss and uses a ceramic magnet for which the reversible temperature coefficient of residual induction is $-0.2 \%$ per ${ }^{\circ} \mathrm{C}$. A change in magnet 
temperature of $1^{\circ} \mathrm{C}$ corresponds to a change in field strength of $2.51 \mathrm{G}$. A 0.1 amp change in current to the shimming coil produces a 0.5 Gauss change in field strength. Therefore, a fluctuation of 0.05 amps in shimming current corresponds to a change in field strength of 0.25 Gauss. This could be produced by a change in magnet temperature of $0.10^{\circ} \mathrm{C}$.

The calculation illustrates that adjustments in shimming coil current would only be eliminated if the magnet temperature were controlled to within $0.10^{\circ} \mathrm{C}$. Control could be improved by adding more heating pads and temperature sensors and by better insulating the magnet assembly. However, in a commercial setting where the gradient and shimming coils would be operating continuously they would produce heat which could lead to a gradual rise in magnet temperature. It might be necessary to provide magnet cooling as well as heating. The coils would have to be designed so that they produced a minimum of resistive heating. Even in a well designed system, precise control of magnet temperature would be extremely difficult to achieve. Automatic adjustment of current to the shimming coils would also be needed. This approach is described in the section which follows.

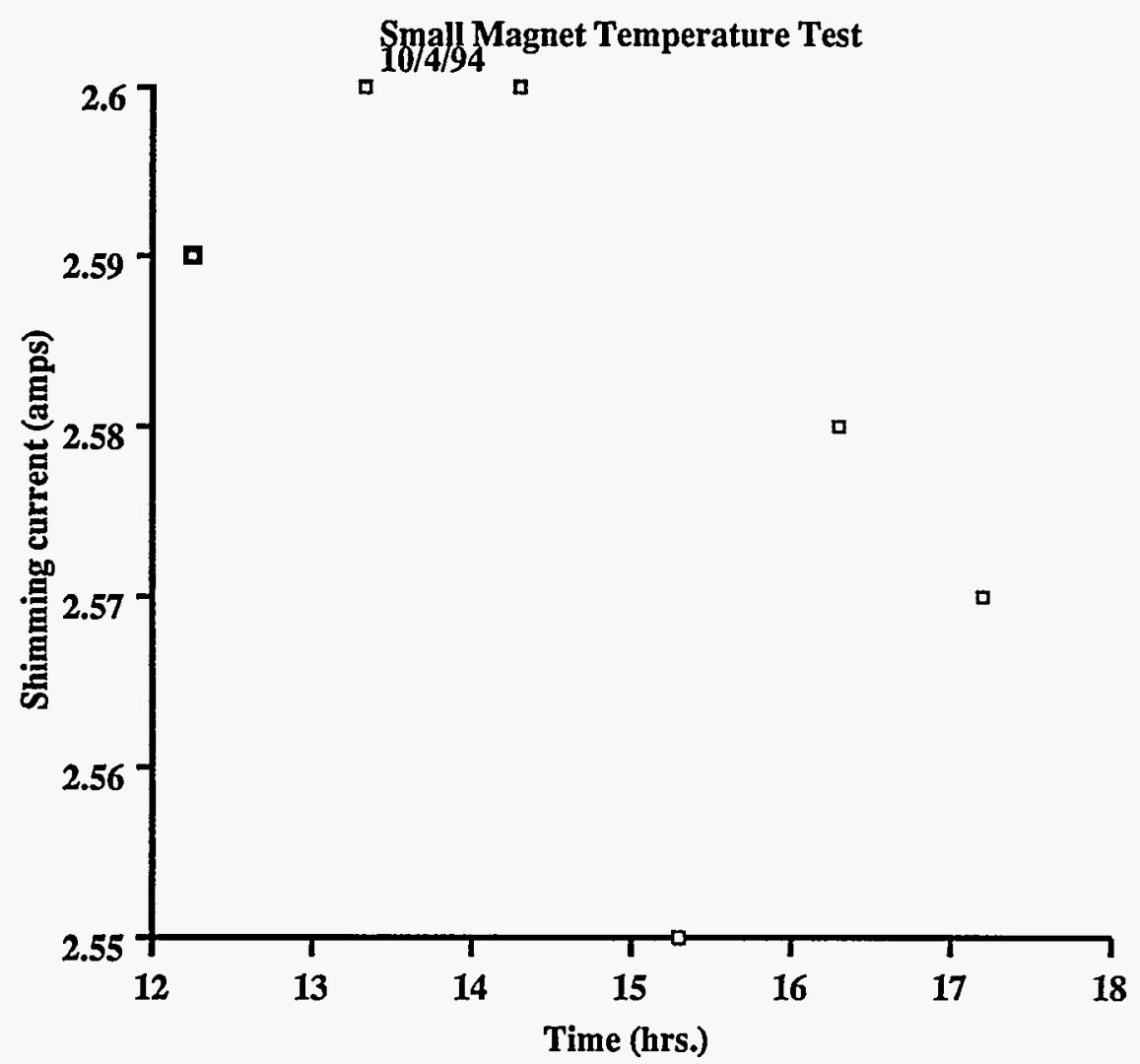

Figure 28. Shimming coil current supplied during magnet temperature control experiments.

\section{Maintaining System Resonance}

The difficulty in maintaining near-perfect control of magnet temperature means that an alternate method must be used to maintain the system on resonance. One approach is to develop a system for automatically adjusting the current to the shimming coils. A system of this type was 
developed and tested using SWRI's LL-4. It used a digital to analog converter (DAC) to control the shimming current driver, the device which supplies current to the shimming coils. The DAC was on a card which plugged into the computer used to control the LL-4.

The tuning system operated as follows. A water sample was placed in the sensor and a $90^{\circ}$ pulse was applied. The signal was digitized by the DAC and provided to the computer which then analyzed the characteristics of the signal to determine whether it had the proper shape. A signal analysis algorithm could estimate the degree of distortion and estimate the change in current to the shimming coil which would be required to attain the proper shape. When the system was first tested, it took approximately 5 minutes to tune the system. However, after the algorithm was modified to make it more efficient, the required tuning time was reduced to less than a minute. On the average, it took only about 7 iterations to tune the frequency when the magnet frequency was considerably different from the resonance frequency. The computer being used to control the LL4 was relatively slow by current standards. A faster computer could perform these 7 steps in approximately 10 seconds.

Several conditions have to be met for the tuning system to work as desired. First, the homogeneity of the magnet should be $700 \mathrm{ppm}$ or less. A poor homogeneity will substantially decrease the FID decay time and make it more difficult for the algorithm to analyze the signal and predict the required reduction in current to the shimming coil driver. The performance of the system would increase with increasing magnet homogeneity. Secondly, a poor signal to noise ratio would also reduce the accuracy of the signal analysis. The effect will be similar to that of poor homogeneity. Thirdly, large magnet temperature fluctuations would cause a substantial change in the $B_{0}$ field and could severely shorten the FID signal.

The system was developed and tested, but was not used routinely for laboratory experiments. Development of other components of the system received a higher priority. In a commercial system, a water sample would be placed in the sensor at appropriate intervals. In the case of a sensor capable of testing several fruits per minute, the water sample could be incorporated into the loading device. For example, the loading device might consist of a plastic piston on which the fruit is positioned by the operator. If the fruit were in place, the piston could be moved downward, positioning the fruit in the middle of the coil. Then the fruit would be interrogated and the piston moved upwards, returning the fruit to the operator. The water sample could be placed on the loading mechanism in such a manner that it would be positioned in the RF coil while the operator reloaded the piston with another fruit. If fruits were moved through the sensor on a continuously moving belt, the water sample could be a hollow plastic sphere filled with water which would be placed on the belt periodically. Project personnel prepared water samples of this type, which they called pseudofruits. They were used routinely for calibration of the sensor (see section entitled "System Evaluations-Tests with Pseudofruits"). 


\section{PULSE SEQUENCES FOR DETERMINATION OF SOLUBLE SOLIDS}

This section of the report describes the two pulse sequences used to interrogate the sample, the Carr-Purcell-Meiboom-Gill (CPMG) used to determine the value of $\mathrm{T}_{2}$, and the Balanced Normalized Hahn Echo (BNHE), which was used to determine the echo ratio. During the Phase I research and the first several months of the Phase II research, project personnel envisioned analyzing the shape of the Free Induction Decay (FID) signal by taking the ratio of the signal amplitudes at two times, one soon after the peak voltage had occurred and other after the signal had decayed to approximately one third of the maximum. Although there was a statistically significant correlation between its ratio and sucrose content, the correlations were not adequate for use with fruits and vegetables. Furthermore, the FID curve is affected by magnet homogeneity (see "System Components-MAR-8 Magnet Assembly"). The cost of a commercial ripeness sensor would be lower if relatively inhomogeneous, and therefore less expensive, magnet assemblies were used. Therefore, measurements which were less sensitive to magnet homogeneity, such as the CPMG and Hahn Echo techniques, were evaluated. The CPMG pulse sequence has been used routinely for many years. The BNHE pulse sequence is an adaptation of the Hahn Echo technique which was developed by Dr. Wing-Kin Wai for use in sensing the sugar content of sucrose solutions and whole fruits and vegetables.

\section{CPMG Pulse Sequence}

Preliminary experiments were conducted with sucrose solutions, pieces of fruit, and small fruits. There was a relatively good correlation between $\mathrm{T}_{2}$, as determined with the CPMG pulse sequence and sugar content (Cho, et al., 1993). The sequence is diagrammed in Figure 29. It consists of a single $90^{\circ}$ pulse ( $\mathrm{p} / 2$ in Fig. 20) followed by a series of $180^{\circ}$ pulses ( $p_{y}$ in Fig. 29) and can be represented as follows (Fukishima and Roeder, 1981):

$$
90^{\circ}-\tau-180^{\circ}-\tau_{\text {echopeak }}-\tau-180^{\circ}-\tau_{\text {echopeak }}-\tau \ldots
$$

where $\tau$ is the delay time between the $90^{\circ}$ and $180^{\circ}$ pulse and the refocusing of the spin isochromats occurs after time $\tau_{\text {echopeak }}$ giving the echo peaks $\mathrm{P}_{1}, \mathrm{P}_{2}, \mathrm{P}_{3}, \ldots$ shown in Fig. 29 . The decay constant of the curve formed by the amplitudes of the echoes (lower diagram in Fig. 29) is $\mathrm{T}_{2}$.

Initial experiments conducted with sweet cherries indicated that $\mathrm{T}_{2}$ was related to the soluble solids content (percent brix) as measured with a refractometer (Cho et al., 1993). The coefficient of determination $\left(r^{2}\right)$ for a linear regression of $T_{2}$ versus percent brix was 0.38 . Subsequent work established that, in the case of sweet cherries, $\mathrm{T}_{2}$ was also related to the firmness of the fruit (Ray et $\mathrm{al}, 1993)$. For three groups of sweet cherries, the values of $\mathrm{r}^{2}$ for a linear regression of $\mathrm{T}_{2}$ versus firmness varied from 0.135 to 0.232 . Although this is not a strong relationship, it does illustrate that factors other than sugar content affect the value of $T_{2}$ which is measured. This was the motivation for searching for other pulse sequences which could be used to detect the soluble solids contents of fruits and vegetables.

A variation of the Hahn echo pulse sequence, which is described in the next section, was used for sugar content measurement. The echo ratio measured with this technique is also affected by $\mathrm{T}_{2}$. Therefore, samples of fruits were interrogated with the CPMG pulse sequence and the value of $\mathrm{T}_{2}$ determined with this procedure was used to correct the echo ratio measurements. 

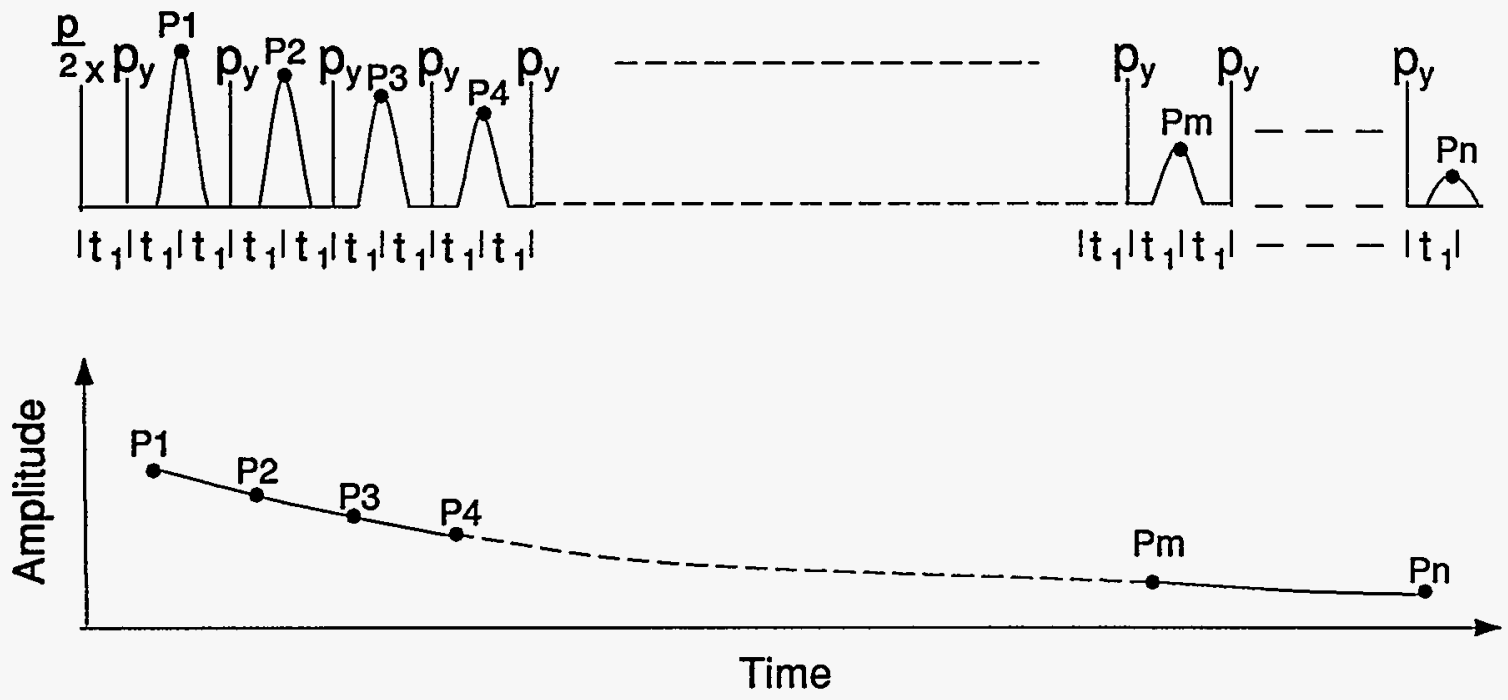

Figure 29. Diagrams of the CPMG pulse sequence for determining $T_{2}$. Upper figure: representation of the pulses, $p_{x}$ and $p_{y}$, and the echo peaks which they produce, $P_{n}$. Lower figure: the envelope of echo peak heights, forms the spin-spin relaxation curve. The curve's decay constant is $T_{2}$.

\section{BNHE Pulse Sequence}

Pseudofruits (see "System Evaluations - Tests with Pseudofruits"), along with sweet cherries and pieces cut from other fruits such as apples, were used for the initial experiments using the MA-3 magnet. As mentioned in the section entitled "System Description - System Components," the LL-4 system was purchased in two increments. The greater flexibility achieved after the addition of the second set of components permitted project personnel to compare FID and CPMG experiments to the Hahn Echo (HE) pulse sequence (Carr and Purcell, 1954). The HE sequence, which had not been evaluated in previous experiments, can be described as: $90^{\circ}-\tau-180^{\circ}$, where the $90^{\circ}$ and $180^{\circ}$ refer to pulses which rotate the net magnetization by $90^{\circ}$ and $180^{\circ}$, respectively. It produces a free induction echo at time $2 \tau$. As mentioned earlier, project personnel observed that correlations between echo peak height and sugar content were better when the MA3 magnet was used with shimming of the $B_{0}$ field by means of addition of small pieces of metal. When project personnel realized that the shimming produced a steeper gradient in the $\mathrm{B}_{0}$ field, they concluded that they were essentially conducting a steady gradient experiment. This meant that the changes in the signal were related to changes in the self-diffusion of water. Project personnel then began to evaluate the steady gradient method as a technique for estimation of the sugar content of fruits and vegetables.

In the first Hahn Echo experiments with sugar solutions, the height of the echo peak was normalized by dividing it by the weight (gms) of the solution. Later, it was observed that the height of an echo peak produced with a relatively short $\tau$ time was proportional to the weight of the sample and did not appear to be influenced by the sugar content. On the other hand, the ratio of the height of the echo produced after a relatively long $\tau$ time, to the height of the peak produced after the relatively short $\tau$ time, was related to the weight percent of sugar present in the sample. The weight of the sample had relatively little effect on this ratio. 
The pulse sequence that was developed employed two $\tau$ times, one short and the other long. It produced two echoes. The first echo was proportional to the weight of the sample. The ratio formed by dividing the height of the second peak by the height of the first peak was related to the amount of sugar. The pulse sequence was called the Normalized Hahn Echo (NHE), and was used to calculate the Spin Echo Ratio, SER, as described below. Other advantages of the pulse sequence are described by Wai (1993).

The starting point for the derivation of the SER is the mathematical description of SEP, the amplitude of the spin echo (SE) peak which occurs at time $2 \tau$ :

$$
\operatorname{SEP}=A(0) \exp \left(-2 \tau / T_{2}\right) \exp \left(-2 \gamma^{2} D G^{2} \tau^{3} / 3\right)
$$

where:

$$
\begin{aligned}
\mathrm{A}(0) & =\text { amplitude of the FID peak which follows the } 90^{\circ} \text { pulse } \\
\tau & =\text { time between the } 90^{\circ} \text { and the } 180^{\circ} \text { pulses. } \\
T_{2} & =\text { spin-spin relaxation rate }(\mathrm{s}) \\
\gamma & \left.=\text { gyromagnetic ratio (rad } \mathrm{s}^{-1} \mathrm{Tesla}^{-1}\right) \\
D & =\text { diffusion coefficient (for pure water at } 25^{\circ} \mathrm{C} \text { equal to } 25.8 \times 10^{-6} \mathrm{~cm}^{2} \mathrm{~s}^{-1} \text {.) } \\
G & =\text { the static gradient applied to the sample }
\end{aligned}
$$

The NHE can be described as $\left(90^{\circ}-\tau_{1}-180^{\circ}-\tau_{1}-\mathrm{SE}-\tau_{2}-180^{\circ}-\tau_{2}-\mathrm{SE}\right)$. It produces two echo peaks. The first peak occurs after the relatively short $\tau$ time, $\tau_{1}$, and the second after the relatively long $\tau$ time, $\tau_{2}$. The ratio of the two echo peak heights (SER) is not dependent on $\tau_{1}$ and can be described by the following equation:

$$
\operatorname{SER}=\exp \left(-2 \tau_{2} / T_{2}\right) \exp \left(-2 \gamma^{2} D G^{2} \tau_{2}^{3} / 3\right)
$$

The parameters in the SER equation are as defined for the SEP equation. Although the sequence was developed by Dr. Wing Kin Wai during the first several months of 1993, it was later discovered that it had been used by Garwin and Reich (1958) for measurements on liquefied Helium. These two researchers were apparently unaware of the advantages which this pulse sequence can provide for determination of soluble solids contents of fruits and vegetables. Note that the SER is affected by $\mathrm{T}_{2}$. If $\mathrm{T}_{2}$ varies among samples, the measured value of SER can be corrected by measuring $\mathrm{T}_{2}$ with the CPMG pulse sequence and then multiplying SER by $\exp \left(2 \tau_{2} / \mathrm{T}_{2}\right)$.

The NHE would work well if both the $\mathrm{B}_{0}$ and $\mathrm{B}_{1}$ fields were perfectly homogeneous. When these fields are not homogeneous, and especially when a static gradient is applied, the net magnetization of the isochromats in the sample does not refocus in the plane where it was located immediately after the $90^{\circ}$ pulse was applied. The results become unpredictable and are dependent on sample size (Wai, et al., 1995). However, Dr. Wai discovered that the effects of inhomogeneity could be reduced by "balancing" the number of $180^{\circ}$ pulses. The new pulse sequence was called the Balanced Normalized Hahn Echo (BNHE) pulse sequence.

A diagram of the BNHE pulse sequence is shown in Figure 30 . Two $180^{\circ}$ pulses, $p_{y}$, are applied using a short $\tau$ time, $t_{1}$. The first echo (not shown in Figure 30 ) is not used, and the second echo has been represented by echo1. Subsequently, two more $180^{\circ}$ pulses are applied to the sample using a long $\tau$ time, $t_{2}$. Again, the third echo (not shown in Figure 30 ) is not used. The fourth echo, produced by the second of the two long $\tau$ times is represented in the figure by 


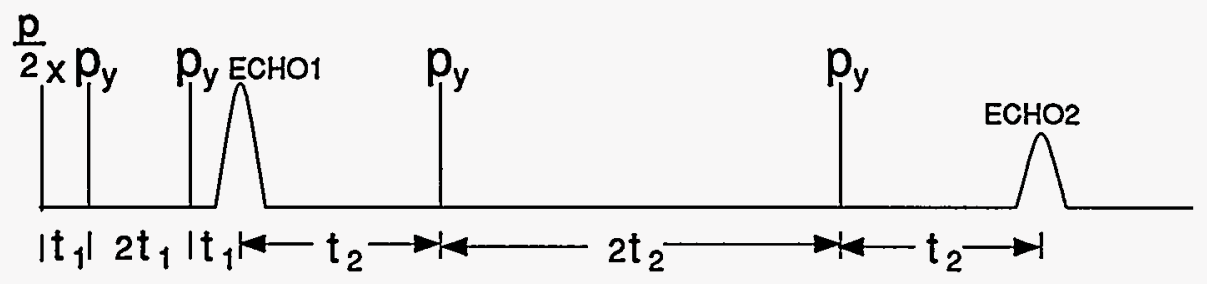

Figure 30. Diagram of BNHE pulse sequence showing the $90^{\circ}$ pulse, $p_{x} / 2$, the $180^{\circ}$ pulses, $p_{y}$, and the two echoes, echo1 and echo2, used to calculate the echo ratio.

ECHO2. A detailed explanation of the rationale for "balancing" the pulses is given by Wai et al. (1995).

The peak amplitude for the echo produced after a short $\tau$ time, echo1, occurs at time $4 \tau_{1}$ and can be expressed as:

$$
A\left(4 \tau_{1}\right)=A(0)\left\{\exp \left(-2 \tau_{1} / T_{2}\right) \exp \left[f\left(\tau_{1}\right) G^{2}\right]\right\}^{2}
$$

where $f\left(\tau_{1}\right)=-(2 / 3) \gamma^{2} D \tau_{2}^{3}$ and the other terms are as defined in the equation for SER. Similarly, the echo peak amplitude for the long $\tau$ time, echo2, occurs at time $4\left(\tau_{1}+\tau_{2}\right)$ and is given by:

$$
A\left(4 \tau_{1}+4 \tau_{2}\right)=A\left(4 \tau_{1}\right)\left\{\exp \left(-2 \tau_{2} / T_{2}\right) \exp \left[f\left(\tau_{2}\right) G^{2}\right]\right\}^{2}
$$

If echo1 $=\mathrm{A}\left(4 \tau_{1}\right)$ and echo $2=\mathrm{A}\left(4 \tau_{1}+4 \tau_{2}\right)$, then the echo ratio, SER', is equal to:

$$
\operatorname{SER}^{\prime}=\frac{\text { echo2 }}{\text { echo1 }}=\exp \left(-4 \tau_{2} / T_{2}\right) \exp \left[-\frac{4}{3} \gamma^{2} D G^{2} \tau_{2}^{3}\right]
$$

Wai (1993) and Wai et al. (1995) demonstrated that SER' is less sensitive to sample size than the SER determined from the NHE. Note that SER' must be corrected for $\mathrm{T}_{2}$. Computations with a computer model developed by Nyenhuis and Lee (1994) corroborated observations that the "balancing" of the CPMG pulse sequence (taking only even numbered peaks) reduces the effects of $\mathrm{B}_{0}$ field inhomogeneity. The BNHE pulse sequence is closely related to the CPMG and therefore the results of Nyenhuis and Lee are consistent with the evidence provided by the experiments of Wai (1993) and Wai et al. (1995). 


\section{SYSTEM EVALUATIONS}

This section of the report describes experimental results obtained with the prototype sensor. As explained in the introduction, it was assumed that the sugar content of the fruits was approximately equivalent to the soluble solids levels as measured with a hand-held refractometer. In fruits such as citrus and tomatoes, which contain significant levels of acids, the refractometer reading differs from the percent sugar by $0.5 \%$ or more. Therefore, the first subsection discusses a small study in which refractometer measurements were compared to sugar contents as determined with High Performance Liquid Chromatography (HPLC). The first method used to evaluate the performance of the prototype was a series of tests on aqueous solutions containing various weight percentages of sucrose. Results of some of these tests are summarized in the second subsection, "Tests with Pseudofruits." The third subsection describes tests conducted on several types of fruits. A discussion of the effects of magnet homogeneity is included in the final subsection.

\section{Refractometer and HPLC Measurements:}

A refractometer measurement of percent soluble solids was used as the standard against which ${ }^{1} \mathrm{H}-\mathrm{MR}$ measurements were compared. The principle behind the refractometer measurement is that dissolved (soluble) solids change the refractive index of a solution in proportion to the weight percentage of solids present (the reading is \% brix). In many fruits, almost all of the dissolved solids are sugars. Therefore, it can be assumed that the refractometer measurement is approximately equivalent to, or in some cases directly proportional to, the sugar content of the fruits.

The refractometer used for these measurements was a hand-held ATC-1 (Atago Company, Ltd., Japan) with automatic temperature compensation. The percent brix reading was accurate to $\pm 0.2 \%$. After completion of the ${ }^{1} \mathrm{H}-\mathrm{MR}$ tests, a section was cut from each fruit and squeezed by hand so that the juice fell onto the prism of the refractometer. For fruits such as sweet cherries, the juice often contained a high proportion of suspended particles. This darkened the juice and made it difficult to get an accurate reading from the refractometer. In such cases, the section could be wrapped in a finely woven nylon cloth. This removed most of the larger particles from the juice.

One additional difficulty with the refractometer tests was the variation in soluble solids readings within a single fruit. The variation was evaluated in the spring of 1995 by means of tests conducted on oranges and apples. During tests in March, one orange segment was taken from the bottom half of the orange and the other from the top half. There was often a difference of 0.1 to $0.5 \%$ brix and in some cases differences as large as $1.3 \%$ brix.

In June of 1995 more thorough evaluations were conducted. Each apple or orange was cut into 8 segments of approximately equal size. Two segments were taken from opposite sides of the top half of the fruit and two from the bottom half. None of the sections had a surface in common. Instead they had common edges. The remaining four sections were used for moisture content measurements. Although readings were nearly identical for some of the fruits, they varied by over $1.0 \%$ for others. For one of the oranges tested on June 8, the readings from the four segments were $10.4 \%, 10.0 \%, 9.9 \%$, and $10.0 \%$ and for another orange the readings were $12.0,13.5,15.0$, and $14.3 \%$. The average difference in refractometer reading (high value minus low value for each orange divided by the total number of oranges) for the 10 oranges in the group was $1.7 \%$. This was a relatively large variation. For seven groups of oranges evaluated in April, May and June and 
ranging in number from 9 to 15 oranges, the average difference, computed in the same manner used for the oranges tested on June 8 , ranged from $0.42 \%$ brix to $1.02 \%$ brix.

The variation for groups of apples purchased from a local grocery was less than that observed for oranges. For Red Delicious apples evaluated on June 12, one of the apples had refractometer readings of $12.4,12.4,12.6$, and $12.4 \%$ and another of the apples had readings of $12.1,12.2,12.8$, and $12.4 \%$. The average difference for the 10 apples in the June 12 group was $0.39 \%$. For the six groups of Golden Delicious and Red Delicious apples evaluated during June and July 1995, the average difference within a group of apples, computed as described above, ranged from $0.25 \%$ to $0.90 \%$. These data illustrate the difficulty in comparing the refractometer reading for a section of the fruit with a ${ }^{1} \mathrm{H}-\mathrm{MR}$ echo ratio measurement which more nearly represents an average for the entire fruit.

When measurements are taken on fruits and vegetables such as oranges and tomatoes, which contain significant proportions of acids, there is an additional complication. The acids are soluble and affect the refractometer reading. This has led to the development of correction equations and tables which can be used to estimate the total solids in the juice from refractometer measurements and acid levels determined by titration (Joslyn, 1970).

Organic acids may also affect the ${ }^{1} \mathrm{H}-\mathrm{MR}$ results. In preliminary experiments with buffered citric acid solutions, the echo ratio decreased from 0.339 at a $\mathrm{pH}$ of 2.5 to 0.334 at a $\mathrm{pH}$ of 6 . This is a change in echo ratio of 0.005 . In one set of BNHE experiments with pseudofruits, the echo ratio changed from 0.405 for a $10 \%$ sucrose solution to 0.424 for a $15 \%$ solution. A change of $1 \%$ (absolute) in sugar content corresponded to a change in the echo ratio of 0.004 . Therefore, it appears possible that the echo ratio of fruits high in acid will be affected by the presence of the acid. However, the readings could be adjusted for acid level by developing a calibration curve for the specific type of fruit. It appears that the acid content would only have a major effect on measurements when acid levels fluctuated considerably among fruits of a given type. Data in the literature indicate that the $\mathrm{pH}$ of mature fruits fluctuates by less than 1.0. Money and coworkers (Money et al., 1958) reported the average $\mathrm{pH}$ of the edible portions of a number of mature fruits. Values ranged from 2.48 for lemon to 4.32 for pears. They also listed maximum and minimum $\mathrm{pH}$ values for the fruits. The maximum minus the minimum varied from 0.25 to 0.75 .

A more precise measurement of the sugar content of fruits and vegetables can be made using High Performance Liquid Chromatography (HPLC). It is capable of identifying specific sugars present in the fruit, such as sucrose, fructose, and glucose. If the system is calibrated with standards, it can also be used to determine the weight percentages of these sugars. HPLC was used to measure sugar contents of a small number of samples of juice that had been squeezed from apples and oranges. The detector on the HPLC was a Water Associates differential refractometer model R401. The injector was a Water Associates 712 WISP, and the integrator was an Hewlett Packard 3390A. The system used a Dionex gradient pump.

The following procedure was used for HPLC measurements on apple juice conducted during the summer of 1994. The juice was first diluted with distilled water and then filtered through a 0.2 micron syringe filter. These samples were chromatographed on an amino RP carbohydrate column. The injection sample size was 15 microliters, the mobile phase was 80:20 acetonitrile:water, and the flow rate was $1.2 \mathrm{~mL} / \mathrm{min}$. Standard samples were prepared by dissolving $12 \mathrm{~g}$ of fructose, $4.00 \mathrm{~g}$ of glucose, and $2.00 \mathrm{~g}$ of sucrose in $88.58 \mathrm{~g}$ of distilled water. The areas under the elution 


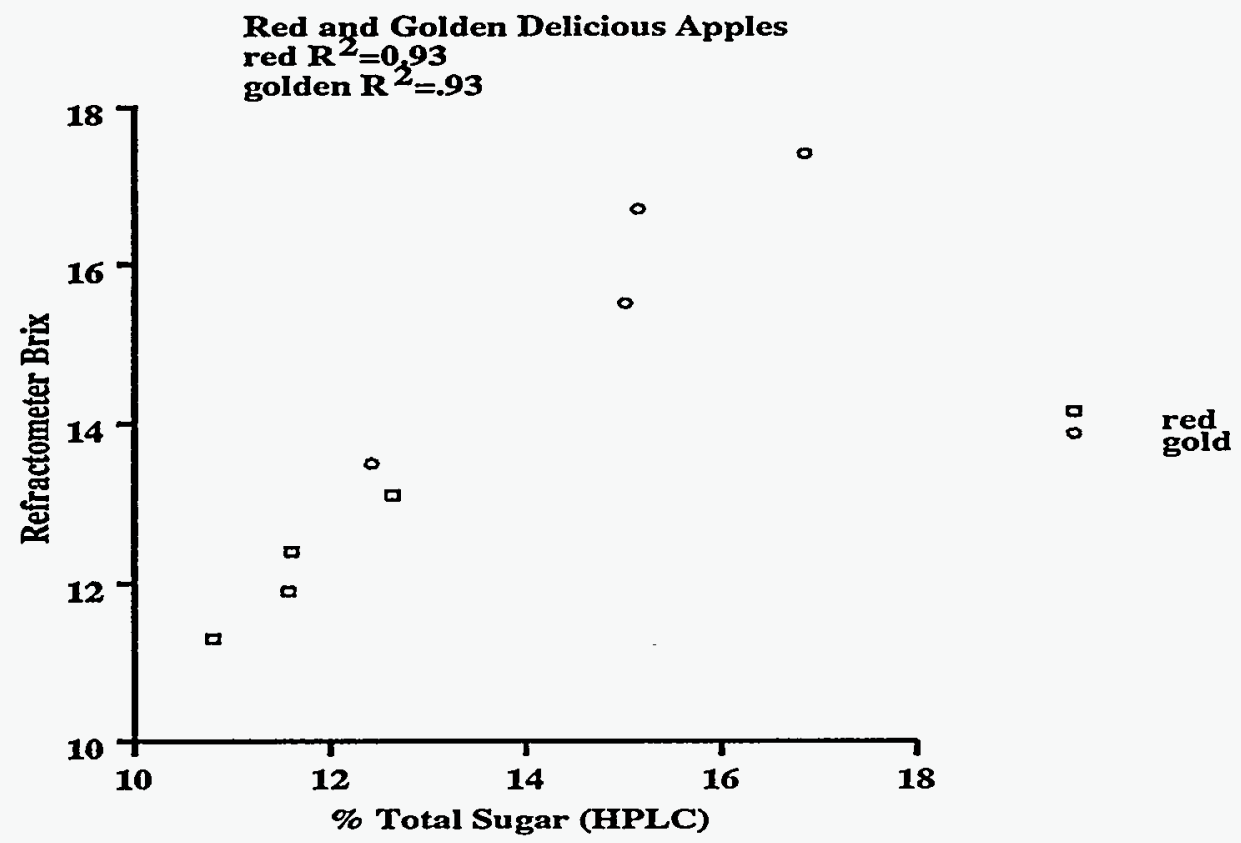

Figure 31. Relationship between refractometer readings on Red Delicious and Golden Delicious apples and the percent total sugars as determined by HPLC measurements.

Table 2. HPLC analyses of amounts of fructose, glucose and sucrose in samples of apple juice.

\begin{tabular}{|c|c|c|c|c|c|c|}
\hline Fruit Ident. & $\begin{array}{c}\text { \% Total } \\
\text { Sugars }\end{array}$ & $\begin{array}{c}\% \\
\text { Fructose }\end{array}$ & $\begin{array}{c}\% \\
\text { Glucose }\end{array}$ & $\begin{array}{c}\text { \% } \\
\text { Sucrose }\end{array}$ & $\begin{array}{c}\text { Refract. } \\
\text { Reading }\end{array}$ & $\begin{array}{c}\text { Adjusted } \\
\text { Echo Ratio }\end{array}$ \\
\hline \hline 1 RD 1A & 10.799 & 7.227 & 3.023 & 0.549 & 11.3 & 0.4183 \\
\hline 2 RD 4A & 11.571 & 7.7 & 3.339 & 0.532 & 11.9 & 0.4275 \\
\hline 3 RD 8A & 11.601 & 7.329 & 3.673 & 0.599 & 12.4 & 0.4306 \\
\hline 4 RD 3A & 12.632 & 8.491 & 3.464 & 0.677 & 13.1 & 0.4295 \\
\hline 5 GD 7A & 12.419 & 8.175 & 2.254 & 1.99 & 13.5 & 0.3747 \\
\hline 7 GD 2B & 15.013 & 9.007 & 2.595 & 3.411 & 15.5 & 0.3818 \\
\hline 8 GD 1A & 15.143 & 8.914 & 3.755 & 2.474 & 16.7 & 0.3886 \\
\hline 9 GD 3A & 16.853 & 9.964 & 3.409 & 3.48 & 17.4 & 0.4061 \\
\hline
\end{tabular}

*RD = Red Delicious; GD = Golden Delicious

peaks obtained for the standards could be used to determine the amount of each type of sugar present in the juice samples from the areas under each of the elution peaks obtained for the juice samples.

A comparison of HPLC determinations with refractometer measurements of percent solids in juice taken from 4 Red Delicious apples and 4 Golden Delicious apples is shown in Figure 31. Table 2 gives the refractometer readings and percentages of total sugars, along with a breakdown of the types of sugars found in each sample. There was a good correlation between the refractometer readings and the percent total sugars. For the Red Delicious apples, the refractometer readings were, on the average, $0.5 \%$ higher than the percent total sugars determined by HPLC analysis. For the Golden Delicious apples, the refractometer readings were $0.9 \%$ higher. Com- 
pared to the Red Delicious apples, the Golden Delicious apples contained a noticeably higher percentage of sucrose.

HPLC tests were also conducted on orange juice samples. As mentioned above, orange juice has both soluble acids and soluble sugars. These tests were done using an ORH-801 column with a mobile phase of $0.01 \mathrm{~N}$ sulfuric acid (heated and stirred during input into the column). The column could detect both the sugars and the citric acid present. It was calibrated using $8 \mu \mathrm{L}$ samples of a series of standard solutions at flow rates of $0.8 \mathrm{~mL} / \mathrm{min}$. The standards were $0.1 \%$ solutions of sucrose, fructose, glucose, and citric acid and a sample containing all four of these compounds. Unfortunately the citric acid and the fructose eluted at approximately the same time.

The difficulty caused by the overlap of the citric acid and fructose peaks was resolved by removing the citric acid. When $0.1 \mathrm{M} \mathrm{Pb}(\mathrm{OAc})_{2}$ and $1.0 \mathrm{M} \mathrm{K}_{2} \mathrm{HPO}_{4}$ were added, the citric acid precipitated. The precipitate was subsequently removed by filtration. The samples were then diluted with water so that they contained $3 \%$ juice. The system was calibrated with standard solutions prepared by dissolving $11.96 \mathrm{~g}$ sucrose, $2.99 \mathrm{~g}$ of fructose, and $3.00 \mathrm{~g}$ of glucose in water to make $100 \mathrm{ml}$ of solution. Trials were conducted using a $6 \%, 3 \%$, and $1.5 \%$ standards and juice samples diluted to obtain $3 \%$ juice. They were chromatographed on the ORH 801 column with $0.01 \mathrm{~N} \mathrm{H}_{2} \mathrm{SO}_{4}$ as the mobile phase, an injection size of $15 \mu \mathrm{L}$ and a flow rate of $0.4 \mathrm{~mL} / \mathrm{min}$. It should be noted that it was assumed that citric acid was the only significant acid present.

The amount of citric acid in the juice samples was determined by titrating a $5 \mathrm{~mL}$ sub-sample with $0.053 \mathrm{~N}$ sodium hydroxide $(\mathrm{NaOH})$. When phenolphthalein is used as an indicator, the color of the solution turns purple at the endpoint, which occurs at $\mathrm{pH} \mathrm{8.2.} \mathrm{Titrations} \mathrm{were} \mathrm{conducted} \mathrm{in}$ a laboratory located in Purdue's Food Science Department. A pH meter was used to improve the precision in detection of the endpoint. The grams of citric acid could be calculated from the number of milliliters of $\mathrm{NaOH}$ needed to reach the endpoint. Three moles of $\mathrm{NaOH}$ are required for every mole of citric acid.

Results of tests on five oranges are summarized in Table 3. In all of the oranges tested, the amounts of fructose and glucose were approximately equal. With the exception of orange \#4, the orange juice samples contained approximately twice as much sucrose as glucose. The acid contend varied from $0.85 \%$ for orange \#5 to $1.49 \%$ for \#4. The brix to acid ratios (not shown in the table) varied from 4.7 for orange \#4 to 14.1 for \#5. Oranges \#2, \#7, and \#10 had ratios near 9.5. Recall that the minimum acceptable brix to acid ratio for fresh oranges is 9 to 1 (see "Consultant Evaluation- Citrus, Stone Fruit, Avocados and Mangoes").

Figure 32 is a plot of refractometer reading versus the HPLC measurement of percent total sugars. The two readings were highly correlated $\left(x^{2}=0.99\right)$, and each refractometer reading was typically $2 \%$ higher than the percent total sugar. Most of the difference can be attributed to the citric acid, which was typically between 1.0 and $1.4 \%$. The remainder of the difference may have been caused by the presence of smaller amounts of other acids and dissolved solids (Hicks, 1990).

\section{Tests with Pseudofruits}

During initial testing of the equipment, the President of Magnetic Instrumentation suggested that standard samples be developed which could be used to evaluate the performance of the ${ }^{1} \mathrm{H}$ MR equipment. Project personnel decided to make "pseudofruits" by filling hollow plastic 
Table 3. Analyses of fructose, glucose, sucrose and citric acid content of orange juice samples

\begin{tabular}{|c|c|c|c|c|c|c|c|}
\hline Fruit & $\begin{array}{c}\text { \% Total } \\
\text { Sugars }\end{array}$ & $\begin{array}{c}\% \\
\text { Fructose }\end{array}$ & $\begin{array}{c}\% \\
\text { Glucose }\end{array}$ & $\begin{array}{c}\% \\
\text { Sucrose }\end{array}$ & $\begin{array}{c}\text { Refract. } \\
\text { Reading }\end{array}$ & $\begin{array}{c}\text { gm Citric } \\
\text { Acid/liter }\end{array}$ & $\begin{array}{c}\text { Adjusted } \\
\text { Echo Ratio }\end{array}$ \\
\hline \hline 2 & 7.66 & 1.67 & 1.81 & 4.18 & 9.6 & 10.2 & 0.4593 \\
\hline 4 & 5.08 & 2.40 & 2.39 & 0.29 & 7.0 & 14.9 & 0.4556 \\
\hline 5 & 9.69 & 2.30 & 2.28 & 5.11 & 12.0 & 8.5 & 0.4648 \\
\hline 7 & 8.75 & 2.14 & 2.22 & 4.391 & 11.5 & 12.0 & 0.4575 \\
\hline 10 & 11.28 & 2.76 & 2.88 & 5.63 & 13.8 & 14.0 & 0.4872 \\
\hline
\end{tabular}

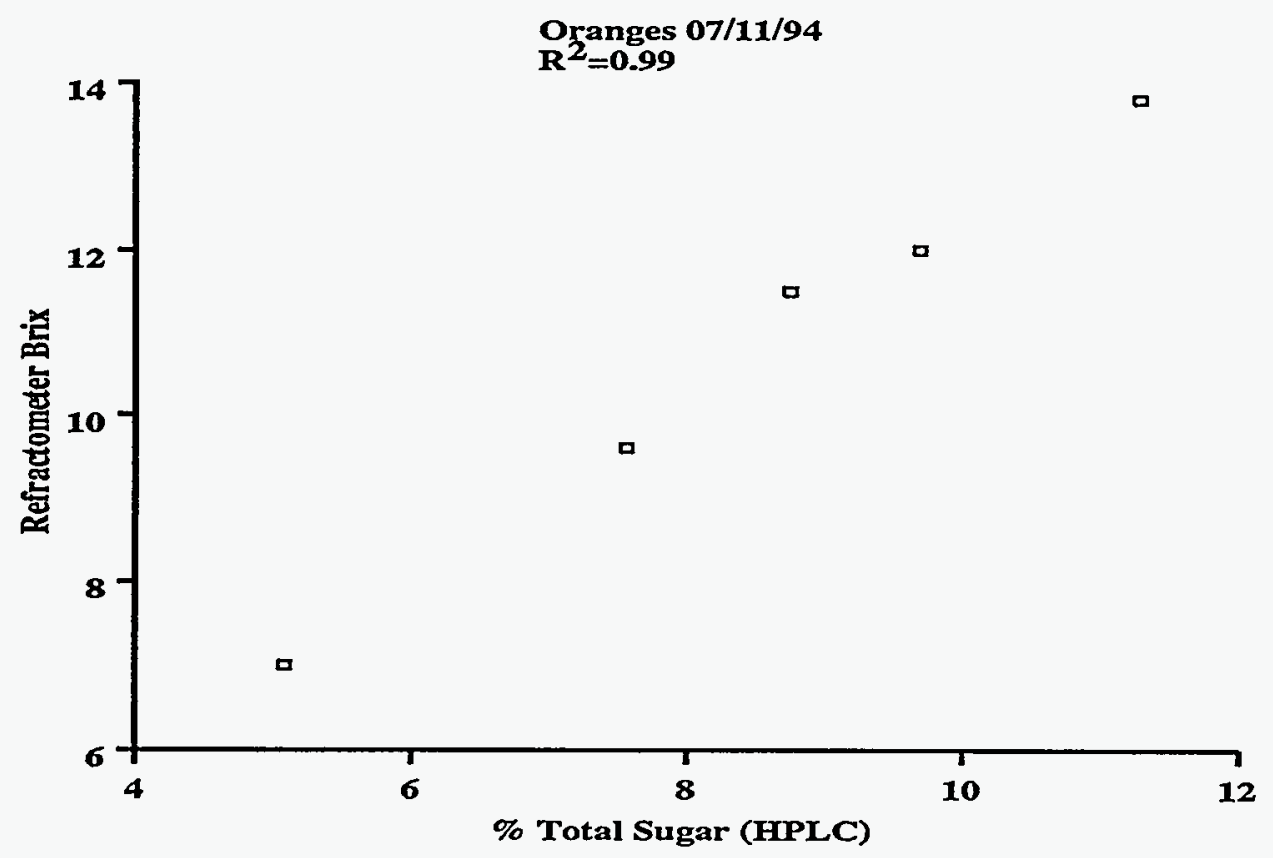

Figure 32. Relationship between refractometer measurements on juice squeezed from oranges and the total sugar content of the orange juice as determined with HPLC measurements.

spheres with aqueous solutions containing various percentages by weight $(0,5,10,15,20,25$ and $30 \%$ ) sucrose. Sucrose solutions were made by mixing distilled water with sucrose in a sterile environment and then filtering the solutions through a $0.2 \mu \mathrm{m}$ syringe tip filter. This removed bacteria and other organisms which could grow in the solutions. The spheres were filled in a laminar transfer hood. The tip of a red hot steel spatula was used to melt two small holes in each sphere and the sucrose solution was injected into the spheres using a hypodermic needle. To the extent that it was possible, the spheres were filled completely so they contained no air or, in the worst case, a relatively small air bubble. The hole was sealed by searing the plastic sphere with the tip of the red hot steel spatula. When all the spheres had been filled, they were autoclaved on a liquid cycle $\left(121^{\circ} \mathrm{C}\right)$ for 15 minutes. Several sizes of pseudofruits were prepared using hollow plastic spheres with the following outside diameters: $20 \mathrm{~mm}, 24.5 \mathrm{~mm}, 37.5 \mathrm{~mm}$, and $70 \mathrm{~mm}$. The $37.5 \mathrm{~mm}$ pseudofruits were used routinely in the MA-3 magnet while the $70 \mathrm{~mm}$ pseudofruits were used routinely in the MA- 8 and MAR- 8 magnets. 
The pseudofruits, along with sweet cherries and pieces cut from other fruits such as apples, were used for the initial experiments conducted shortly after SWRI's LL-4 system was assembled and placed in service. The principle advantages of the pseudofruits were that they eliminated the effects of sample size and the effects of the heterogeneity of the fruits. This heterogeneity is caused by the cellular nature of the fruit and the fact that most fruit contain several types of tissue (e.g. seeds, rind, core) and cells (e.g. parenchyma cells and vascular elements). Pseudofruits were used for many of the initial Hahn echo and Normalized Hahn echo experiments. After the Balanced Normalized Hahn Echo (BNHE) pulse sequence was developed, they were used to develop calibration equations that were subsequently applied to various fruits.

Results of tests with pseudofruits containing $0 \%, 5 \%, 10 \%, 15 \%, 20 \%, 25 \%$, and $30 \%$ sucrose by weight are shown in Figure 33. The coefficients of determination $\left(\mathrm{r}^{2}\right)$ for tests with pseudofruits at a constant temperature were consistently 0.96 or higher and were typically 0.98 . During initial experiments, it became apparent that temperature has a significant effect on diffusion dependent measurements such as echo ratios. The effect of temperature was determined by running tests on pseudofruits equilibrated to different temperatures. The thermostat in the laboratory was set to the desired temperature the evening before each experiment. The pseudofruits were kept in the laboratory and, therefore, they also equilibrated to the desired temperature. The tests were conducted the following morning and were completed within several hours. Temperatures used for successive experiments were $19,20.5,21,26$, and $30.7^{\circ} \mathrm{C}$. As temperature increased, the echo ratio decreased (Figure 33). However, there was consistently a linear relationship between adjusted echo ratio (the echo ratio corrected for differences in $\mathrm{T}_{2}$ ) and percent sucrose. Some of the curves appear to be slightly non-linear when percent sucrose exceeds $20 \%$. This may, in part, be caused by the fact that the diffusion coefficient of water varies linearly with percent sucrose at lower values of percent sucrose. However, it becomes non-linear above 20\% sucrose (Wai, 1993).

The BNHE pulse sequence reduces, but does not eliminate, the effects of sample size on echo ratio. This was confirmed by both experiments on pseudofruits with diameters of $24.6 \mathrm{~mm}$ and $37.5 \mathrm{~mm}$, and computations performed with a computer model (Yee et al., 1995). In Yee's computations the size effect was greater for larger samples and larger gradients in the $\mathrm{B}_{0}$ field.

\section{Tests with Fruits}

During phase I of the project, low field experiments on sweet cherries and grapes were conducted with a $10 \mathrm{MHz}$ Pulsed ${ }^{1} \mathrm{H}-\mathrm{MR}$ spectrometer located at the University of Illinois (Cho, et al., 1993). The CPMG pulse sequence was used to interrogate samples. Coefficients of determination $\left(\mathrm{r}^{2}\right)$ for the linear regression of $\mathrm{T}_{2}$ versus refractometer reading were 0.44 and 0.38 for seedless grapes and sweet cherries, respectively. The firmness of the sweet cherries was also tested. The value of $\mathrm{r}^{2}$ for a linear regression of $\log$ of apparent modulus of elasticity versus $\log$ of $\mathrm{T}_{2}$ was 0.41 (Stroshine, et al., 1991). Subsequent tests during the summer of 1992 using SWRI's LL4 and the MA-3 magnet also indicated a correlation between firmness and $\mathrm{T}_{2}$ for sweet cherries $\left(r^{2}=0.23\right)$ and core samples taken from apples $\left(r^{2}=0.29\right)$. [Note: after these tests were performed, it was discovered that, under certain circumstances, the values of $T_{2}$ may have been inaccurate because the RF power amplifier was not operating properly (Stroshine, et al., 1994). The problem was subsequently corrected.] These results indicate that factors other than sugar content affect $T_{2}$. As mentioned previously, the effect of firmness on $T_{2}$ motivated a search for other pulse sequences which could detect the sugar content of whole fruits. 


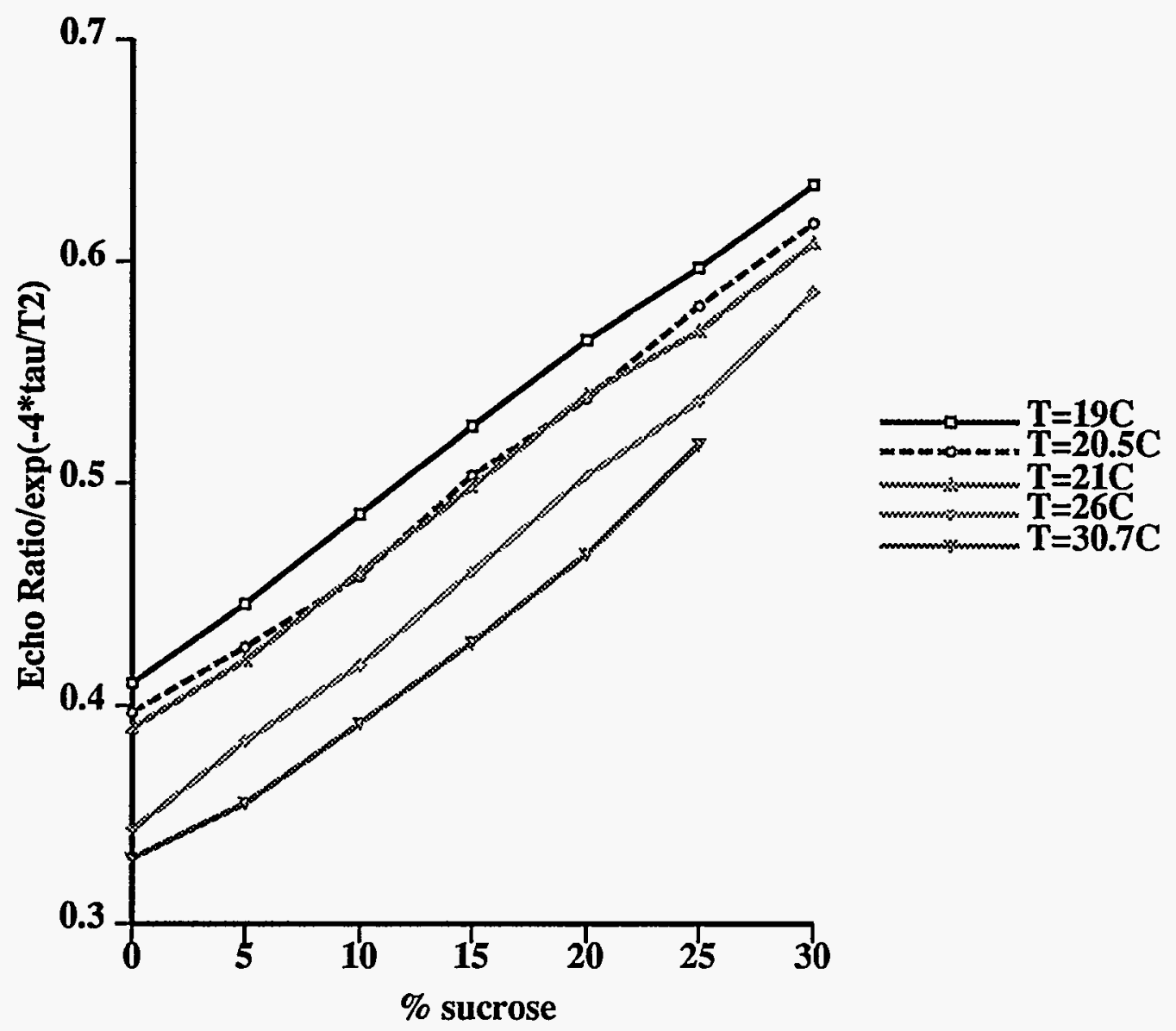

Figure 33. Results of experiments with pseudofruits showing effect of temperature on echo ratio measurements. Note that echo ratios were adjusted for variations in $\mathrm{T}_{2}$.

During the first several months of the phase II project, only the MA-3 magnet was available for tests. This limited the maximum dimension of the sample to approximately $30 \mathrm{~mm}$. Although the sample did not have to be spherical, this was the preferred shape. Many researchers prefer to use spherical samples. There are at least two factors which help to explain this preference. The homogeneity of a well designed magnet is uniform within a region bounded by a sphere. The sample also distorts the $\mathrm{B}_{0}$ magnetic field slightly and a spherical sample will produce a symmetrical distortion. Many of the tests were conducted with spherical or nearly spherical fruits. Others were conducted with cylindrical samples cut from fruits. Tests on oranges were conducted on segments of oranges or pieces of orange segments.

Wai (1993) conducted tests on a variety of fruits and vegetables using the BNHE pulse sequence both with and without correction for $\mathrm{T}_{2}$. Results are summarized in Table 4 . The correlations for apples, bananas, sweet cherries and oranges were reasonably good $\left(r^{2}>0.75\right)$ while correlations were relatively poor for blueberries, pears, and potatoes. The $T_{2}$ correction made a significant improvement in the $\mathrm{r}^{2}$ for sweet cherries, nectarines, pineapple, and potato. However, the $r^{2}$ value for potatoes was still very low. Potatoes contain a very low percentage of sugar, usu- 
Table 4. Results of BNHE tests on cylindrical samples cut from fruits and vegetables (Wai, 1993).

\begin{tabular}{|c|c|c|c|c|c|c|c|}
\hline Fruit/Veg. & $\begin{array}{c}\text { Number } \\
\text { Samples }\end{array}$ & $\begin{array}{c}\text { Max. } \\
\text { \% Brix* }\end{array}$ & $\begin{array}{c}\text { Min. } \\
\text { \% Brix }\end{array}$ & $\begin{array}{c}\text { Avg. } \\
\text { \% Brix }\end{array}$ & $\begin{array}{c}\mathbf{T}_{\text {2b }} \text { (ms) and } \\
\text { C.0.V. }\end{array}$ & $\begin{array}{c}\mathbf{r}^{2} \text { for ER } \\
\text { vs. \% Brix }\end{array}$ & $\begin{array}{c}\mathbf{r}^{2} \text { for AER } \text { \% Brix } \\
\text { vs. }\end{array}$ \\
\hline \hline Apples & 11 & 14.6 & 11.9 & 13.2 & $935 / 8.1 \%$ & 0.77 & 0.76 \\
\hline Bananas & 10 & 25.5 & 15.0 & 19.4 & $431 / 12.7 \%$ & 0.81 & 0.76 \\
\hline Blueberries & 30 & 18.0 & 9.6 & 13.2 & $499 / 16.4 \%$ & 0.19 & 0.38 \\
\hline $\begin{array}{c}\text { Sweet } \\
\text { Cherries }\end{array}$ & 116 & 23.2 & 10.6 & 14.9 & $490 / 8.2 \%$ & 0.58 & 0.90 \\
\hline Nectarines & 25 & 16.9 & 11.5 & 13.4 & $586 / 9.4 \%$ & 0.53 & 0.71 \\
\hline Oranges & 10 & 14.7 & 9.0 & 12.2 & $794 / 8.1 \%$ & 0.79 & 0.83 \\
\hline Peaches & 9 & 13.0 & 10.2 & 11.1 & $687 / 10.0 \%$ & 0.55 & 0.44 \\
\hline Pears & 12 & 15.6 & 12.6 & 13.8 & $779 / 4.7 \%$ & 0.66 & 0.38 \\
\hline Pineapple & 8 & 15.2 & 10.8 & 12.9 & $155 / 12.9 \%$ & 0.25 & 0.49 \\
\hline Potato & 14 & 7.2 & 5.4 & 6.5 & $323 / 4.3 \%$ & 0.00 & 0.35 \\
\hline
\end{tabular}

* As determined with a refractometer; $+T_{2 b}$ is $T_{2}$ determined for points 500 to 1000 of the CPMG pulse sequence.; $\left\lceil E R\right.$ is echo ratio from BNHE pulse sequence; $¥$ AER is ER adjusted for $T_{2 b}$.

ally less than $2 \%$. The refractometer readings averaged $6.5 \%$ indicating the presence of dissolved solids other than sugars. Therefore, the low $\mathrm{r}^{2}$ was anticipated. The blueberries were relatively small in relation to the diameter of the RF coil. Their low $r^{2}$ may have been caused by a poor signal to noise ratio. The explanation for the variation in the effect of $\mathrm{T}_{2}$ correction is not known. It should also be noted that, in many cases, a relatively small number of samples were tested. These results are preliminary. Additional research on specific fruits could lead to insights which would improve the correlations.

Figure 34 shows results of grape juice tests using Magnetic Instrumentation's LF-1A sensor and the MAR-8 magnet. The smaller shielded coil normally used with the MA-3 magnet was placed in the MAR- 8 for the purpose of conducting these tests. Samples were prepared by mixing grape juice concentrate, purchased from the store, with varying proportions of water. The samples were placed in $60 \mathrm{ml}$ glass bottles which were sealed with plastic screw-on caps. These bottles were inserted into the MAR-8. After completion of the tests, the percent brix in each grape juice sample was determined with a hand-held refractometer. Before the grape juice samples were run, a set of pseudofruits was also tested. The linear regression of the grape juice echo ratio, corrected for $\mathrm{T}_{2}$, versus refractometer brix, had an $\mathrm{r}^{2}$ of 0.953 and the regression of corrected echo ratio for pseudofruits versus percent sucrose had an $\mathrm{r}^{2}$ of 0.949 . The $\mathrm{r}^{2}$ for the pseudofruits was lower than normal, primarily because of an unusually high corrected echo ratio for the pseudofruit containing $5 \%$ sucrose. The correlation for the grape juice samples was relatively high. The results suggest that ${ }^{1} \mathrm{H}-\mathrm{MR}$ could be used for monitoring the sugar content of juice during processing.

The results of tests on whole oranges conducted with SWRI's LL-4 sensor and the MA-8 magnet are shown in Figure 35. The linear regression of echo ratio, adjusted for $\mathrm{T}_{2}$, (AER) versus refractometer reading $(\mathrm{BRX})$ had an $\mathrm{r}^{2}$ of 0.51 . In a series of six tests conducted during February 


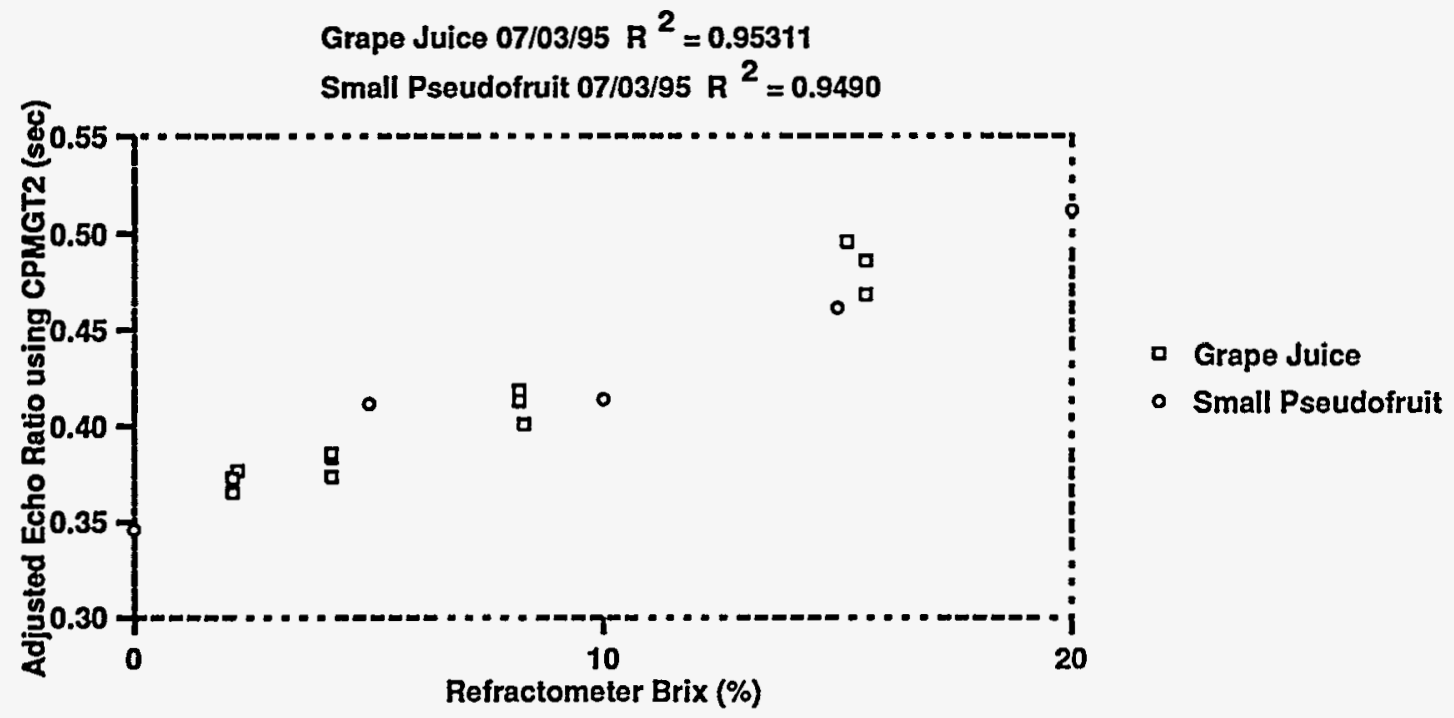

Figure 34. Echo ratio of grape juice samples, adjusted using values of $T_{2}$ determined with the CPMG pulse, versus percent brix as determined with a refractometer. Tests conducted 7/3/95.

through July of 1995 , the values of $\mathrm{r}^{2}$ were of a similar magnitude or lower. These correlations are considerably lower than the $r^{2}$ of 0.83 observed for the same linear regression on orange segments tested in the MA-3 magnet (Table 4).

In order to determine whether other signal parameters could be used to improve the measurements of BRX, multiple regression analyses were conducted on the data shown in Figure 35 . The multiple regression of BRX versus AER and $\mathrm{T}_{2}$ had an $\mathrm{r}^{2}$ of 0.698 . When the voltage of the echo 1 peak (EP1V, see Fig. 30) was included in the multiple regression, the $r^{2}$ increased slightly to 0.701. In tests conducted on April 11 with the MAR-8 magnet, the multiple regression of BRX versus AER and $T_{2}$ had an $r^{2}$ of 0.91 while the $r^{2}$ for the linear regression of $B R X$ versus AER was only 0.34 . In some instances, the addition of EP1V and $T_{2}$ improved the BRX prediction.

Some of the lower correlations observed in the March-July tests on oranges appeared to be caused by large variations in the sizes of the oranges. For example, in a test of 19 oranges conducted on May 24 , the $r^{2}$ for BRX versus AER, $T_{2}$ and EP1V increased from 0.28 to 0.58 when only oranges weighing more than 150 grams $(10$ of 19$)$ were included in the multiple regression. The $r^{2}$ for BRX versus AER, $T_{2}$, and EP1V further increased to 0.802 when only oranges weighing more than 200 grams (7 of 19) were included. This suggests that, for this test, the lower correlation was caused by the increase in the signal to noise ratio (lower filling factor) for the smaller oranges. Additional tests are needed to identify factors which affect the AER versus BRX correlation. These factors could include the following: the heterogeneous nature of the whole fruit; the design of the RF coil, gradient coil and shielding; or other equipment limitations.

Compared to oranges, apples showed a consistently higher correlation between AER and BRX. For tests conducted in 1993 (Table 4), 1994, and 1995, values of $r^{2}$ for the linear regression 


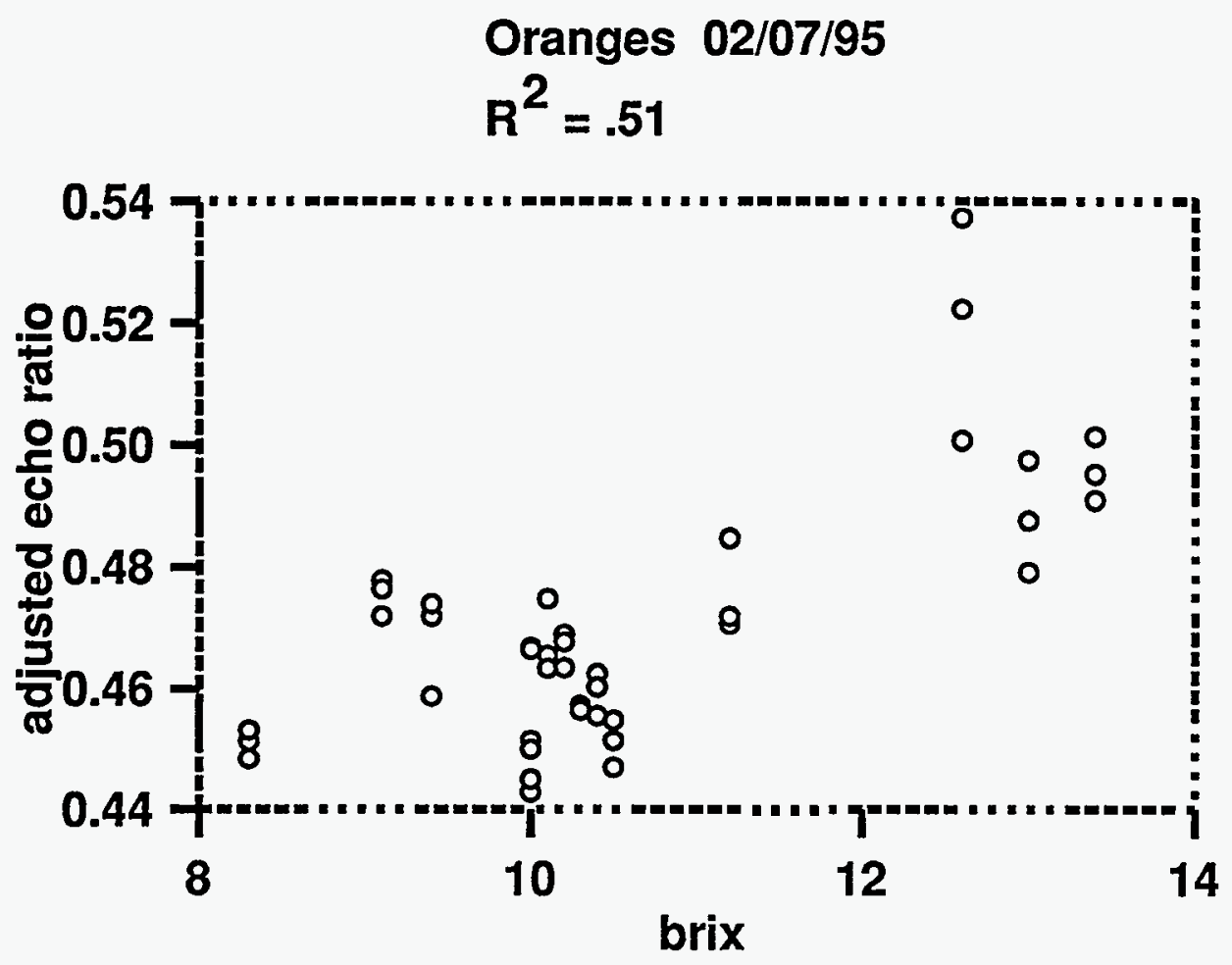

Figure 35. Echo ratio of oranges, adjusted using the value of $T_{2}$ determined from a CPMG test, versus percent brix as measured with a refractometer. Data collected 2/07/95.

of AER versus BRX were usually 0.5 or higher. The $r^{2}$ of the linear regression of AER versus BRX for tests conducted on Red Delicious apples on June 12, 1995 was 0.90 (Figure 36). Multiple regression analysis was conducted on the results of this test and three other tests conducted in June and July of 1995. Although the addition of EPV1 and $T_{2}$ did not improve the correlations for the data shown in Figure 36, it did improve correlations for the other tests. For 10 Golden Delicious apples tested on July 13,1995, the $\mathrm{r}^{2}$ for AER versus BRX was 0.66 . The $\mathrm{r}^{2}$ for multiple regression analysis of $B R X$ versus $A E R$ and $T_{2}$ was 0.85 and the $r^{2}$ for $B R X$ versus $A E R, T_{2}$, and $E P 1 V$ was also 0.85. For $B R X$ versus $A E R$ and $E P 1 V$ the $r^{2}$ was 0.57 . It appears that, in this case, there was additional information provided by both the EP1V and the $\mathrm{T}_{2}$ measurements. As mentioned in the discussion of results for oranges, additional tests should be conducted to determine factors which affect this correlation.

\section{Magnet Homogeneity}

One concern was the effect of the magnet homogeneity on the measurements. A magnet which has a very homogeneous $B_{0}$ field is more expensive to build. This would significantly affect the cost of the sensor. As mentioned previously, one of the objectives of the Phase II project was to determine the effect of magnet homogeneity on the measurement of fruit ripeness. During the spring of 1995, tests were conducted with oranges using both the MA-8 magnet, which has 


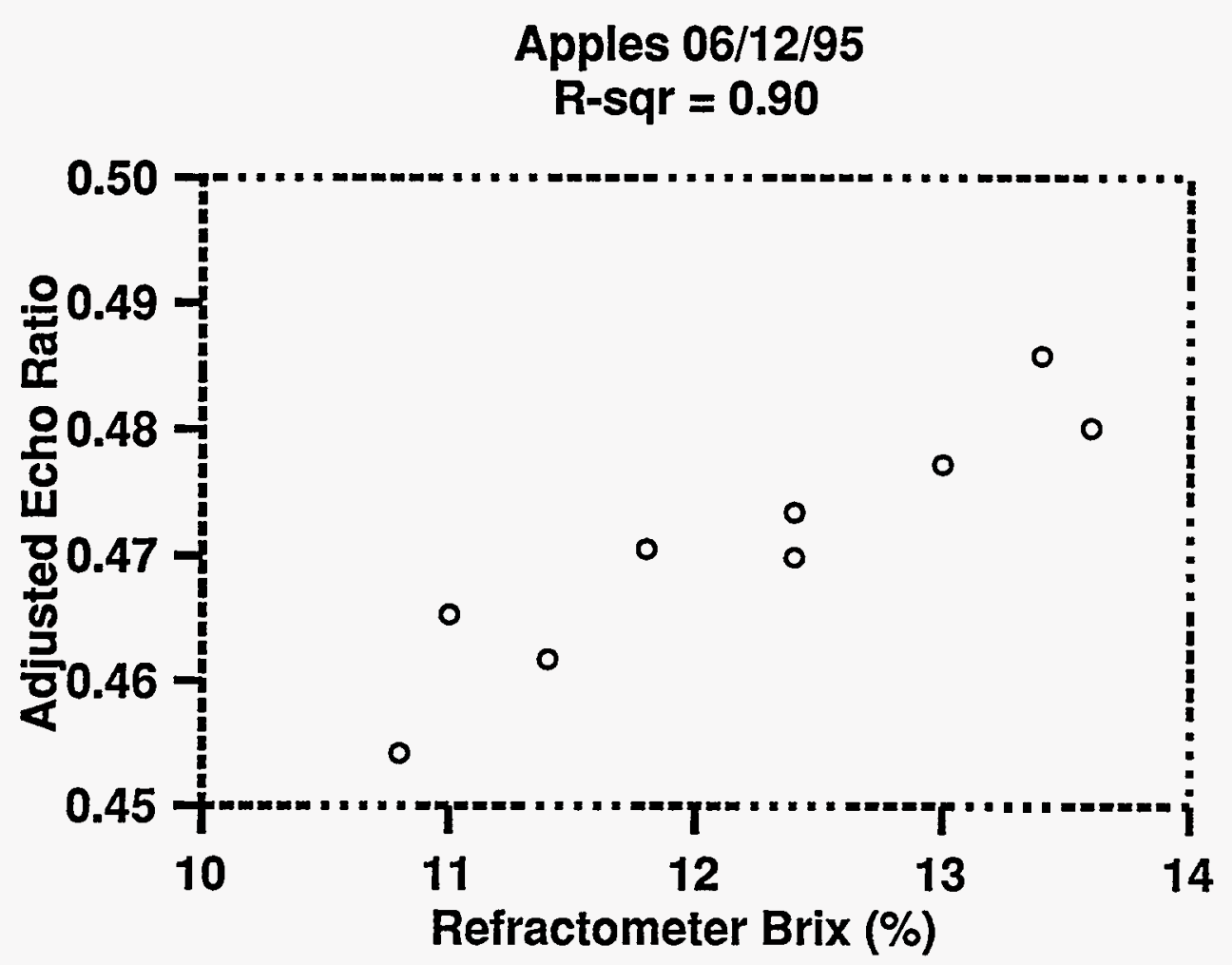

Figure 36. Echo ratios of Red Delicious apples, adjusted using $\mathrm{T}_{2}$ determined from a CPMG test, versus percent brix as determined from a refractometer. Tests were conducted 6/12/95.

a homogeneity of approximately 600 to $800 \mathrm{ppm}$, and the MAR-8 magnet, which has a homogeneity of approximately $106 \mathrm{ppm}$. For samples with diameters less than $7 \mathrm{~cm}$ which are centered between the pole faces of the MAR-8 magnet, the homogeneity is approximately $46 \mathrm{ppm}$.

Comparison of the MA-8 and MAR-8 results was complicated by difficulties experienced with the RF coil of the MAR-8 magnet. The diameters of the RF coils used in the two magnets were identical. However, the air gap on the MAR-8 magnet was much smaller and the outer surface of the RF coil made contact with the shields on the pole faces. Although the RF coil was well insulated from the pole face, there still appeared to be inductive coupling between the RF coil and the pole faces and this caused losses. The coupling may explain why the $90^{\circ}$ and $180^{\circ}$ pulse lengths were much greater for the MAR-8 magnet as compared to the MA-8 magnet. Coupling may also have affected the echo peak amplitudes. When coupling was present, there was no obvious improvement in the correlations attained by the use of the more homogeneous field. Measurements made with the CPMG pulse sequence should be relatively insensitive to homogeneity. The BNHE pulse sequence is closely related to the CPMG. The observed effects of homogeneity are consistent with these facts. However, theory suggests that the effect of sample size may be greater in a less homogeneous field (Yee et al., 1995). Therefore additional tests are needed. At the time of the writing of this report, an RF coil with a diameter of $7 \mathrm{~cm}$ had been constructed for the MAR-8 magnet. It was to be used for further evaluations of the effects of inhomogeneity, especially as they relate to size. It should be noted that most fruits are sized during the grading process and that fruit sorted in the ripeness sensor should be relatively uniform in size. 


\section{SUMMARY}

This report has summarized research on the development of a ripeness sensor which would nondestructively determine the sugar content of fruits and vegetables. The sensor utilizes proton magnetic resonance as a means of interrogating the fruit. The work was conducted between September 1, 1992 and July 30, 1995.

An economic study was conducted to determine the benefits which would be obtained from use of the sensor by the fruit industry. The study included an estimate of energy savings, a survey sent to fruit packing houses and chain grocery stores, and reports from paid consultants. Large amounts of energy are required to process, store, and transport fruit before it reaches the consumer. Therefore, reduction in the amount of fruit which must be thrown away due to over-ripeness could result in substantial energy savings. The consensus of the fruit industry was that the sensor would be most beneficial if it were used by packing houses for the sorting of fruits. Potential savings to the packing houses would vary with the type of fruit, the condition of the fruit during a particular growing season, and the maturity of the fruit at the time of harvest. A rapid device capable of on-line sorting ( 6 fruits/second on multiple lanes) would be the most useful. However, some of the packers would also be able to use a device capable of testing 12 fruits/minute. This would be particularly true if the device were portable and could be taken into orchards.

A prototype sensor was assembled and tested. The first prototype consisted of a magnet, built by Purdue personnel, which was capable of holding samples up to $30 \mathrm{~mm}$ in diameter. This magnet was used with electronic components built by Southwest Research Institute of San Antonio, Texas. During the course of the project, Purdue personnel and Magnetic Instrumentation, Inc. of Indianapolis, Indiana built a larger magnet capable of testing samples up to $80 \mathrm{~mm}$ in diameter. In addition, Magnetic Instrumentation engineers developed their own electronic components. In 1994 a third magnet, which was also capable of testing samples $80 \mathrm{~mm}$ in diameter, was purchased from the Field Effects division of Intermagnetics General Corporation. This magnet had a much higher homogeneity than the two magnets built by project personnel. Both the SWRI system and the Magnetic Instrumentation system were tested with the three magnets. Performance of the two systems was comparable. The increased homogeneity achieved with the magnet built by Field Effects did not appear to offer any advantages in sensing of sugar content of fruits, vegetables, and fruit juices. However, evaluations of the homogeneity effect are continuing.

One of the parameters frequently measured in magnetic resonance studies is the spin-spin relaxation constant, $T_{2}$. This is a good parameter to measure for fruit ripeness sensing because it can be measured rapidly and does not require a magnet which produces a highly homogeneous magnetic field. Magnets which produce such highly homogeneous fields are expensive and magnet cost has a large impact on the cost of a sensor. Unfortunately, the correlation between $T_{2}$ and sugar content of fruits and sucrose solutions was too low. One of the major accomplishments of the project was the development of a special pulse sequence ideally suited for determination of sugar content of fruits. The pulse sequence, called the Balanced Normalized Hahn Echo (BNHE), had all the advantages of the $\mathrm{T}_{2}$ measurement and gave better correlations with the percent sugar in sucrose solutions.

The BNHE pulse sequence was evaluated for use in sensing the sugar content of fruits and vegetables. It performed very well with grape juice samples and reasonably well with Red Deli- 
cious and Golden Delicious apples. Although a correlation was also observed with oranges, the accuracy with oranges was still lower than desired. Multiple regression analysis indicated that the correlations could be improved by utilizing additional signal parameters.

Although the project ended on June 30,1995, research on fruit ripeness sensing will continue. Project personnel will attempt to determine factors affecting correlations for whole fruits and thereby improve the accuracy for sensing sugar contents of fruits such as oranges and apples. The application of the technology to the sensing of fruit juices will be studied. Project personnel are presently evaluating the use of the Pulsed Field Gradient (PFG) technique for the sensing of sugar content and other quality parameters. The PFG technique is frequently utilized in research. Very few, if any, scientists are still using the Steady Gradient (SG) technique evaluated in this research project. Although the PFG is more difficult to implement than the SG, it may give greater accuracy. Insufficient data have been gathered with the PFG to allow those results to be included in this report.

In conclusion, initial results with development of a proton magnetic resonance are promising. Much has been accomplished, and much remains to be done. Development of the sensor is an extremely demanding task. However, the potential benefits from this technology are great and continued effort is warranted. 


\section{REFERENCES}

Awan, S. 1992. Design of a Computer Based Low Resolution NMR System. Unpublished M.S. Thesis. Department of Electrical Engineering, Purdue University, W. Lafayette, Indiana.

Carr, H.Y. and E.M. Purcell. 1954. Effects of diffusion on free precession in nuclear magnetic resonance. Physical Review 94(3):630-638.

Chen, P., M.J. McCarthy and R. Kauten. 1989. NMR for Internal Quality Evaluation of Fruits and Vegetables. Transactions of ASAE 32(5):1747-1753.

Chen, P., M.J. McCarthy, R. Kauten, Y. Sarig, and S. Han. 1993. Maturity evaluation of Avocados by NMR Methods. Journal of Agricultural Engineering Research 55:177-187.

Cho, S.I. 1989. Development of a Nuclear Magnetic Resonance Based Sensor to Detect Ripeness of Fruit. Ph.D. dissertation. Agricultural Engineering Department, Purdue University, West Lafayette, Indiana.

Cho, S.I., and R.L. Stroshine. 1992. Ripeness Sensor Development. DOE/ID/12917-T1 (DE93003283). Final Report for work performed under contract No.1 FC02-89D12917. U.S. Department of Energy, Pittsburgh Energy Technology Center, Pittsburgh, PA. 50 pgs.

Cho, S.I., G.W. Krutz, H.G. Gibson, and K. Haghighi. 1990. Magnet Console Design of an NMRBased Sensor to Detect Ripeness of Fruit. Transactions of ASAE 56(4):1043-1050.

Fluck, R.C., and C.D. Baird. 1980. Agricultural Energetics. AVI Publishing Company, Inc., Westport, Connecticut.

Fukushima, E. and S.B.W. Roeder. 1981. Experimental Pulse NMR, A Nuts and Bolts Approach. Addison-Wesley Publishing Company, Reading, Massachusetts. 539 p.

Hardenburg, R.E., A.E. Watada, and C.Y. Wang. 1986. The Commercial Storage of Fruits, Vegetables, and Florist and Nursery Stocks. USDA-ARS Agriculture Handbook \#66. Government Printing Office, Washington, D.C.

Joslyn, MA. 1970. Refractometric Methods. Chapter 8 in: M.A. Joslyn (editor) Methods in Food Analysis, 2nd Edition. Academic Press, New York. 829 pgs.

Li, Y., R.L. Stroshine, and G.W,. Krutz. 1992. Design of Permanent Magnet Housing for a Nondestructive Fruit Ripeness Sensor. Paper 92-6508. ASAE, St. Joseph, Michigan.

Li, Y., W.K. Wai, R.L. Stroshine, and G.W. Krutz. 1992. Nondestructive sugar content sensing of intact fruit using low field and low resolution pulsed magnetic resonance. Paper 92-6598. ASAE, St. Joseph, Michigan.

McCarthy, M.J., B. Zion, and P. Chen. 1995. Diamagnetic Susceptibility Changes in Apple Tissue after Bruising. J. Sci. Food Agric. 67:13-20.

Money, R.W. et al. 1958. Analytical Data on some Common Fruits. Journal of Science in Food and Agriculture 9(1):18-20.

Nyenhuis, J.A. and O.P. Yee. 1994. Simulation of Nuclear Magnetic Resonance Spin Echoes using the Bloch Equation: Influence of Magnetic Field Inhomogeneities. Journal of Applied Physics 76(10):6909-6911. 
Ray, J.A. 1993. Low Resolution Magnetic Resonance Evaluation of Weight, Soluble Solids and Firmness of Sweet Cherries. Unpublished Master of Science Thesis. Department of Agricultural and Biological Engineering, Purdue University, W. Lafayette, Indiana.

Ray, J.A., R.L. Stroshine, G. W. Krutz, and W.K. Wai. 1993. Quality sorting of sweet cherries using magnetic resonance. Paper 93-6071. ASAE, St. Joseph, Michigan.

Stroshine, R.L., W.K. Wai, and G.W. Krutz. 1993. Non-Destructive Ripeness Sensing of Intact Avocado, Nectarine and Orange using Proton Magnetic Resonance. Paper 93-6535. ASAE, St. Joseph, Michigan.

Stroshine, R.L., W.K. Wai, K.M. Keener, and G.W. Krutz. 1994. New Developments in Fruit Ripeness Sensing using Magnetic Resonance. Paper 94-6539, ASAE, St. Joseph, Michigan

USDA. 1992. Agricultural Statistics. United States Government Printing Office, Washington, D.C.

Wai, W.K. 1993. Use of Gradient Spin-echo Magnetic Resonance for Non-Destructive Measurement of Soluble Solids Content of Fruits. Ph.D. Thesis. Department of Agricultural and Biological Engineering., Purdue University, W. Lafayette, Indiana.

Wai, W.K., S.I. Cho, R.L. Stroshine, G.W. Krutz, and K. Haghighi. 1991. FEM Solenoid Probe Coil for a Magnetic Resonance Fruit Sweetness Sensor. Paper 91-7554. ASAE, St. Joseph, Michigan.

Wai, W.K. R.L. Stroshine, and G.W. Krutz. 1995. Modifications of the Hahn Echo Pulse Sequence for Fast Measurement of Percent Soluble Solids Content of Fruits in Proton Magnetic Resonance ( $\left.{ }^{1} \mathrm{H}-\mathrm{MR}\right)$. Transactions of ASAE:38(3):849-855.

Yee, O.P., J.A. Nyenhuis, W.K. Wai, and R.L. Stroshine. 1995. Magnetic Field Inhomogeneity Effects on Spin Echo NMR Diffusion Measurements. IEEE Transactions - Magnetism: (In press)

Zion, B., P. Chen and M.J. McCarthy. 1993a. Evaluation of quality of fresh prunes by their NMR spectra. Paper 93-6073. ASAE. St. Joseph, Michigan.

Zion, B., P. Chen and M.J. McCarthy. 1993b. Image analysis technique for Detection of Bruises in Magnetic Resonance Images of Apples. Paper 93-3084. ASAE, St. Joseph, Michigan

Zion, B., M.J. McCarthy, and P. Chen. 1994. Real-Time Detection of Pits in Processed Cherries by Magnetic Resonance Projections. Levensm.-Wiss. u.-Technol. 27:457-462. 


\section{Appendix A}

Tabular Summary of the Results of the Survey

Conducted for the Economic Evaluation

\section{Table A1. Results of survey of produce managers for chain grocery stores.}

Grocery 99 mailed, $27 \%$ returned

Q1. Would the sensor improve quality for customers if used at retail level?

yes

no $46 \%$ $54 \%$

Q2. Would the sensor improve quality for customers if used prior to retail level? yes

no $100 \%$ 0

Q4. Would you be able to charge a premium?

yes

no $22 \%$ temporarily $56 \%$ $22 \%$

Q5. Estimated annual loss unknown $39 \%$ range average $\$ 18,000$ to $\$ 5$ million $\$ 1$ million

Q6. Eestimated yearly financial gain using sensor no gain unknown $13 \%$ range average $40 \%$

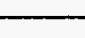

$\$ 12,600$ to 3.5 million $\$ 800,000$

Q7. Affordable cost packers should sort $\quad \$ 10,000$ $67 \%$ $19 \%$ 


\begin{tabular}{|c|c|c|}
\hline \multicolumn{3}{|c|}{$\begin{array}{l}\text { Table A2. Summary of results from economic survey } \\
\text { of citrus and stone fruit packers. }\end{array}$} \\
\hline & $\begin{array}{l}\text { CA, AZ, FL (citrus) } \\
48 \text { mailed } \\
31 \% \text { returned }\end{array}$ & $\begin{array}{l}\text { Miscellaneous } \\
56 \text { mailed } \\
20 \% \text { returned }\end{array}$ \\
\hline Q1. Acceptable rate & $\begin{array}{l}\min ) \\
\text { range/average } \\
30-2200 / 600\end{array}$ & $\begin{array}{l}\text { range/average } \\
12-600 / 370\end{array}$ \\
\hline $\begin{array}{l}\text { Q2. Could it be usefu } \\
\qquad \begin{array}{l}12 / \mathrm{min} \\
300 / \mathrm{min}\end{array}\end{array}$ & $\begin{array}{l}\text { orting at your facility? } \\
57 \% \quad \text { yes } \\
100 \% \text { yes }\end{array}$ & $\begin{array}{ll}25 \% & \text { yes } \\
60 \% & \text { yes }\end{array}$ \\
\hline $\begin{array}{l}\text { Q3. Could it provide } \\
\qquad \begin{array}{l}12 / \mathrm{min} \\
300 / \mathrm{min}\end{array}\end{array}$ & $\begin{array}{l}\text { uniform quality? } \\
14 \% \quad \text { yes } \\
67 \% \text { yes }\end{array}$ & $\begin{array}{ll}30 \% & \text { yes } \\
60 \% & \text { yes }\end{array}$ \\
\hline $\begin{array}{l}\text { Q4a. Necessary accur } \\
\qquad \begin{array}{r}12 / \mathrm{min} \\
300 / \mathrm{min}\end{array}\end{array}$ & $\begin{array}{l}\text { obrix) } \\
\text { range/\% wanting } 1 \% \text { brix } \\
1-2 \% \text { brix } / 82 \% \\
1-2 \% \text { brix } / 85 \%\end{array}$ & $\begin{array}{l}\text { range/\% wanting } 1 \% \text { brix } \\
1-2 \% \text { brix } / 93 \% \\
1-2 \% \text { brix } / 56 \%\end{array}$ \\
\hline $\begin{array}{l}\text { Q4b. Affordable cost } \\
\qquad \begin{array}{l}12 / \mathrm{min} \\
300 / \mathrm{min}\end{array}\end{array}$ & $\begin{array}{l}\text { range/average } \\
\$ 10,000-\$ 30,000 / \$ 12,000 \\
\$ 20,000-\$ 100,000 / \$ 70,000\end{array}$ & $\begin{array}{l}\text { range/average } \\
\$ 1,000-\$ 40,000 / \$ 15,000 \\
\$ 40,000-\$ 300,000 / \$ 170,000\end{array}$ \\
\hline $\begin{array}{l}\text { Q5. Would it change } \\
\qquad \begin{array}{l}12 / \mathrm{min} \\
300 / \mathrm{min}\end{array}\end{array}$ & $\begin{array}{l}\text { nt or selection sent to processing } \\
60 \% \text { yes } \\
100 \% \text { yes }\end{array}$ & $\begin{array}{ll}9 \% & \text { yes } \\
91 \% & \text { yes }\end{array}$ \\
\hline $\begin{array}{l}\text { Q6. Would it reduce } \\
\qquad \begin{array}{l}12 / \mathrm{min} \\
300 / \mathrm{min}\end{array}\end{array}$ & $\begin{array}{l}\text { or improve quality for customers } \\
50 \% \text { yes } \\
100 \% \text { yes }\end{array}$ & $\begin{array}{ll}33 \% & \text { yes } \\
89 \% & \text { yes }\end{array}$ \\
\hline Q7. Could you charg & $\begin{array}{ll}20 \% & \text { yes } \\
40 \% & \text { yes }\end{array}$ & $\begin{array}{ll}43 \% & \text { yes } \\
70 \% & \text { yes }\end{array}$ \\
\hline Q11. Annual compar & $\begin{array}{l}\text { due to over-ripeness } \\
\text { range/average } \\
\$ 20,000-\$ 1,000,000 / \$ 500,000\end{array}$ & $\begin{array}{l}\text { range/average } \\
\$ 30,000-\$ 100,000 / \$ 85,000\end{array}$ \\
\hline Q12. Estimated ann & $\begin{array}{l}\text { using ripeness sensor } \\
\text { range/average } \\
\$ 25,000\end{array}$ & $\begin{array}{l}\text { range/average } \\
\$ 110,000-\$ 400,000 / \$ 300,000\end{array}$ \\
\hline Comments: & * sugar/acid ratio important & \\
\hline
\end{tabular}




\begin{tabular}{|c|c|c|c|c|}
\hline \multicolumn{5}{|c|}{$\begin{array}{l}\text { Table A3. Summary of results from economic survey } \\
\text { of apple packers. }\end{array}$} \\
\hline & $\begin{array}{l}\text { Washington (apples) } \\
42 \text { mailed } \\
52 \% \text { returned }\end{array}$ & $\begin{array}{l}\text { New York (apples) } \\
19 \text { mailed } \\
47 \% \text { returned }\end{array}$ & \multicolumn{2}{|c|}{$\begin{array}{l}\text { Michigan (apples) } \\
47 \text { mailed } \\
28 \% \text { returned }\end{array}$} \\
\hline Q1. Acceptable rat & $\begin{array}{l}\text { (fruits/min) } \\
\text { range/average } \\
12-600 / 300\end{array}$ & $\begin{array}{l}\text { range/average } \\
120-600 / 360\end{array}$ & $\begin{array}{l}\text { range/ } \\
12-600\end{array}$ & $\begin{array}{l}\text { verage } \\
1300\end{array}$ \\
\hline $\begin{array}{l}\text { Q2. Could it be use } \\
12 / \mathrm{min} \\
300 / \mathrm{min}\end{array}$ & $\begin{array}{ll}\text { ul for sorting at your facility? } \\
33 \% \quad \text { yes } \\
95 \% \quad \text { yes }\end{array}$ & $\begin{array}{ll}14 \% & \text { yes } \\
89 \% & \text { yes }\end{array}$ & $\begin{array}{l}10 \% \\
90 \%\end{array}$ & $\begin{array}{l}\text { yes } \\
\text { yes }\end{array}$ \\
\hline $\begin{array}{l}\text { Q3. Could it provic } \\
12 / \mathrm{min} \\
300 / \mathrm{min}\end{array}$ & $\begin{array}{ll}\text { more uniform quality? } \\
11 \% & \text { yes } \\
95 \% & \text { yes } \\
\end{array}$ & $\begin{array}{ll}25 \% & \text { yes } \\
86 \% & \text { yes } \\
\end{array}$ & $\begin{array}{l}20 \% \\
80 \%\end{array}$ & $\begin{array}{l}\text { yes } \\
\text { yes }\end{array}$ \\
\hline $\begin{array}{l}\text { Q4a. Necessary ac } \\
\qquad \begin{array}{l}12 / \mathrm{min} \\
300 / \mathrm{min}\end{array}\end{array}$ & $\begin{array}{l}\text { uracy (\%brix) } \\
\text { range/\% wanting } 1 \% \text { brix } \\
1-4 \% \text { brix } / 83 \% \\
104 \% \text { brix } / 53 \%\end{array}$ & $\begin{array}{l}\text { range/\% wanting } 1 \% \text { brix } \\
1-4 \% \text { brix } / 83 \% \\
1-4 \% \text { brix } / 50 \%\end{array}$ & $\begin{array}{l}\text { range/ } \\
1-2 \% \mathrm{~b} \\
1-4 \% \mathrm{~b}\end{array}$ & $\begin{array}{l}\text { \% wanting } 1 \% \text { brix } \\
\text { ix } / 36 \% \\
\text { ix } / 26 \%\end{array}$ \\
\hline $\begin{array}{c}\text { Q4b. Affordable c } \\
\\
12 / \mathrm{min} \\
300 / \mathrm{min}\end{array}$ & $\begin{array}{l}\text { st } \\
\text { range/average } \\
\$ 500 \text { to } \$ 40,000 / \$ 15,000 \\
\$ 10,000 \text { to } \$ 200,000 \text { / } \\
\$ 80,000 \text { t }\end{array}$ & $\begin{array}{l}\text { range/average } \\
\$ 5000 \text { to } \$ 10,000 / \$ 7,000 \\
\$ 5000 \text { to } \$ 100,000 / \\
\$ 60,000\end{array}$ & $\begin{array}{l}\text { range/ } \\
\$ 200-\$ \\
\$ 10,00 \\
\$ 50,00\end{array}$ & $\begin{array}{l}\text { verage } \\
10,000 / \$ 3,500 \\
0-\$ 100,000 / \\
0\end{array}$ \\
\hline 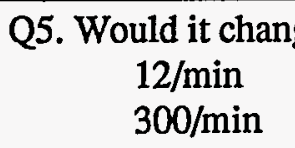 & $\begin{array}{l}\text { amount of selection sent to p } \\
\begin{array}{ll}17 \% & \text { yes } \\
83 \% & \text { yes }\end{array}\end{array}$ & $\begin{array}{ll}\text { rocessing? } \\
0 \% & \text { yes } \\
86 \% & \text { yes }\end{array}$ & $\begin{array}{l}25 \% \\
90 \%\end{array}$ & $\begin{array}{l}\text { yes } \\
\text { yes }\end{array}$ \\
\hline $\begin{array}{l}\text { Q6. Would it redu } \\
12 / \mathrm{min} \\
300 / \mathrm{min}\end{array}$ & $\begin{array}{l}\text { waste or improve quality for } \\
31 \% \text { yes } \\
100 \% \text { yes }\end{array}$ & \begin{tabular}{ll}
\multicolumn{3}{c}{ customers? } \\
$20 \%$ & yes \\
$100 \%$ & yes
\end{tabular} & $\begin{array}{l}0 \% \\
80 \%\end{array}$ & $\begin{array}{l}\text { yes } \\
\text { yes }\end{array}$ \\
\hline Q7. Could you cha & \begin{tabular}{ll}
3 & \multicolumn{3}{c}{ a premium? } \\
$7 \%$ & yes \\
$55 \%$ & yes
\end{tabular} & $\begin{array}{ll}0 \% & \text { yes } \\
67 \% & \text { yes }\end{array}$ & $\begin{array}{l}0 \% \\
30 \%\end{array}$ & $\begin{array}{l}\text { yes } \\
\text { yes }\end{array}$ \\
\hline Q1. Annual com & $\begin{array}{l}\text { loss due to over-ripeness } \\
\text { range/average } \\
\$ 10,000-\$ 200,000 \text { / } \\
\$ 100,000 \\
\text { bad years - } \$ 100,000 \text { to } \$ 4 \mathrm{~m}\end{array}$ & $\begin{array}{l}\text { range/average } \\
\$ 10,000-\$ 35,000 / \$ 20,000 \\
\text { nillion }\end{array}$ & $\begin{array}{l}\text { range/a } \\
\$ 2,000 \\
\$ 175,0\end{array}$ & $\begin{array}{l}\text { verage } \\
-\$ 750,000 / \\
00\end{array}$ \\
\hline Q12. Estimated an & $\begin{array}{l}\text { dal gain using ripeness sensor } \\
\text { range/average } \\
\$ 10,000-\$ 750,000 / \\
\$ 150,000 \\
* \text { firmness important }\end{array}$ & $\begin{array}{l}\text { range/average } \\
\$ 7,000-\$ 40,000 / \$ 20,000 \\
* \text { firmness important }\end{array}$ & $\begin{array}{l}\text { range/c } \\
\$ 10,00 \\
\$ 200,0 \\
* \text { firmr }\end{array}$ & $\begin{array}{l}\text { verage } \\
0-\$ 400,000 / \\
00 \\
\text { less important }\end{array}$ \\
\hline
\end{tabular}

